\title{
De gallo peregrino, le coq voyageur
}

Meleagris gallopavo L. 1758 en Europe, à travers les textes anciens (XV' ${ }^{e_{-}}$ XVIII ${ }^{\mathrm{e}}$ siecles)

\section{Serge Bahuchet}

\section{(2) OpenEdition}

\section{Journals}

\section{Édition électronique}

URL : https://journals.openedition.org/ethnoecologie/6839

DOI : $10.4000 /$ ethnoecologie.6839

ISSN : 2267-2419

\section{Éditeur}

Laboratoire Éco-anthropologie

\section{Référence électronique}

Serge Bahuchet, «De gallo peregrino, le coq voyageur », Revue d'ethnoécologie [En ligne], 19 | 2021, mis en ligne le 30 juin 2021, consulté le 17 décembre 2021. URL : http://journals.openedition.org/ ethnoecologie/6839; DOI : https://doi.org/10.4000/ethnoecologie.6839

Ce document a été généré automatiquement le 17 décembre 2021.

\section{(c) $(1)(9)$}

Revue d'ethnoécologie est mis à disposition selon les termes de la licence Creative Commons Attribution - Pas d'Utilisation Commerciale - Pas de Modification 4.0 International. 


\title{
De gallo peregrino, le coq voyageur
}

Meleagris gallopavo L. 1758 en Europe, à travers les textes anciens (XV ${ }^{\mathrm{e}}$ XVIII ${ }^{\mathrm{e}}$ siecles)

\section{Serge Bahuchet}

\begin{abstract}
« DU COQ-D’INDE. 35. - Le dindon est certainement un des plus beaux cadeaux que le Nouveau Monde ait fait à l'ancien. "

Brillat-Savarin, Physiologie du goût (Méditation
\end{abstract}

VI), 1825

\section{Introduction}

1 L'Amérique a fourni à l'Europe des plantes alimentaires majeures, dont plusieurs ont été adoptées immédiatement après leur découverte (maïs, courges, haricots, piments). Parmi les cinq animaux domestiqués par les Amérindiens, trois ont rapidement été ramenés en Europe: le canard musqué, le cochon d'Inde et le dindon. Les deux camélidés, lama et alpaca, n'ont pas connu de destin majeur en dehors de leur continent d'origine (cf. Geoffroy Saint-Hilaire 1861 : 26-24, Bahuchet 2017).

2 Des deux oiseaux, l'un, le canard musqué s'est rapidement fondu dans la basse-cour, au point de ne pas laisser véritablement de traces dans les écrits du temps. L'autre, le dindon, est finalement le seul animal américain à avoir pris une importance économique et alimentaire universelle. Comment cet emprunt de l'Ancien Monde au Nouveau s'est-il passé ?

Dans cet article, on examinera les conditions et les conséquences de la découverte du dindon Meleagris gallopavo L. (Phasianideae). Je vais tenter de cerner comment ce nouvel animal va s'introduire et s'implanter dans les langues, à travers la terminologie, dans le savoir scientifique, et dans les usages et les pratiques en vue de préciser les étapes de son acceptation et de son inclusion dans le corpus alimentaire européen. Cette enquête sera conduite par l'analyse chronologique des témoignages écrits successifs, c'est-àdire les archives qui ont pu être révélées par des historiens, et surtout les livres, afin de 
mettre en évidence les étapes de l'adoption du dindon dans notre civilisation européenne.

\section{Des sources très bien documentées}

4 Plusieurs publications ont soigneusement scruté les sources historiques concernant l'introduction du dindon en Europe, fournissant une base quasi exhaustive sur laquelle toute nouvelle recherche s'appuie, et auxquelles il est vain d'espérer ajouter quelque chose d'original, sauf à mener des recherches plus approfondies dans les archives. L'ouvrage de base, sur lequel s'appuient toutes les publications postérieures, est Schorger 1966 (précédé de l'article précurseur et bien informé de Wright 1914) et complété par l'ouvrage richement illustré de Eiche 2004. Flandrin 1992, puis Plouvier 1995 ont étudié la place du dindon dans les livres de cuisine, et Poplin 1992 introduit le dindon dans notre bestiaire. Plus récemment, Boudier 2009, Orlandi 2011, De Grossi Mazzorin \& Epifani 2015 ont apporté de nouveaux documents historiques à ceux qui avaient été déjà publiés.

5 Pour cet article, je suis reparti des sources précédemment découvertes par les auteurs antérieurs, en retournant autant que faire se peut aux textes originaux. J'ai ainsi mobilisé des sources d'origines multiples, afin de disposer d'informations différentes se complétant les unes les autres, récits historiques, livres de cuisine et de santé, dictionnaires monolingues et plurilingues, livres d'agriculture et d'économie domestique, dans les quatre pays méditerranéens, Espagne, Portugal, France et Italie, et en Angleterre. Sauf mention contraire, les traductions ont été réalisées par mes soins, et les textes originaux sont portés en notes.

6 J'ai limité mon propos aux sources historiques, publications et archives, et j'ai sciemment laissé de côté les études archéologiques et archéozoologiques, qui sont en cours de développement et sur lesquelles un ouvrage de synthèse est en préparation (Exploring the history of the turkey domestication and management, édité par A. Manin, C. Speller, E. Corona \& E. Thornton, aux éditions du MNHN).

7 Sur la découverte et l'introduction du dindon en Europe, il n'y a pas eu de nouveaux documents qui modifient un tableau déjà bien connu, qui forme une sorte de consensus. On connaît dorénavant les grandes étapes; tout au plus peut-on attendre des éclaircissements et des précisions sur des détails. Cet essai a donc comme objectif de résumer l'état des connaissances sur l'introduction du dindon en Europe, tout en s'efforçant d'apporter quelques informations complémentaires, à partir des documents de l'époque, dans le but de cerner la place qu'a pu prendre cet oiseau dans l'agriculture et l'alimentation européenne.

8 Je distinguerai plusieurs étapes, pour lesquelles je mobiliserai le maximum de témoignages contemporains: qui a découvert le dindon, cette nouvelle volaille? Comment a-t-il été introduit en Espagne, et à partir de là, comment se diffuse-t-il en Europe ? Comment passe-t-il des volières princières et des tables nobles, aux bassescours? Comment les difficultés initiales de son élevage sont-elles surmontées, et quelle place le dindon gagne-t-il dans la cuisine? 


\section{Rappel du contexte historique}

9 La découverte et l'introduction du dindon en Europe se situe dans une période géopolitique particulièrement complexe et dramatique, en ce qui concerne les relations entre les pays européens, une période au cours de laquelle l'organisation du monde change considérablement. On peut retenir de cette période les dates et événements suivants [Tableau 1].

Tableau 1 : Principales dates et principaux événements en Europe

\begin{tabular}{|c|c|c|c|}
\hline $1442-1458$ & Règne d'Alphonse $V$ d'Aragon sur le Royaume des & 1519-1522 & Tour du monde de Magellan \\
\hline 1453 & Prise de Constantinople par les Ottomans & \multirow[t]{3}{*}{$1521-1526$} & \multirow{3}{*}{ 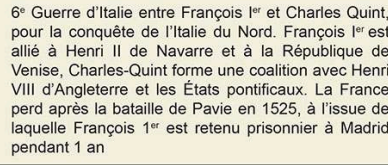 } \\
\hline 1478 & $\begin{array}{l}\text { Instauration du tribunal du Saint-Office de l'Inquisition } \\
\text { en Espagne }\end{array}$ & & \\
\hline \multirow[t]{2}{*}{1479} & \multirow{2}{*}{$\begin{array}{l}\text { Accession au trône des Rois Catholiques, Isabelle de } \\
\text { Castille et Ferdinand d'Aragon. Le royaume de Naples } \\
\text { (toute 'lttalie au sud de Rome, avec la Sicile) est ipso- } \\
\text { facto rattaché à la couronne d'Espagne }\end{array}$} & & \\
\hline & & \multirow[t]{2}{*}{$1521-1529$} & \multirow{2}{*}{$\begin{array}{l}\text { Conquêtes du sultan ottoman Soliman le Magnifique } \\
\text { en Europe contre le Saint Empire (Belgrade, Buda } \\
\text { Bosnie, Croatie, Dalmatie) qui se conclut par le siège } \\
\text { de Vienne en } 1529 \text { et la retraite des troupes ottomanes }\end{array}$} \\
\hline 1488 & $\begin{array}{l}\text { Le portugais Bartolome Diaz atteint le Cap de Bonne } \\
\text { Espérance au sud de l'Afrique }\end{array}$ & & \\
\hline \multirow[t]{3}{*}{1492} & $\begin{array}{l}\text { Prise de Grenade, expulsion ou conversion forcée } \\
\text { des Juifs et des Maures (1492-1496) }\end{array}$ & 1523-1533 & Conquête du Pérou par Pizarro \\
\hline & \multirow{2}{*}{$\begin{array}{l}\text { 1er voyage de Christophe Colomb, découverte du } \\
\text { Nouveau Monde et installation espagnole à Hispaniola } \\
\text { (aujourd'hui Haiti-Saint Domingue) }\end{array}$} & 1524 & $\begin{array}{l}\text { Au cours de la } 6^{\circ} \text { guerre d't'talie, les troupes espagnoles } \\
\text { envahissent la Provence (juillet à octobre) }\end{array}$ \\
\hline & & 1527 & Sac de Rome par l'armée de Charles Quint \\
\hline \multirow{3}{*}{1494} & $\begin{array}{l}\text { Traité de Tordesillas partageant le monde entre les } \\
\text { Portugais et les Espagnols }\end{array}$ & 1529 & « Protestants », nom donné aux Luthériens \\
\hline & \multirow{2}{*}{$\begin{array}{l}\text { Début des guerres d't'talie entre la France, la ligue des } \\
\text { princes italiens et le royaume de Naples; pillage de } \\
\text { Rome par les troupes françaises de Charles VIII. Les } \\
\text { guerres d'tlalie dureront jusqu'en } 1559\end{array}$} & \multirow[t]{3}{*}{1534} & Jacques Cartier explore le Saint Laurent \\
\hline & & & Fondation de l'Eglise anglicane \\
\hline 1496 & $\begin{array}{l}\text { Edit d'expulsion ou conversion forcée des Juifs du } \\
\text { Portugal }\end{array}$ & & $\begin{array}{l}\text { Fondation de la Compagnie de Jésus par Ignace de } \\
\text { Loyola }\end{array}$ \\
\hline 1498 & Vasco de Gama aborde a Calicut (Inde) & 1536 & \multirow{3}{*}{$\begin{array}{l}\text { Guerre entre la France (Henri II) et I'Espagne (Philippe } \\
\text { II), dans I'Est de la France, en Italie puis dans les } \\
\text { Flandres. Elle se termine en } 1557 \text { par la défaite } \\
\text { française de Saint-Quentin et le traité de Cateau- } \\
\text { Cambrésis, en } 1559\end{array}$} \\
\hline 1500 & $\begin{array}{l}\text { Pedro Cabral découvre le Brésil, alors qu'il fait voile } \\
\text { vers les Indes }\end{array}$ & 1552 & \\
\hline 1515 & $\begin{array}{l}\text { Charles de Habsbourg est proclamé souverain des } \\
\text { Pays-Bas ; il est nommé Roi d'Espagne en } 1516\end{array}$ & & \\
\hline \multirow[t]{3}{*}{1517} & Les 95 theses de Luther & 1557 & Crise financière et faillites en Espagne et en Allemagne \\
\hline & \multirow{2}{*}{$\begin{array}{l}\text { Arrivée du premier contingent d'esclaves africains à } \\
\text { Hispaniola }\end{array}$} & 1562 & Début des guerres de religion en France \\
\hline & & \multirow[t]{2}{*}{1571} & \multirow{2}{*}{$\begin{array}{l}\text { Défaite des Ottomans contre la flotte de la Sainte- } \\
\text { Ligue lors de la bataille navale de Lépante }\end{array}$} \\
\hline \multirow[t]{4}{*}{1519} & \multirow{3}{*}{$\begin{array}{l}\text { Charles de Habsbourg est élu Empereur du Saint } \\
\text { Empire Germanique, sous le nom de Charles Quint. } \\
\text { II régne ainsi sur le royaume d'Espagne (y compris le } \\
\text { Nouveau Monde), l'Allemagne et I'Autriche, une partie } \\
\text { des Pays Bas, et le royaume de Naples }\end{array}$} & & \\
\hline & & 1572 & 24 août, massacre de la Saint-Barthélémy (France) \\
\hline & & \multirow[t]{2}{*}{1581} & \multirow{2}{*}{$\begin{array}{l}\text { Philippe II d'Espagne devient roi du Portugal } \\
\text { réunissant ainsi la péninsule ibérique avec toutes les } \\
\text { colonies associées }\end{array}$} \\
\hline & Cortez conquiert le Mexique & & \\
\hline
\end{tabular}

\section{Qui a vu le premier dindon?}

Il y a de grandes incertitudes sur le premier, parmi les Européens, qui ait vu et décrit des dindons dans le Nouveau Monde, et surtout qui les a ramenés en Espagne.

11 La mention selon laquelle Christophe Colomb en aurait rencontré lors de son quatrième et dernier voyage en 1502-1504, sur la côte du Honduras, est ténue ; elle s'appuie sur une simple phrase de la lettre au Roi ${ }^{1}$, puisque Colomb n'a pas tenu de journal pour ce voyage, mentionnant : «j'ai vu nombre de poules, très grandes, dont la plume ressemble à de la laine...». Cette lettre est complétée par deux textes ultérieurs. Le témoignage rapporté par Pierre Martyr d'Anguiera ${ }^{2}$, dans ses Décades du nouveau monde (chapitre IV de la $3^{\mathrm{e}}$ décade), à propos de ce quatrième voyage, au cours duquel Colomb longe la côte du Panama et du Honduras en mai 1502 :

«Ce lieu abrite [divers animaux] ainsi que des oiseaux variés parmi lesquels ils élèvent, en guise de volailles, ceux qui ressemblent à des paonnes par la couleur, la taille, le goût et la saveur comme nous l'avons dit plusieurs fois. » (éd. Gauvin 2003 : $\left.238^{3}\right)$. 
12 Fernando Colomb, dans la biographie de son père, rapporte que "le Préfet » Bartolomeo Colomb, envoyé par son frère l'Amiral Christophe Colomb, aborde sur la côte du Honduras vers le 14 août 1502 et que, quelques jours après, vinrent vers les Espagnols plus de 200 Indiens chargés de divers vivres « avec des poules de terre qui sont meilleures que les nôtres ${ }^{4} »$.

13 Il n'y a malheureusement aucune évidence que Colomb ait rapporté des dindons à Séville au retour de ce voyage dramatique, au contraire même, puisqu'il avait été capturé par son successeur et revenait en Espagne prisonnier.

Le premier voyage à avoir touché la côte du Venezuela est celui de Pedro Alonso Nuñez ou Niño, en 1499-1500 (cf. Orlandi 2011: 77). Son groupe contacte longuement des Indiens à Curiana, ainsi décrits par Pierre Martyr :

« Les femmes élèvent à la maison des oies et des canards comme les femmes de chez nous. Des paons vivent dans les bois - mais ils ne sont pas ornés ni multicolores car le mâle diffère peu de la femelle (...) " " Nos hommes passèrent là quelques jours dans l'abondance : en effet on remettait quatre aiguilles ou épingles à celui qui ramenait un paon (...)» (Première décade, livre 8 ; éd. Gauvin $2003: 172,174$ )

Toutefois, il est possible que ces oiseaux aient pu appartenir à une autre espèce sauvage, le dindon ocellé Meleagris ocellata, endémique du Yucatan et du Guatemala (A. Manin, comm. pers., cf. Manin et al. 2018).

Il est dit que « Les nôtres rapportèrent de cette région de très beaux cercopithèques et plusieurs perroquets de toutes les couleurs. " (op. cit. : 178), mais surtout une grande quantité de perles « certaines grosses comme des noisettes » (que Martyr a pu voir) - ce qui valut à Nuñez d'être emprisonné à son arrivée à Pontevedra en Galice, pour en avoir caché une partie! Il n'y a malheureusement pas de mention de "paons » rapportés en Espagne par cette expédition, même si le fait est possible.

Quelques années après, la côte d'Amérique centrale a été parcourue, du Honduras au Yucatan, par les navigateurs espagnols Victor Yañez Pinzon et Juan Diaz de Solis, entre 1508 et $1509^{5}$. Au cours de ce voyage, ils virent des "paons", dont Pierre Martyr rapporte ainsi le récit, dans le contexte d'un contact difficile entre les Espagnols et les indigènes; les caciques redoutant le pillage de leurs villages, ils demandent la paix et envoient à Vincent Yañez des ambassadeurs avec des cadeaux :

«Ils donnèrent, en plus de l'or et de l'encens, des paons qu'on ne rencontre que chez eux; ils diffèrent sensiblement des nôtres par la variété des couleurs. Les femelles étaient vivantes, car on les réservait pour la propagation de l'espèce : quant aux mâles, ils en donnèrent un grand nombre, mais pour les manger sur-lechamp. » (trad. Gaffarel 1907 : 198).

C'est ce texte semble-t-il qui est considéré comme la preuve d'un transport par Yañez des dindons vers l'Espagne ( $c f$. Wright 1914) mais, bien que le fait soit possible, son interprétation prête à discussion, si l'on en juge par les traductions successives ${ }^{6}$.

\section{Quel est cet oiseau?}

La rencontre avec le dindon conduit à être confronté à quelque chose de jamais vu. Pour le décrire, les observateurs vont donc comparer sa morphologie avec ce qui est déjà connu en Europe. Cet oiseau pourrait ressembler à une poule mais il est énorme, et il ressemble à un paon parce que le mâle a une queue qui fait la roue. Dans le Somario de la natural y general historia de las Indias, Gonzalo Fernandez de Oviedo en 1526 en donne 
la première description naturaliste locale et il s'attache longuement à comparer et contraster le paon des Indes avec celui d'Espagne, en faveur du nouvel oiseau :

«Il y a des paons blonds, et d'autres noirs, et leur queue a la même forme que ceux des paons d'Espagne ; mais [pas] le plumage et la couleur : les uns sont tout blonds et le ventre avec un peu de la poitrine blanche, et d'autres tout noirs, et aussi le ventre et une partie de la poitrine blancs; et tous portent sur la tête une belle crête ou panache, de plumes vermillon pour celui qui est vermillon, et noires pour celui qui est noir, et ils sont meilleurs à manger que ceux d'Espagne. Ces paons sont sauvages, et certains sont domestiqués dans les maisons, que l'on prend tout petits. Les arbalétriers en tuent beaucoup car ils sont en grande quantité. (....) ${ }^{7}$ (Somario de la natural y general historia de las Indias, 1526, Pavos, Cap. xxxvij).

On relève que le dindon est mi-sauvage, mi-domestique, ce qui laisse à penser à un élevage en liberté, en grande quantité ${ }^{8}$. Oviedo s'attarde ensuite à comparer le plumage, la tête nue, et surtout la queue. Pour conclure, il revient sur ses qualités gustatives :

«La chair de ces paons est très bonne et incomparablement meilleure et plus tendre que celle des paons d'Espagne. ${ }^{9}$ (Somario... 1526).

50 ans après, le cuisinier italien Bartolomeo Scappi va lui aussi comparer le dindon au paon, en ces termes :

«Le coq et la poule d'Inde sont beaucoup plus gros de corps que notre paon, et le coq fait lui aussi la roue comme le paon, et il a des plumes noires et blanches; son cou est dépourvu de poils, et la tête porte une corne de chair, qui, quand le coq s'irrite, gonfle et devient tellement grosse qu'elle lui couvre toute la moustache; (...) sur la poitrine, au milieu des plumes, il a une touffe de soie semblable à celle du porc; il a la chair beaucoup plus blanche et plus molle que celle de notre paon, et elle s'attendrit plus vite que le chapon ou d'autres volailles semblables ${ }^{10}$.» (Scappi 1570 ch. 141)

Dans les mêmes années, les premières descriptions zoologiques vont trébucher sur plusieurs difficultés: en premier lieu, comment décrire un animal entièrement nouveau, c'est-à-dire à quoi le comparer ? Ensuite, comment le baptiser, et enfin comment l'intégrer dans le champ du connu - c'est-à-dire le confronter aux textes classiques venant des auteurs de l'Antiquité.

Les naturalistes du XVI ${ }^{e}$ puis du XVII ${ }^{\mathrm{e}}$ siècle montrent la difficulté de confronter les textes des anciens de l'Antiquité, avec les observations objectives qu'ils font. En effet, la science de ce temps est basée sur l'analyse, le commentaire et l'exégèse des textes des savants de l'Antiquité (Varron, Columelle, Pline...). On le voit dans les ouvrages des botanistes, qui s'efforcent de définir quelles sont les plantes qui ont été décrites par Théophraste ou Dioscoride, et aussi pour les livres de zoologie.

Concernant le dindon, les gravures attestent que les auteurs (ou leurs dessinateurs) connaissent l'oiseau et l'ont vu. En témoignent quelques phrases incidentes, par exemple chez Gessner: "Du coq voyageur: Celui que j'ai vu qui venait du nouveau monde... », et plus loin encore "Celui que j'ai vu ${ }^{11} \ldots$ ». La première gravure, excellente, est celle publiée par Conrad Gessner en 1553 (Icones avium omnium : 56), puis reprise en 1555 par le même Gessner (Historiae animalium Liber III qui est de Avium natura : 464-465) [Figure 1]. La même année Pierre Belon illustre le dindon (De l'histoire de la nature des oiseaux : 148-149) [Figure 2]. Et pourtant les textes de ces auteurs sont très décevants dans leur imprécision, et par le peu d'information qu'ils apportent sur l'animal. Tous citent les grands auteurs de référence, et s'embrouillent, discutant à partir des textes latins pour affirmer ou contester que ces anciens aient connus ou non cet oiseau. La 
confusion est complète avec la pintade, à travers son nom grec Meleagris, confusion augmentée par le nom d'Indes donnée par les explorateurs aux Iles des Antilles puis au continent, et donc à l'oiseau, le coq et la poule d'Inde.

Figure 1 : Le gallopavo de Conrad Gessner en 1553 (Icones avium omnium)

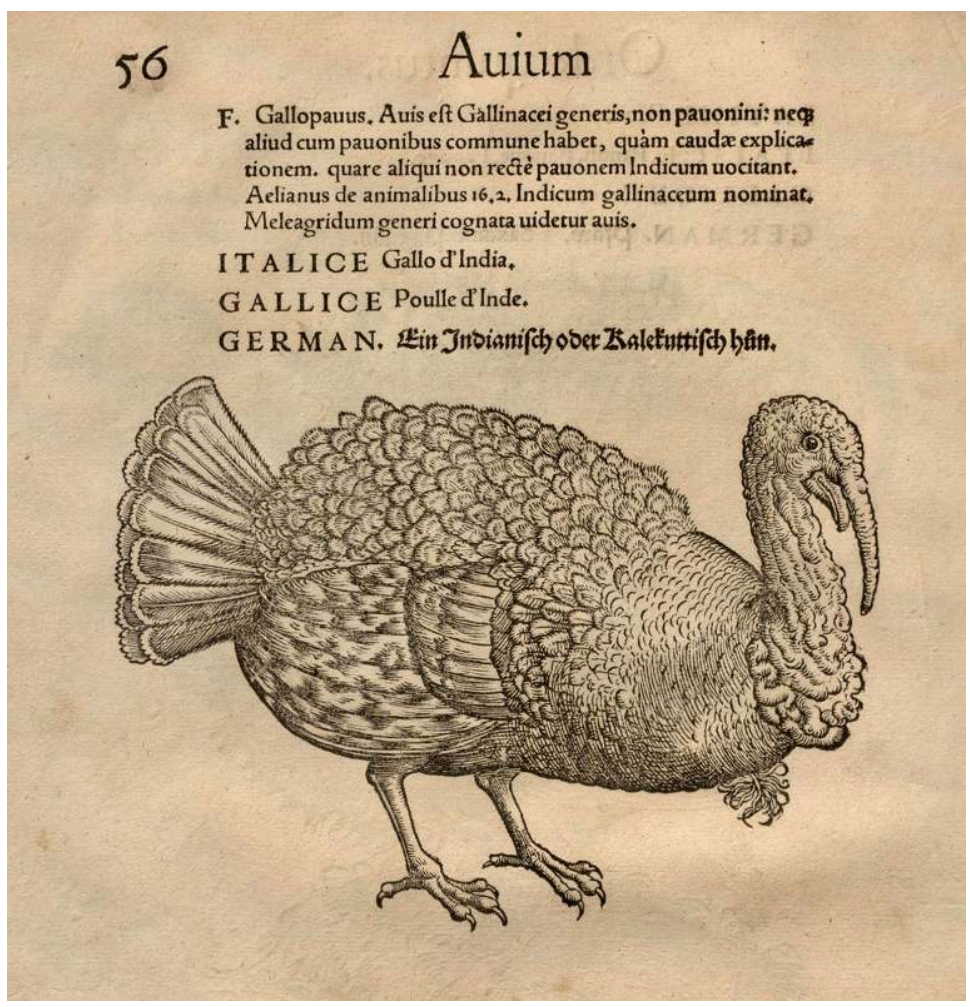


Figure 2 : Le coc d'Inde de Pierre Belon, De l'histoire de la nature des oiseaux avec leurs descriptions et naîfs portraicts $(1555)$

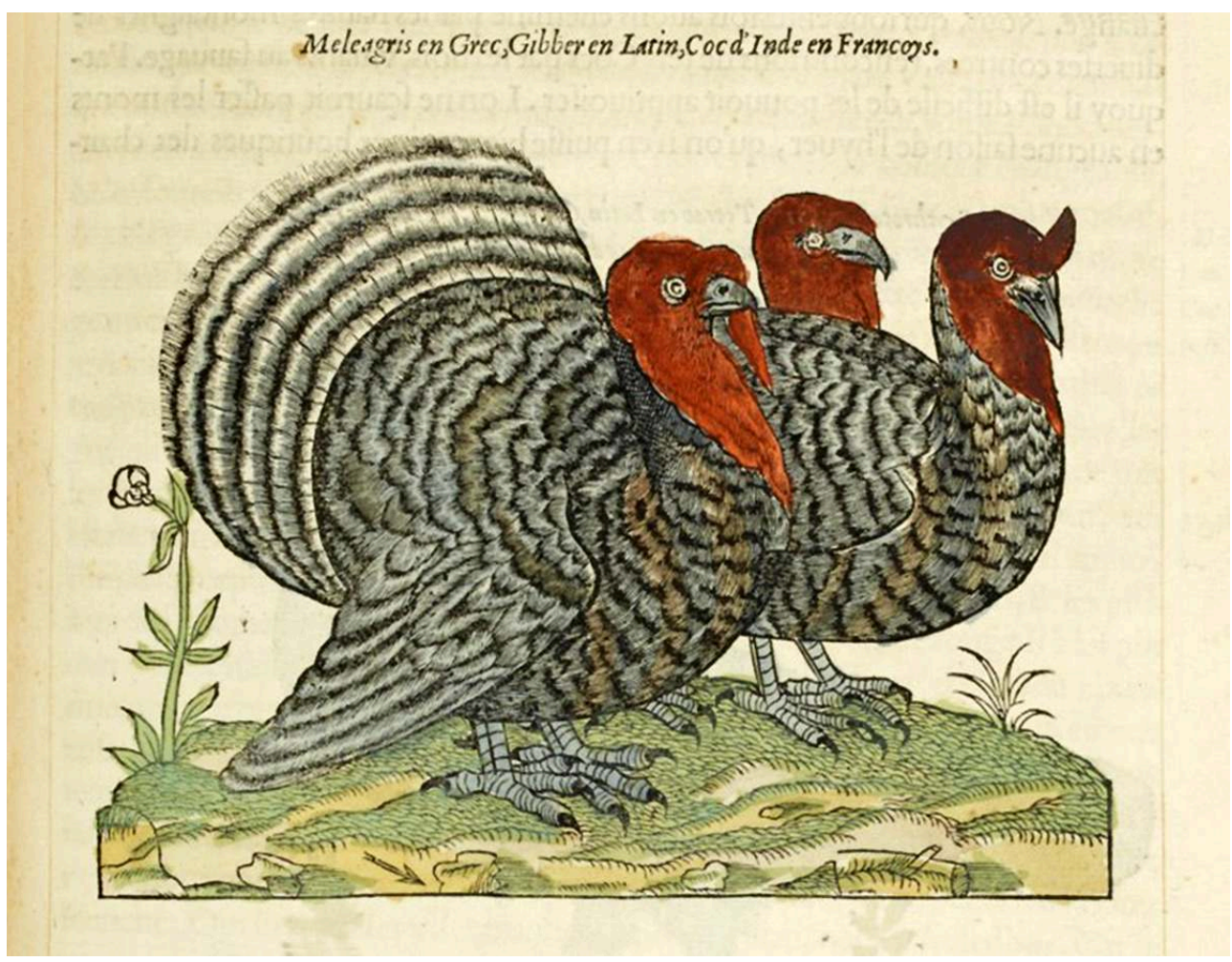

"Ces Cocs d'Inde ont vn toffet de poils durs, gros, \& noirs en la poictrine, resemblants à ceux de la queuë d'vn Cheual, [...] ». On remarque la confusion autour de Meleagris dans l'oiseau de droite, probablement la dinde mais sa caroncule est dressée, à l'exemple de l'excroissance cornée caractéristique de la pintade, alors que celui de gauche montre la caroncule charnue du dindon.

Source gallica.bnf.fr/Bibliothèque nationale de France

Un peu plus tard, en 1600, le naturaliste Ulisse Aldrovandi dans son deuxième volume de l'ornithologie, dessine d'une manière réaliste à la fois le mâle (Gallopavo) et la femelle (Gallina Indica) ${ }^{12}$ [Figure 3]. Plus loin dans le livre, dans la section sur les poules, il représente une forme fantaisiste, on pourrait dire presque mythique de Gallus indicus auritus tridactylus, qui a été souvent reproduite (p. 330-331) ${ }^{13}$. Toutefois rien dans la description associée à cette planche n'autorise un quelconque rapprochement avec le Gallopavo (p. 35). 
Figure 3 : Le gallopavo dans les Ornithologiae d'Ulisse Aldrovandi (1600)

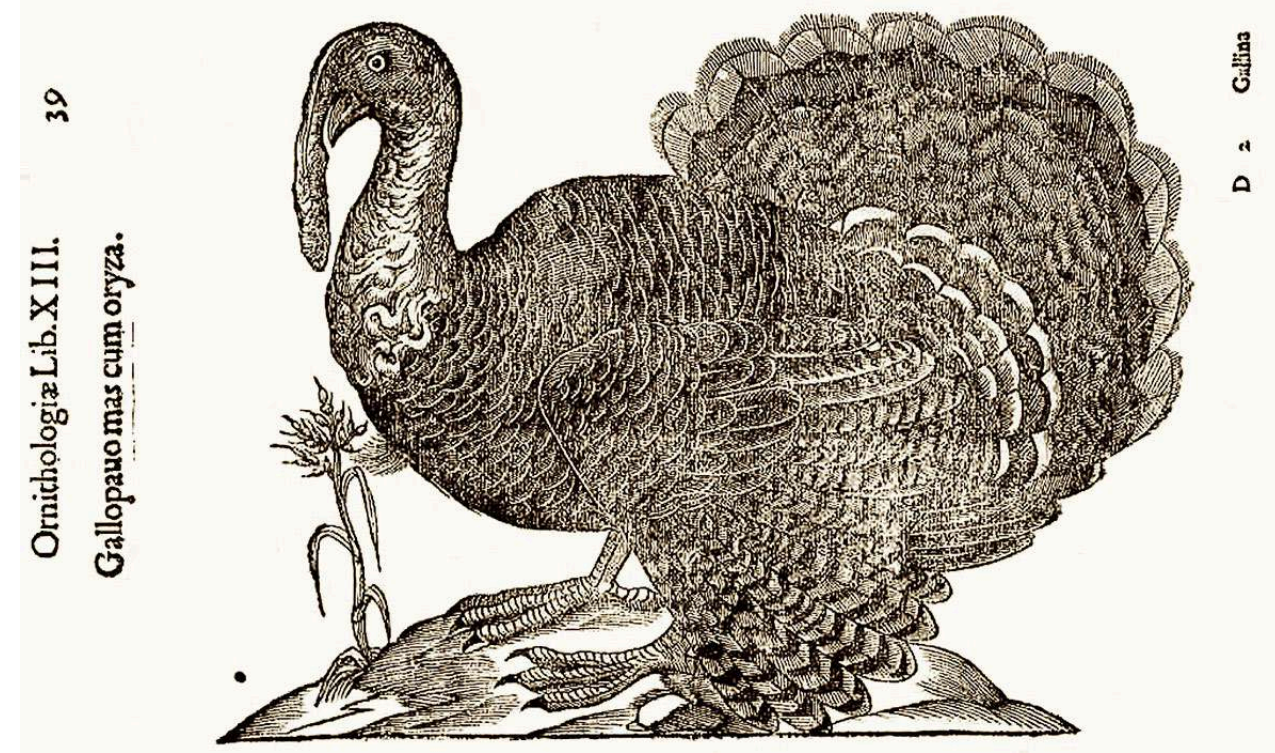

La découverte du Nouveau Monde, avec une flore mais surtout une faune inconnue, si distincte de celle de la Méditerranée, a posé des problèmes aux naturalistes européens ; finalement, un siècle après, reconnaître leur statut taxonomique a aidé à se défaire de la science antique. Les considérations du Père Joseph de Acosta qui séjourne en Amérique du sud au $16^{\mathrm{e}}$ siècle (Historia natural y moral de las Indias, Histoire naturelle et morale des Indes, 1590) sont éclairantes, bien qu'il ne rencontre pas le dindon. Il s'interroge sur une faune qu'il voit au Pérou, qui ne se retrouve dans aucune autre région du monde (c'est-à-dire en Europe) : qui les a fait venir au Pérou, ou comment y sont-ils venus? "Par aventure, Dieu a-t-il fait une autre nouvelle création d'animaux? » En un mot, sont-ils eux aussi sortis de l'Arche de Noé ? Il étend alors sa réflexion aux animaux d'Afrique et d'Asie, inconnus en Europe,

« mil autres différentes espèces d'oiseaux et d'animaux de forêt qui jamais n'ont été connues ni de figure ni de nom, et desquelles il n'est fait aucune mention soit entre les Latins soit entre les Grecs... » (trad. fr. 1598 par Robert Regnault, Livre III ch. XXXVI : 195).

27 Un exemple extrême et tardif est riche d'enseignement: Jan Johnston en 1657, dans l'article II de son Historiae naturalis de avibus, traite ensemble «Pavone albo, pavonibus Iaponensis \& gallopavone » (p. 39), et il se réfère lui aussi aux auteurs classiques, Varron, Pline, Diodore, Theophraste, Gallien, Strabon, Columelle, etc. Mais ses illustrations laissent perplexe : la planche 24 présente un superbe dindon et une dinde, très réalistes (la légende "Gallopavus mas cum Orÿzae " permet de les attribuer assurément à Aldrovandi), et sur la même planche, une pintade (Gallina Africanae). La planche 29 montre un "Gallus indicus, Welscher han", un beau dindon blanc faisant la roue (mais sans caroncule), au milieu de nombreuses races de coqs (dont un à cornes...) ; la planche 30, encore au milieu de plusieurs races de coqs, présente le Gallus indicus mirabilis, cette sorte d'oiseau miraculeux présenté dans Aldrovandi, à côté d'une pintade Gallina Guinea beaucoup plus réaliste que celle de la planche 24 , avec sa crête cornée caractéristique.

Cette confusion persistante se retrouve de loin en loin dans les textes des cuisiniers, par exemple dans le livre italien de Baldassare Pisanelli Trattato della natura de cibi e del bere 
(1583), où la partie sur le gallo d'India désigne assez certainement la pintade, et non le dindon (voir plus loin).

\section{Comment nommer cette nouvelle volaille?}

Quels sont les termes anciens et actuels, et à partir de quand se fixent-ils ? J'ai cherché quand ils apparaissent dans les ouvrages avec le sens moderne de "dindon ", par rapport aux oiseaux similaires déjà connus, le paon et la pintade [Tableaux 2 et 3].

Tableau 2 : Noms anciens (d'après les dictionnaires et les livres de cuisine)

\begin{tabular}{c|c|c|c|c} 
Signification & Français & Espagnol & Italien & Portugais \\
\hline Le mâle & Coq d'Inde, coq-dinde & $\begin{array}{c}\text { Gallipavo, pavo de India, } \\
\text { gallo de las Indias }\end{array}$ & Gallipavo, gallo d'India, gallinaccio & Perù \\
\hline La femelle & $\begin{array}{c}\text { Poule d'Inde, poulle d'Inde, } \\
\text { poule-dinde, dinde }\end{array}$ & Polla de Indias, gallina de la Indias, pava & Gallina d'India, pollanche d'India & Perua \\
\hline Les petits & $\begin{array}{c}\text { Poulet d'Inde, poulet-dinde, } \\
\text { dindon, dindonneau }\end{array}$ & Pavipollos, pavillos & Pollastre & \\
\hline Paon & Paon & Pavo, pavón & Pavone, paone & Pavão
\end{tabular}

Tableau 3 : Noms dans les langues actuelles

\begin{tabular}{c|c|c|c|c} 
Français & Espagnol & Italien & Portugais & Anglais \\
\hline Dinde, dindon & Pava, pavo & Tacchina, tacchino & Perua, peru & Turkey \\
\hline Pintade & Pintada & Gallina faraona & Pintada, galinha da India & Guinea-fowl \\
\hline Paon & Pavo real & Pavone & Pavão & Peacock
\end{tabular}

à « Dindon » ne se fixe pas avant le début du XviII e siècle :

- 1495, Antonio de Nebrija Dictionarium latinohispanicum: «Pavo o pava o pavon. Pauus.i.pavo.onis »

- 1570, Cristóbal de las Casas Vocabolario de las dos lenguas toscana y castellana : «Gallina. gallina. Pauone. pauon »

- 1591, Richard Percival A Dictionarie in Spanish and English, and Latine : "Pavo, pava y pavon, a peacock, Pavo.»

31 C'est à ce moment que la différence entre « dindon » et " paon » se formalise :

- 1611, Sebastián de Covarrubias, Tesoro de la lengua castellana: "Pavo, que por otro nombre le llama gallo de las Indias. Pavon, por otro nombre pauo real [...]» (Pavo, que l'on appelle d'un autre nom coq des Indes. Pavon, autre nom du paon royal)

- 1617, John Minsheu A Dictionnary in Spanish and English : «Pávo, o pavón. L. pávo. A. a peacock. Pavón de las Indias. L. Gallo-pavo. A. a Turkie-cock. $»^{14}$

- 1675, Caesar Oudin Thresor des deux langues françoise et espagnolle: «Gallipavo, coq d'Inde ; Pavo de India, coq d'Inde. »

- 1737, Real Academia Española Diccionario de la lengua castellana : « Pavo. Ave domestica, mucho mejor que la gallina. Lat. Gallus Indicus. [...]. Pavon. La mas hermosa de las aves [...]. Llámase tambien Pavo real. Lat. Pavo. [...]»

32 En résumé, en abordant en Amérique centrale, les Espagnols ont rencontré de gros volatiles domestiques (Meleagris gallopavo L.), qu'ils hésitent à nommer gallina (poule) ou pavo (paon). Ayant opté définitivement pour pavo, le Paon véritable (Pavo cristatus L.) d'origine eurasiatique et élevé en Europe depuis l'Antiquité, devient pavo real (« Paon royal ») ou pavón (« grand Paon »). 
En italien, au xvi ${ }^{\mathrm{e}}$ siècle, les cuisiniers utilisent le terme Gallina d'India (par exemple Romoli 1560, Scappi 1570), éventuellement à côté de Pavone lorsque le paon est lui aussi dans les recettes (par exemple chez Messisbugo 1549, Cervio 1593).

La formule gallina d'India est utilisée tout au long du XVII ${ }^{\mathrm{e}}$ siècle, avec des variantes (gallinaccio, gallo d'India, gallipavo ${ }^{15}$ ):

- 1603, Pierre Canal Dictionnaire français-italien : « Poule d'Inde, Gallina d'India »

- 1627, Caesar Oudin Thresor des trois langues: «Poulle ou coq d'Inde; gallo d'India, gallipavo ; pavo de Indias, gallipavo »

- 1752, Annibal Antonini Dictionnaire italien-français : « Gallinaccio. Dindon, coq d'Inde. »

Une variante inattendue, « la poule bossue » :

- 1678, Nathanaël Düez Dictionnaire italien-français: «Gallina gobba. Poulle d'Inde ». [Gobba : bossue].

- 1691, Oudin, achevé par Veneroni : « Gallina gobba, Poule d'Inde. Gallina rusticilla, Poule d'Inde. Gallinaccio, Poulet d'Inde. »

Et finalement le nom actuel tacchino apparaît au xviII ${ }^{\mathrm{e}}$ siècle :

- 1773, Vincenzo Corrado Il cuoco galante : «Capitolo V. Delli Tacchini, o Galli d'India »

- 1796, François d'Alberti Nouveau dictionnaire françois-italien : « Dindon, Coq d'Inde. Pollo d'India; Gallo d'India. ». Plus loin : « Tacchino. Gallo d'India. Sorte de coq d'Inde. »

À partir de là, les dictionnaires utilisent ce nom pour désigner le dindon, avec ou sans référence à l'ancien nom gallo d'India. Le Vocabolario universale italiano de 1829, de la Société typographique, donne une explication très intéressante :

«Tacchino. Specie di uccello gallinaceo che ha la testa rossa e cerulea, e sparsa di alcuni peli. [...] ; altrimenti Pollino, Pollo d'India ; e più generalmente Gallo d'India, Gallonaccio. [...] Tacchino diff. da Pollo d'India. Pollo d'India è della lingua nobile italiana, e Tacchino è della toscana. »

(Espèce d'oiseau gallinacée qui a la tête rouge et bleue, avec quelques rares poils. (...) Tacchino diffère de Pollo d'India, qui est de la langue noble italienne, alors que Tacchino est de la langue toscane.)

\section{Tanara écrivait en 1674 :}

«...questo animale non hà per ancor determinato certo nome; chi lo chiama Gallo d'India, chi Pauone Gallo, chi Gallo Pauone, chi Gallinazzio, e da'Rustici è chiamato Tocco $[. .$.$] »$

(cet animal n'a pas encore de nom déterminé ; certains l'appellent Gallo d'India, d'autres Pavone Gallo, d'autres Gallo Pavone, d'autres encore Gallinazzio, et les paysans l'appellent Tocco)

9 L'étymologie de Tacchino est inconnue. Certains articles considèrent tocco comme une onomatopée à l'origine de tacchino (étrange onomatopée, pour un oiseau qui glousse!). Mais les dictionnaires étymologiques indiquent leur ignorance avançant, sans y croire vraiment, une éventuelle référence à tacca pour les taches du plumage (O. Pianigiani 1907 Vocabolario etimologico della lingua italiana), voire au turc tang « poule» (F. Zambaldi 1889 Vocabolario etimologico italiano)!

Quoi qu'il en soit, ce terme de tacchino s'impose définitivement au XIX ${ }^{e}$ siècle.

En français, "dinde » est une élision de "poule d'Inde », terme qui domine jusqu'au milieu du XVII ${ }^{e}$ siècle, non sans fluctuations dues à la fois à la recherche de précisions quant aux stades de croissance de l'oiseau, et à l'incertitude de l'orthographe de cette période. On passe ainsi de " coc d'Inde » ou " poulle d'Inde ", à " d'Inde » tout court, et rapidement Dinde. Olivier de Serres (1600) nous en fournit l'exemple, qui utilise toutes 
les formes possibles : la poulaille d'inde, la poule d'inde, les poules d'indes, les d'indes, la dinde, les coqs d'inde, le d'indard, les d'indards, les d'indons, les petits d'indons, les dindons.

Dans son grand œuvre Rabelais, décrivant des festins extraordinaires, mentionne à plusieurs reprises parmi la liste des mets, d'abord des poulles des Indes (1542, Livre 1, La vie tres horrifique du Grand Gargantua), puis des Cocqs, poulles, \& poulletz d'Inde (Le Quart Livre, des faictz et dictz heroiques du noble Pantagruel, $\left.1548^{16}\right)$. Les termes coq et poule d'Inde sont présents dans les textes de 1559 (journal de Gouberville) et de 1583 (Linocier ; voir plus loin).

Dans les livres de cuisine du XVII ${ }^{e}$ siècle, on trouve toutes les formes utilisées par Olivier de Serres : poules et poulets d'Inde, dindons et dindonneaux (pour désigner les jeunes; ainsi dans La Varenne 1651, Pierre de Lune 1656), plus rarement coq d'Inde (dans L'Escole 1662) qui semble sortir de l'usage, voire être remplacé par « dindon ", à mesure que les jeunes sont des « dindonneaux ».

-1690, Furetière, Dictionnaire universel (s. v. Poule) : « ...poules d'Inde, qui sont de très grosses poules venuës de l'Amérique... »

Dans tous les livres du XvIII , à partir du Cuisinier moderne de La Chapelle (1735), on utilise définitivement dindon, dinde et dindonneau (même si un "poulet d'Inde " apparaît par inadvertance). Les Dons de Comus (1739) distinguent le dindon vieux, du « dindon jeune ou dindonneau ».

Dans les dictionnaires du XVIII ${ }^{e}$ siècle, «Dindon » désigne les petits, que l'on nomme actuellement « dindonneaux» :

- Ce terme n'est pas encore dans la première édition de Trévoux (1738-1742, encore " coq d'Inde », Dictionnaire universel françois et latin) ; mais « Dindes » et « Poules d'inde » apparaissent dans le Dictionnaire Economique de Noël Chomel (1741), et dans l'Encyclopédie (tome IV, 1754): "Dinde: Coq d'Inde. Dindon: jeune coq d'Inde. Dindonneau: est un jeune dindon, lorsqu'il n'est guère plus gros que le poing. » De même dans la $4^{e}$ édition du Dictionnaire de l'Académie (1762) : «Dindon, coq d'Inde », et dans la $6^{e}$ édition de Trévoux de 1771 : «Dinde : Coq d'Inde. On appelle ainsi quelquefois la poule d'Inde. Dindon : coq d'Inde. ».

- La même année 1771 Buffon décrit « le Dindon » dans le Tome II de l'Histoire naturelle des Oiseaux [Figure 4]. 
Figure 4 : Dindon et dinde dans la basse-cour ; Buffon, Histoire naturelle des oiseaux, T. II, 1771

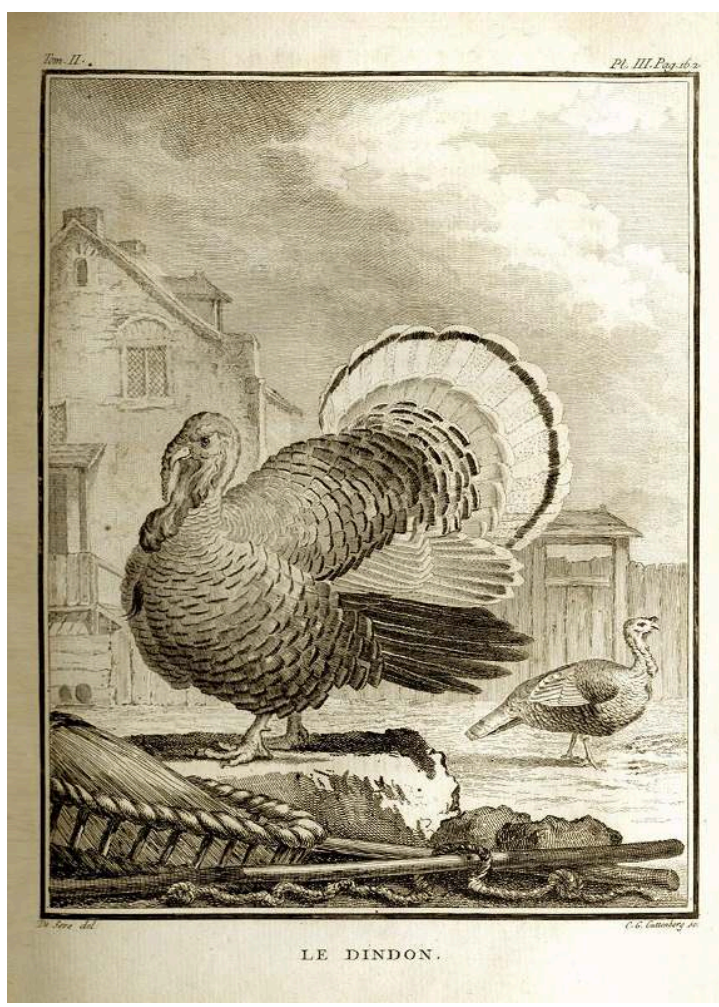

Le mot « dinde » est initialement tant masculin que féminin, pour désigner aussi bien le coq que la poule d'Inde. L'emploie de « dindon » pour le mâle, et non plus pour le petit, émerge peu à peu :

- Féraud, Dictionnaire critique de la langue française (1787-1788) : « Dinde : On apèle ainsi quelquefois une poule d'inde. Dindon, Coq-d'inde. »

- Ce n'est que dans la 6e édition Dictionnaire de l'Académie (1832) qu'il n'y a plus de référence au coq d'Inde: «DINDON. Gros oiseau de basse cour dont la chair est très estimée ». Même si dans l'édition de 1835 l'explication donne à nouveau : "DINDE. La femelle du dindon, appelée autrement Poule d'Inde. »

En portugais, il semble que l'oiseau américain ait été aussitôt désigné par un nom propre, perú, du même nom désignant l'Amérique du sud, sans aucune référence au paon eurasiatique (pavão), et par élision de «Poule du Pérou » (Gallinha do Perú), tout comme les autres langues latines ont fait référence à l'Inde (" poule des Indes ») :

- 1728, Raphael Bluteau Vocabulario portuguez e latino: "Perû. Ave domestica (...), em Italia lhe chamão, Gallo Indiano, \& Gallo d'India; em França Coqdinde; em Castella Pavo, ou Gallo de las Indias. (...) Gallus Indicus. »

- 1789, Antonio de Moraes Silva Diccionario da lingua portugueza: «Perù : Ave de penna, vulgar, e caseira. $O$ vûlgo affectadamente diz perum : chamase Perú, por virem do Perú, e a principio se chamarão Gallinhas do Perú.» (Oiseau commun à plume, domestique. Vulgairement dit perum : on les appelle Pérou, à cause du vice-royaume du Pérou, et au début on les appelait Poules du Pérou.)

En anglais notre oiseau a tout de suite été nommé Turkey, avec diverses graphies, généralement prolongé de kok, cock, fowles. La comparaison avec les autres langues nous assure de sa signification :

- 1584, A. W. A Book of Cookrye : "Turky Fowles" 
- 1611, Randle Cotgrave A dictionarie of the French and English tongues : "Dindar. A Turkiecocke; Seeke Indar. (...) Indar. A Turkie Cocke. (...) (s.v. Inde) D’Inde. A Turkie Henne. Coq d'Inde. A Turkie Cocke. $»^{17}$

Le caractère incongru de ce volatile et son origine inconnue sont marqués par un nom géographique exotique que l'on accole à «coq» ou à "poule»: Inde (India) pour l'espagnol, le français et l'italien, Pérou (Perú) pour le portugais, Turquie (turkey) pour l'anglais, Calicut (un port du sud de l'Inde) pour l'allemand ${ }^{18}$, sans que cela indique nécessairement une localisation précise.

\section{Quand arrive le premier dindon en Europe?}

Le document le plus important, maintes fois cité ${ }^{19}$, et le plus ancien à ce jour, est la lettre royale émise de Burgos le 24 octobre 1511, adressée à Miguel de Pasamonte, trésorier général des Indes, résumée ainsi sur le site des Archives générales des Indes :

«Real Cédula a Miguel de Pasamonte, tesorero general de Indias, para que envíe en cada navío de los que vengan, 10 pavos, mitad machos y mitad hembras, de los que se crían en La Española que se llevaron de Tierra Firme, y haga que los entreguen en la Casa de Contratación de Sevilla donde los tendrán para lo que les mande.» (Archivo General de Indias, INDIFERENTE,418,L.3,F.182V) ${ }^{20}$

(Lettre royale à Miguel de Pasamonte, trésorier général des Indes, pour qu'il envoie en chaque navire qui viendra, 10 "paons ", moitié mâles, moitié femelles, de ceux qui sont élevés à Hispaniola, qui arriveront à la Terre Ferme, et là de les envoyer à la Casa de la Contratación à Séville, où ils seront à disposition de ceux qui les demanderont.)

51 Il s'agit donc là du terminus ante quem, la date indiquant que le dindon est nécessairement connu et peut-être arrivé en Espagne, avant 1511. Et cette réquisition indique qu'il était déjà reconnu comme utile, voire précieux, et possible d'élevage ${ }^{21}$.

Il importe de rappeler que si le dindon est un animal d'élevage au Mexique, qui est son probable foyer de domestication ${ }^{22}$, Cortès n'atteint cette région et la ville de Mexico qu'en $1519^{23}$ : donc la rencontre avec cette volaille en Amérique centrale (Venezuela, Honduras, Yucatan) et l'introduction en Espagne avant 1511, sont antérieures à la conquête du Mexique.

Quels sont les premiers témoignages historiques attestant de la présence du dindon dans les différents pays ? Je porte ici la date du premier texte dont j'ai eu connaissance, dans les différents pays européens ${ }^{24}$.

- 1511 - Espagne : réquisition royale au Trésorier général des Indes.

- 1520 - Italie : l'Evêque de Santo Domingo, Alessandro Geraldini, envoie un dindon et une dinde blanche au Cardinal Lorenzo Pucci, à Rome pour sa volière. (Un témoignage de la place du dindon dans les jardins princiers) (Eiche $2004: 22$; Boudier $2009: 82)^{25}$.

- 1534 - France : Marguerite d'Angoulême, Reine de Navarre possède des dindons dans le parc de son château d'Alençon. (Est-ce la trace de l'introduction du dindon en France, via la Navarre?).

- 1541 - Angleterre : l'archevêque Thomas Cranmer impose au clergé de restreindre la consommation de la volaille (dont turkeycocke) et des gros poissons. (Le dindon était donc déjà largement diffusé, reproduit et consommé au point de permettre les excès).

- 1557 - Belgique : des pouilles et des coqs d'Inde sont servies au cours d'un banquet à Liège (Lancelot de Casteau Ouverture de cuisine, 1604).

- 1560 - Allemagne, Arnstad: 150 dindons sont servis à un banquet de mariage 
(Schorger 1966 : 471). Un texte de 1573 apporte quelques informations historiques, le Rei Rusticae Libri quatuor (une adaptation des livres latins d'agriculture) de Conrad Heresbach comporte une section sur «les oiseaux des Indes » : "Ces oiseaux qu'on nomme d'Indes, sont récents devant nous : en effet ce n'est pas avant l'an 1530 de notre seigneur que nous les avons eus devant nous, pas plus que les auteurs anciens qui supposaient les nommer Melegrides ${ }^{26} »(1573: 290)$.

Evidemment aucun de ces textes n'indique la première arrivée de cette volaille, tout au contraire ils nous informent sur sa présence antérieure aux dates des événements.

Quelques documents nous informent des relations soutenues entre les différents pays, à partir du point d'entrée qui est l'Espagne, ou directement depuis la colonie espagnole d'Hispaniola ${ }^{27}$ ( $c f$. l'Evêque Geraldini en 1520). La présence de dindes dans le parc du château de la Reine de Navarre à Alençon en Normandie, suggère une possible introduction provenant du Royaume de Navarre qui s'étendait de chaque côté des Pyrénées centrales, entre Béarn, Guyenne et Castille, et s'approvisionnait dans toutes ces régions (voir plus loin sur les marchés du roi de Navarre).

Angela Orlandi, étudiant les archives de Florence, met en évidence les relations commerciales intenses entre l'Espagne et l'Italie ; les familles de commerçants italiens avaient des filiales dans les principales villes, notamment Cadix, Séville et Valladolid. Elle décrit la Séville du début du XVI ${ }^{e}$ siècle comme une ville "peuplée d'Italiens, Flamands, Portugais, Français, Allemands, Anglais, devenant un centre d'intérêts internationaux.» (2011: 75). Les commerçants se trouvaient ainsi à la source des produits du Nouveau Monde, qu'ils diffusaient ensuite dans leurs pays respectifs. Dépouillant les archives florentines de la famille Botti, présente à Cadix à partir de 1519, elle a trouvé des lettres demandant d'expédier à Florence des nouvelles semences (en 1562, s'agit-il de maïs ?), et des galli d'India (en 1533 puis 1547). L'envoi de 1533 n'a pas abouti, car les oiseaux ont été saisis à l'escale de Marseille par le capitaine des galères royales, qui se les est accaparés ! (p. 79 : « come erano cose da piacere, l'à volute per lui.»). Matteo Botti insiste sur le coût de ces oiseaux : "je les ai eus pour très cher » (lettre d'octobre 1547), et ailleurs que trois poussins lui ont coûté aussi cher qu'un cheval (« come se fussino uno cavallo ", lettre de janvier 1548).

Une question reste en suspens, à propos de l'Angleterre. Une tradition est répétée, qui donne la date de 1524 ou de 1526 pour l'introduction directe du dindon, sans le passage par l'Espagne, par William Strickland, de Boyton dans le Yorkshire, un marin de Sebastien Cabot ( $c f$. Eiche $2004: 17-18$ ). Une autre tradition suggère l'importation du dindon par des marchands turcs, venant de Séville (Orlandi 2011 : 78). Mais aucun texte ne semble le confirmer ni ne le documente précisément, pour l'heure.

\section{Quels sont les usages des dindons?}

\section{Un curieux oiseau, digne des volières, jardins et élevages des nobles}

Tous les premiers témoignages attestent de l'intérêt des nobles pour cet oiseau remarquable, qu'ils vont ajouter aux collections vivantes de leurs volières et parcs (Boudier 2009).

- 1520 - Italie : j'ai déjà cité l'envoi d'un couple de dindons au Cardinal Pucci, à Rome " pour que le coq témoigne du travail merveilleux de la nature $\|^{28}$ pour sa volière.

- 1531 - Italie : Giovanmaria della Porta obtient deux dindes du Cardinal Salviati pour 
les jardins du Duc d'Urbin («knowing how much Your Lordship takes pleasure in new animals... », Eiche $2004: 22)$.

- 1534 - France, Alençon : Marguerite d'Angoulême ${ }^{29}$, Reine de Navarre, afferme le parc de son château d'Alençon et charge, par le bail, le fermier d'avoir soin de ses dindes (Odolant-Desnos $1787: 562$ ).

- 1539 - France, Alençon : Jeanne, princesse de Navarre, fille de la Reine Marguerite, quitta Alençon pour poursuivre son éducation au Plessis-lez-Tours, et « laissa six poules dindes, les premières qui aient paru en France. $»^{30}$

- 1559 - La Hague, sieur de Gouberville : mercredi 27 décembre 1559 :

«Le mercredi XXVIIe, jour Sct-Jehan (...). Au matin, avant que je fusse levé, ung serviteur de Malin Lucas, de Scte-Croyx, à la Hague, m'apporta ung coq et une poule d'Inde. Je luy donné IIII s. ; il disna céans (...). » (Robillard de Beaurepaire 1892 : 541)

- 1566 - un don digne des rois :

«Chez nous on en faisait le plus grand cas; \& on l'estimait même assez pour être offert aux Rois comme un don digne d'eux. Lorsque Charles IX passa par Amiens en 1566, parmi les présens que le Corps-de-ville vint mettre à ses pieds, il y eut douze dindons. » (Le Grand d'Aussy 1782 : 292)

\section{Un mets de choix pour les festins des nobles}

60 Les témoignages abondent sur la qualité luxueuse de cette volaille encore chère. Ainsi, Geofroy Linocier affirme "C'est un delicieux manger, digne des tables des Seigneurs. » (1583, L'histoire des plantes...), ou le Thresor de santé « On les sert communément aux tables des hommes de moyens. » (1607). En Italie, Stefani indique que les petits dindons, en été, sont tendres «et très appréciés sur les tables des grands seigneurs (Signori grandi) »(1662).

Donnons ici quelques dates les plus anciennes d'événements au cours desquels des dindons ont été servis :

- 1546 - décembre, Rouen : « magnifique banquet » offert par Baptiste Le Chandelier (v. 1490-1549), Conseiller au Parlement de Rouen et Prince de la confrérie des Palinods, à l'issue de sa dernière année de charge. Il en rédige la description dans un grand poème en latin, Parthenia. Dans ce banquet de trois services avec plus de 80 plats, sont présents trois plats de poules d'Inde $e^{31}$. (Bouquet 1883). (C'est semble-t-il la première occurrence de dindon dans un festin en France.)

- 1549 - le 19 juin, Paris : banquet offert à Catherine de Médicis à l'évêché de Paris, au cours duquel sont servis 66 dindes et 40 pâtés faits de 5 dindons ${ }^{32}$.

- 1555 - 16 octobre, Londres: des Turkies ${ }^{33}$ sont servies au dîner des Serjeants-at-Law nouvellement élus, chaque nouveau membre apportant sa part au banquet.

- 1557 - décembre, Liège : des pouilles et des coqs d'Inde sont servis au cours du banquet pour Robert de Berghes, Evêque et Prince de Liège (Lancelot de Casteau Ouverture de cuisine, 1604).

- 1565 - 5 décembre, Bruxelles : banquet pour le mariage d'Alexandre Farnèse et Maria du Portugal (Eiche : 41-43, deux gravures montrent le cortège des serviteurs, portant des pâtés de dindon et de paon).

- 1570 - 26 novembre, banquet pour les noces de Charles IX ${ }^{34}$.

- 1581 - mai, Mantoue : au cours du banquet royal des noces du Prince de Mantoue, sont servies des Pollanche d'India rôties ou braisées (Vincenzio Cervio Il trinciante 1593).

- 1610 - janvier, Rome : banquet offert par le Cardinal Aldobrandino, Camerlingue de la 
Santa Chiesa a tutti li monsignori auditori di Rota (membres du tribunal du Saint Siège), avec des pâtés de dinde ${ }^{35}$ servis froids et des rôts ; de même en février, banquet offert à l'ambassadeur de France ${ }^{36}$ (Vittorio Lancellotti Lo scalco pratico, 1627).

\section{Trop d'ostentation?}

Deux textes destinés à réduire la consommation luxueuse et ostentatoire sont connus, qui concernent explicitement le dindon, l'un d'Angleterre, d'origine religieuse, et l'autre d'Italie, d'origine civile :

- 1541 - Angleterre: l'archevêque de Canterbury Thomas Cranmer promulgue de restreindre la consommation des aliments ostentatoires dans le clergé (dont turkeycocke) (cf. Eiche, Blay) : « Il a aussi été établi que pour les plus grands poissons ou oiseaux, on n'en serve qu'un par repas, ainsi des grue, cygne, dindon, églefin, brochet, tanche, et pour les plus petits seulement deux, pour les chapons, les faisans, les lapins, les bécasses. $»^{37}$

- 1557 - Italie : le Conseil de Venise passe un décret contre le luxe dans les fêtes, publiques ou privées (22 mars 1557, De' Conviti) : « il sera interdit de servir dans les fêtes des perdrix et des dindons (galli d'India), sinon de la manière suivante : on ne peut pas servir deux de ces aliments rôtis, dindons ou perdrix, comme il sera illicite de servir au

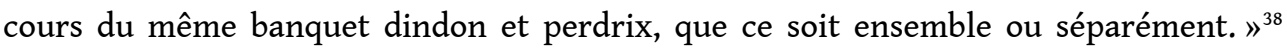
(Zanon $1763: 32$ ).

63 Des lois somptuaires régissant l'achat et la consommation d'oiseaux de luxe dont les dindons ont été promulguées dans plusieurs villes, à Venise déjà en $1547^{39}$, Bologne en 1553, Parme en 1559, à Modène en 1563, à Cesena en 1575 et à nouveau en 1584 (De Grossi Mazzorin \& Epifani 2015 : 59-60). À Venise les lois somptuaires sur les banquets visaient à réduire la dépense et la compétition entre les grandes familles, qui pouvaient conduire à des dettes excessives voire à des ruines, et qui entravaient grandement l'approvisionnement de la cité elle-même (cf. Faugeron 2016).

\section{Son élevage et sa distribution}

64 Au milieu du XVI ${ }^{\mathrm{e}}$ siècle en France, le dindon n'est pas présent dans les marchés, et il ne figure pas dans la liste des volailles et des gibiers «à poil et à plumes " que sont autorisés à vendre les membres de la corporation des volaillers. En témoignent son absence dans l'ordonnance du 20 octobre 1546 taxant les prix de la volaille (Lespinasse 1886 : 347-348), dans le règlement de Charles IX sur les volaillers de 1563 (Le Grand d'Aussy 1782 : 289), et son règlement pour la police générale du Royaume du 4 février $1567^{40}$ (La Mare 1710 : 1377). Cela signifie que, bien qu'il soit déjà connu et élevé, il reste produit directement par ou pour les nobles pour leur usage propre, et il est donc indisponible pour les bourgeois ${ }^{41}$.

Peu à peu, son élevage se diffuse dans la campagne. Quelques citations en attestent :

- 1627 - Du Chesne Le pourtraict de la santé : « ...cette viande est auiourd'huy si commune en France, que les bassecours des bonnes maisons, les granges \& mestairies des vilageois en sont pleines.»

- 1705 - Lemery Traité des aliments : «Le Coq d'Inde est un oiseau assez connu, \& d'un aussi grand usage parmi les aliments que le Chapon \& le Poulet (...)»

- 1751 - L'Encyclopédie (Tome IV, p. 179) : «Coq d'Inde : cet animal est d'une grande 
ressource dans la basse-cour ; il multiplie beaucoup \& souvent, \& la chair en est délicate quand il est jeune. ».

- 1763 - (en Italie du Nord) Zanon Del'agricoltura dell'arti e del commercio : « les coqs et les poules d'Inde couvrent une partie de nos campagnes, ils sont devenus la nourriture des paysans et du petit peuple ; ils abaissent les prix de la viande de bœuf et de veaux, et sont l'objet d'un commerce actif, prédominant ${ }^{42}$. (Vol. I : 34-35).

À la fin $d u x v I^{e}$ siècle, cet oiseau est destiné aux classes sociales élevées, qui le produisent elles-mêmes; au début $\mathrm{du}$ xvII ${ }^{\mathrm{e}}$ siècle son élevage est répandu dans la paysannerie. Entre temps, les difficultés liées à la fragilité de cet animal tropical ont été résolues (voir plus loin).

Il convient cependant de prendre en compte l'analyse de Flandrin, bien qu'il ne mentionne pas particulièrement les dindons, qui indique que les paysans produisent des volailles pour les catégories sociales élevées, mais pas pour leur propre consommation: "les volailles (poules et oisons) étaient plutôt destinées à la vente et aux redevances seigneuriales, tandis que les paysans se contentaient de porc salé » (1996: 600).

En 1538, Henri d'Albret, Roi de Navarre, passe un traité avec Adam Mennyer « marchant boucher et poissonnier » pour approvisionner sa maisonnée en vivres, dans lequel sont inscrits " coq dinde et poulet ", à côté de « signe, sigonne, houtarde, grue, pan, faisant » etc., au prix de 25 sols la pièce (Dartigue 1937 : 413). Dartigue insiste sur le fait qu'Henri d'Albret entretenait des relations commerciales suivies avec l'Espagne, par les cols des Pyrénées. Ces traités, ou marchés, étaient passés devant notaires, et le "pourvoyeur" s'engageait à fournir aux grands seigneurs un approvisionnement régulier de certaines denrées à des prix convenus à l'avance (Couperie 1964: 467). Analysant de nombreux «marchés de pourvoierie » du XvII e siècle, Couperie montre que «les coqs et poules d'Inde, poulets d'Inde et dindons" y sont bien présents, pourvus d'une valeur certaine mais qui décroît dans le siècle: de plus de huit fois le prix d'une poule dans le marché d'Henri d'Albret en 1538, ils n'en valent plus que le double en 1711 (pp. 471-472).

\section{Difficulté de l'élevage}

Il faudra du temps pour que l'élevage du dindon soit maîtrisé. Quelques textes en témoignent.

En Italie, il a la réputation d'un animal fragile lorsqu'il est petit, et agressif une fois adulte. Agostino Gallo, publie en 1565 ses Dieci giornate della vera agricoltura, e piaceri della villa, sous forme d'un dialogue entre Messer Giovanni Battista et Messer Vincenzo qui lui rend visite, à Brescia. Abordant le chapitre des coqs et des poules d'Inde, Messer Gio. Battista termine ainsi sa description :

«[...] Et bien que leur élevage coûte assez cher, toutefois, étant délicats à manger, il est bien d'en avoir, et surtout pour chaque personne noble, pour être honoré avec les amis, quand les coqs sont bien gras, comme j'en ai eus quelques fois, et morts, ils arrivent à peser trente à trente-cinq livres chacun, sachant que les femelles font à peine la moitié, elles couvent leurs œufs en permanence et chacune en a seize, jusqu'à dix-huit. ${ }^{43}[. .$.$] »$

71 À quoi son ami Vincenzo objecte : 
"Je n'ai jamais voulu garder ces oiseaux, d'une part parce qu'ils meurent facilement quand ils sont petits; et d'autre part parce qu'ils sont sales, malhonnêtes et horribles à voir à cause de leur crête. $»^{44}$

Gio. Battista lui répond :

«Quand les poussins naissent, il faut les tenir pendant un mois dans un endroit qui n'est pas froid, et ne pas les laisser sortir jusqu'à ce qu'ils soient couverts de plumes, ou qu'il fasse chaud, ils ne doivent pas manquer de diverses herbes $d u$ potager cuites, de pain et de ricotta [fromage]. ${ }^{45}$

73 Le commerçant florentin Matteo Botti donne un bon exemple de la difficulté d'élever ces oiseaux, qu'il voulait faire venir d'Andalousie pour sa ferme toscane : il perdit son dindon arrivé malade, puis les quatre dindonneaux qui s'entretuèrent dans une querelle, ne lui restant que la dinde ("La gallina sta pure, sino qui, sana et certo sono belli. » (lettre d'octobre 1547). A la suite de cet échec, il cesse ses essais d'élevage, demandant finalement de ne pas lui envoyer les trois poussins commandés, qui lui coûtent si cher ! (Orlandi $2011: 80$ ).

4 La même année que le livre de Gallo, 1565, le premier texte français sur la dinde n'est pas plus engageant. Voici la description des Poulles d'Inde dans la Maison rustique de Charles Estienne :

«Celuy qui nous apporta cest oyseau en France, soit que nous l'appellons coq, ou paon d'Inde, nous a plustost enrichy de gueule, que de profit, car c'est un droit coffre à avoine, un gouffre de mangeaille, où l'on ne peut prendre autre plaisir que de bruit \& fureur, quant aux grands : ou d'un continuel piollement, quant aux petits ${ }^{46}$. Vray est que la chair en est delicate, mais fade \& de dure digestion : c'est pourquoy lon la fait saupoudrer, \& fort larder \& aromatizer. Il y a trop plus de plaisir \& de bonté de chair au Paon. » (1565, chapitre $15: 68)$.

5 En 1569 encore, c'est le même argument qui conduit Prudent le Choyselat, dans son Discours oeconomique, destiné à conduire sa maison pour tirer " grandissime profit » à partir d'une petite somme, à privilégier l'élevage de poules communes, et surtout pas des poules d'Inde :

«Et afin de ne faire plus lõgs propos, advise à colloquer ta somme en achapt de poulles, nõ Meleagrides, que Belon en sa peregrinatiõ a voulu dire estre noz poulles Indiennes, qui sont vrays greniers à avoyne, mais des poulles comunes du pays, \& y negocie par la forme cy apres escrite: Et ne sois si impatient que tu n'attende le periode. » $\left(\mathrm{f}^{\circ} 6 \mathrm{~V}^{\circ}\right)$ (repris sans changement dans les éditions ultérieures).

Bruyant, gourmant, à la chair fade... Olivier de Serres dans le Cinquième Lieu du Théâtre d'agriculture et mesnage des champs (1600), consacré à «la conduite du poulailler, du colombier, de la garenne, du parc, de l'étang, du rucher \& des vers à soie ", donne un tableau différent, en une sorte de réponse à Estienne. Le chapitre consacré à «la poulaille d'Inde » commence ainsi :

«La commodité qu'on tire de la poulaille d'Inde, à cause de l'abondance des precieuses chairs, dont elle honore la table du seigneur en toutes saisons, \& les œufs de mesnage qu'elle donne en certain temps de l'annee; font surpasser les difficultés de son esleuement \& nourriture, sous lesquelles on fouloit gouuerner ce bestail, lors que premierement il vint à nostre cognoissance. Croiant que parce qu'il est estranger, ne pourroit viure \& se multiplier de par deçà, qu'auec extreme souci \& despense. Mais le temps maistre des arts, nous a enseigné ces oiseaux-ci, estre de passable entretien, sans excessif coust, s'esleuer presques en tout aer, bien-que le chaud lui soit le plus propre \& agreable, cõme le plus approchant de son naturel, \& se cõseruer auec moderee solicitude. » 
77 Il propose un autre mode d'élevage, non pas dans la basse-cour ni même « laissees sans soin » autour des fermes (où ces oiseaux «font des maux» aux blés, vignes, jardins, et même aux prairies, ce que dénonçait déjà Estienne) ; il recommande de constituer de petits troupeaux de 6 à 7 douzaines de bêtes, sous la garde d'un garçon qui les mène

«pourmener par la campagne, trouvant beaucoup de mangeaille, des racines, de la vermine, des herbes, des grains des fruits sauvages dont \& pour-néant [gratuitement] elles se paissent très-bien ".

78 En revanche, si on les garde dans la basse-cour, elles sont d'un naturel gourmand et coûtent fort cher en grain. Et de conclure son chapitre en insistant sur la taille de l'animal qui produit une belle masse de chair, sans nécessité d'engraissement:

«Qvant à l'engraisser, cela nest necessaire par traictement particulier : dautant que par l'ordinaire nourriture \& conduite, ceste poulaille se maintient tous-jours en poinct d'estre mangee. »

79 C'est ce mode d'élevage qui va être adopté. Cent ans plus tard, les recommandations pratiques sont conformes au Théâtre d'agriculture. Ainsi Liger (1700), dans l'Oeconomie générale de la campagne (chapitre VI, Des Poules-d'Inde) :

«C'est une chose bien avantageuse pour le ménage, de voir sa basse-court garnie de Poulets \& de Poules d'Inde. Ces animaux rendent beaucoup de profit; \& quelque peine qu'on puisse prendre à les élever, on ne doit point en avoir regret ; le plaisir d'en joüir de quelque manière qu'il nous plaît, nous dédommage aisément des soins qu'ils nous ont coûté. » (p. 73).

80 Il explique ensuite longuement comment élever ces volailles, les faire reproduire (« du nombre de Poules-d'Inde qu'il faut donner à un Coq»), soigner les poussins très fragiles, puis comment « quelque petit garçon » pourra mener paître les dindes :

« Le matin, si-tôt que le Soleil est levé on fait partir ce petit Dindonnier, auquel on recommande fortement de ne point abandonner son troupeau, \& de le conduire tantôt d'un côté, \& tantôt de l'autre, afin que la diversité des pâturages réveille l'appetit de ces animaux, \& les fasse croître au plûtôt. (...) Le soir venu, ce Dindonnier conduira ses Dindes devant luy, pour les mettre dans leur Poulailler: mais avant que de les y renfermer, il observera soigneusement de leur jetter un peu de grain, pour leur faire prendre des forces. La Mere de Famille ne manquera point aussi de faire tous les soirs la revûë de ses Dindes, \& de les compter, afin que le conducteur veille beaucoup sur elles, \& n'en laisse point égarer.» (p. 77).

81 Ainsi trouve-t-on dans l'Encyclopédie (1751, Tome IV : 1011) les recommandations suivantes pour l'élevage des petits dindonneaux : «il n'est guère d'animaux de bassecour plus difficile à élever. Le froid leur est mortel. ». Il ne faut donc pas les sortir, ou seulement brièvement en plein soleil. Il faut les nourrir quatre fois par jour, avec des préparations de mie de pain, de feuilles d'orties hachées, de son, de sarrasin moulu, de millet... «Lorsqu'ils sont forts, on les abandonne au dindonnier. » Ce dindonnier, c'est un

«valet chargé de mener paître les dindons \& les dindes. On ne mene ces volailles aux champs, que quelque tems après le soleil levé. On les remene dans la basse-cour sur les dix heures, où elles restent jusqu'à midi qu'elles retournent aux pâturages pour jusqu'au soir.»

82 Le dictionnaire Trévoux (éd. 1771) complète : "En plusieurs endroits de France on mène les dindes paître à la campagne par troupeaux, comme des moutons. » (sv Dinde), et plus loin: "Dindonnier. Pâtre, conducteur de dindes, ou de dindons. (...) Le Dindonnier a une grande gaûle pour conduire ses dindes. ». Buffon précise : « comme ils 
[les dindons] sont fort craintifs, ils se laissent aisément conduire, il ne faut que l'ombre d'une baguette pour en mener des troupeaux même très-considérables » $(1771: 145)$.

«Cet oiseau est actuellement naturalisé en France ; il y est même devenu des plus communs. Dans l'arriere saison, on en voit paître dans nos campagnes une si grande quantité, qu'ils paroissent former des especes de troupeaux. » écrit Buchoz en 1777 (Traité économique et physique des oiseaux de basse-cour, Liège, Desoer, p. 27).

L'élevage de dindons prend de l'ampleur ainsi que la consommation et la pratique de conduire les troupeaux vers les lieux de commerce. Deux témoignages sur cette pratique, le premier par Vincenzo Tanara, en Italie en 1644, dans son Economia del cittadino in villa, qui affirme avoir vu conduire deux centaines de dindons, à pied, du Royaume de Naples à Rome, soit un parcours de cent milles ${ }^{47}$, guidés par des garçons (putarelli). En France, Le Grand d'Aussy rapporte que «tous les ans, \& depuis plus d'un siècle, nos Paysans du Querci et du Périgord conduisent (...) jusqu'au centre de l'Espagne, des troupeaux entiers de dindons (...)» (Le Grand d'Aussy 1782 : 294).

$\mathrm{Au}$ début $\mathrm{du} \mathrm{XIX}^{\mathrm{e}}$ siècle, ces transhumances à destination des marchés prennent de l'ampleur, comme en témoigne l'enquête des préfets dans l'Indre :

" les dindes et les oies sont l'espèce de volaille que l'on élève en plus grande quantité (...) elles sont conduites au pacage par troupeaux; elles ont aussi leurs gardes et ce sont les enfants de huit à neuf ans qui sont chargés de ce soin: les dindes sont aussi conduites pendant l'hiver au marché par troupeaux. La plus grande quantité est consommée dans le pays; on en expédie cependant pour Orléans. » Mémoire statistique du département de l'Indre, par le C $C^{\text {te }}$ d'Alphonse, préfet ; Paris, Imprimerie Nationale, an XII [1803-1804] : 193-194

Figure 5 : "Gardeurs de dindons dans les Landes de Gascogne » avec leurs baguettes (carte postale, cachet de la poste juin 1914)

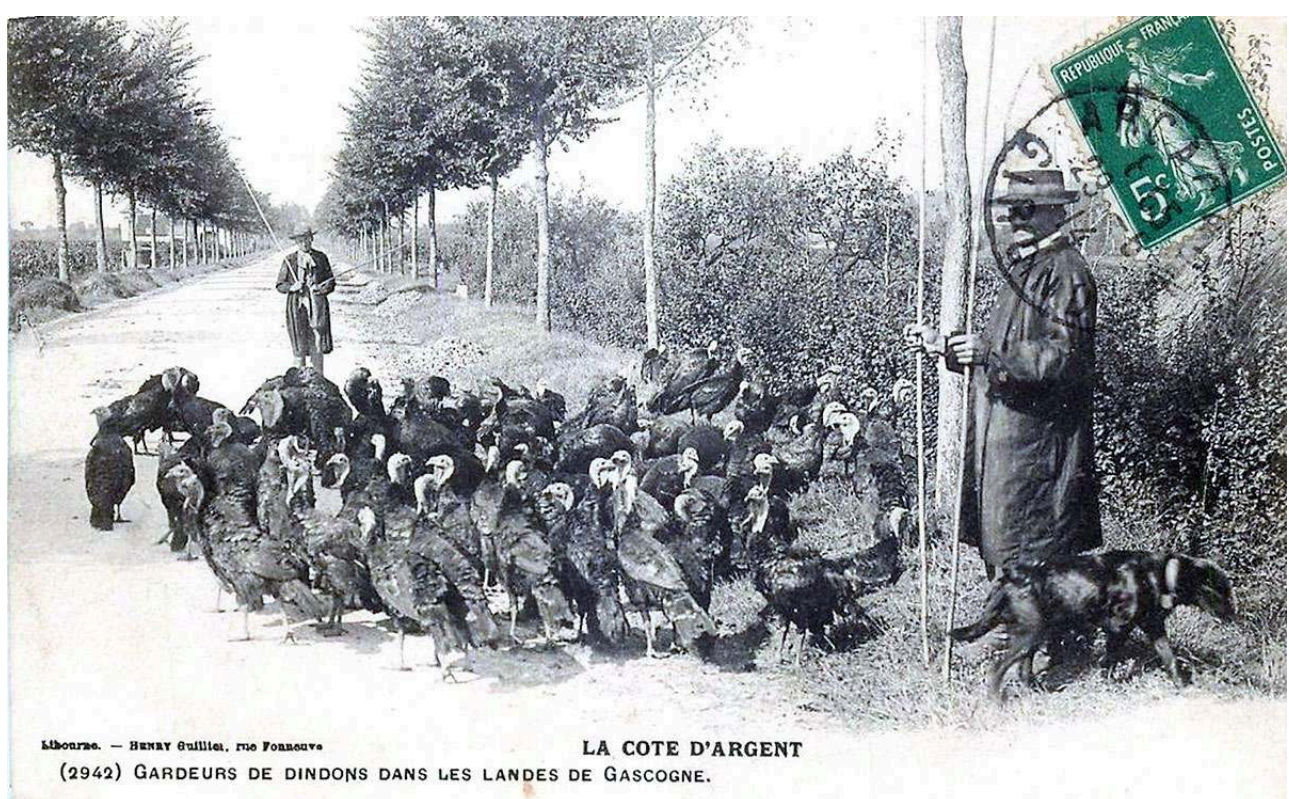

\section{Le choix}

85 La réputation initiale du dindon est celle d'une viande difficile à digérer, par exemple : «Sa chair est double et triple, et pareillement difficile à digérer ${ }^{48}$ écrivent Savonarola \& B. Boldo dans leur Libro della natura e virtù delle cose nutriscono (1576 : 124). Même 
prévention en France, exprimée par exemple dans Le thrésor de santé ou ménage de la vie humaine (1607), « Du coq et de la poule d'Inde » : «Vray est que leur chair est tendre \& delicate, neanmoins elle engendre un gros suc, se digere mal-aisément, \& abonde en viscositez, parquoy il est bon de les saupoudrer \& aromatizer. » (p. 204). De là viendra une attention soutenue à l'âge propice à la consommation et, en lien, à la saison favorable à l'abattage, enfin sur la durée de préparation de la viande (mortification) et aux sauces et accompagnements (voir section suivante).

Vingt ans plus tard cependant, le tableau change, et l'animal est considéré positivement, comme en témoigne Joseph Du Chesne, conseiller et médecin ordinaire du roi Henri IV, dans son Pourtraict de la sante (1627), à propos du coq d'Inde :

«C'est une friande, excellente, bonne et saine viande, de facile digestion, de tres-

bonne nourriture, engendrant quantité de bon sang \& de semence : bref c'est une

viande des meilleures, plus saines \& delicieuses qui se trouvent. » (p. 423).

Selon le cuisinier italien Romoli (1560), les jeunes naissant en mars, ils seront bons en août; quant aux jeunes dindes, elles seront excellentes entre cinq et six mois. En revanche, la viande des dindes adultes sera meilleure au plus froid de l'année ${ }^{49}$. Stefani (1662) confirme que la saison propice à la consommation de ces volailles sont les mois d'été (juin, juillet, août), durant lesquels ils sont encore petits, et tendres ${ }^{50}$. Scappi (1570) recommande de ne pas laisser reposer en hiver plus de 4 jours avant d'être vidé, et deux jours en été ${ }^{51}$; mais pour les dindonneaux (la pollancha giovane) «Prenez la volaille morte depuis 1 jour en été et de trois jours en hiver car la viande se faisande vite et ainsi elle a une chair plus blanche. ${ }^{52}$ ”

Je donnerai ici les recommandations d'un cuisinier allemand mais œuvrant en Italie, Mattia Giegher, officier-tranchant de l'ambassade d'Allemagne à Padoue en 1639 [Figure 6]:

« La vraie saison pour les coqs et poules d'Inde (Gallo e gallina d'India) est la partie la plus froide de l'année, et étant de viande très dure, il est bien de les laisser morts quelques jours, afin qu'ils s'attendrissent. Des jeunes on ne devrait pas faire mention car ordinairement on ne les tue pas dans notre pays, cependant si quelqu'un avait le goût d'en manger, il faut savoir que les mâles doivent avoir au moins quatre mois, et les femelles (pollanche) cinq ou six..$^{53}$ " (Li tre trattati di Messer Mattia Giegher 1639 : 5) 
Figure 6 : La découpe du Gallo d'india, Li tre trattati di Messer Mattia Giegher, 1639

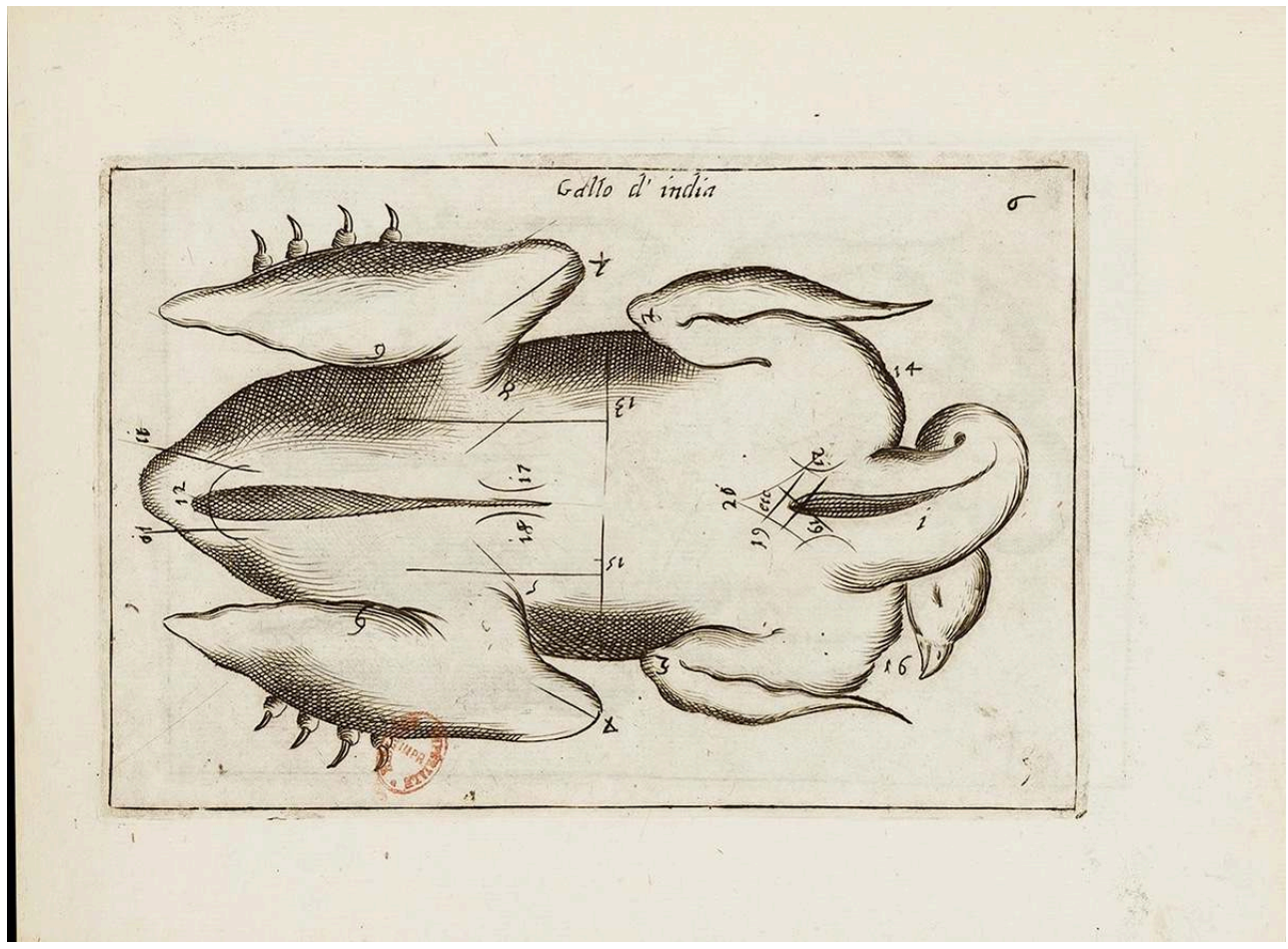

Source gallica.bnf.fr/Bibliothèque nationale de France

Côté français, selon Pierre de Lune, dindons et dindonneaux peuvent se servir « aux bonnes tables" pendant toute l'année (aux quatre saisons). Plus précisément, on prélève les dindons de l'année entre Pâques et la Saint Jean ( 24 juin), les poulets d'Inde de la St Jean à la Saint Rémi ( $1^{\text {er }}$ octobre) où " ces viandes sont à leur bonté », et de la St Rémi jusqu'à Pâques, les poulets et les coqs d'Inde (La Varenne, Pierre de Lune). Les cuisiniers français ne fournissent aucune recommandation sur la durée de mortification des dindons après l'abattage. En revanche, ils préfèrent unanimement les jeunes dindonneaux, puis les dindes (les femelles), et apprécient assez peu les mâles (dindons), considérés comme durs et réservés pour la cuisson en daube. Voyons le Traité des aliments de Lemery (1705) :

«Les meilleurs Coqs d'Inde, pour le goût \& pour la santé sont ceux qui sont jeunes, gras, \& qui ont été nourris avec un grand soin. (...) Cependant quand il est un peu trop vieux, sa chair est dure, coriasse, \& difficile à digerer. » (p. 295).

\section{Marin précise dans les dons de Comus (1739) :}

« Le Dindon vieux se met en pâte \& à la daube. Le Dindon jeune, ou le Dindonneau, fournit davantage à la cuisine, ou se diversifie davantage. Le corps se met à la broche \& fait du rot : pour entrée on le met à l'échalotte, en filet (...)».

\section{C'est toujours l'opinion de Le Grand d'Aussy à la fin du XviII ${ }^{\mathrm{e}}$ siècle :}

«Nous autres, aujourd'hui, nous en trouvons la chair dure \& séche. Nous ne mangeons rôti que le dindonneau. Pour le dindon, on ne le sert guères qu'en daube ou en pâté ; à moins qu'il ne soit farci de truffes, comme ceux qui nous arrivent du Périgord. » (Histoire de la vie privée des Français, 1782 : 293). 


\section{Comment le dindon entre-t-il dans la cuisine?}

92 En examinant des livres de cuisine imprimés pays par pays et par ordre chronologique, je vais tenter de cerner la place qu'a pu prendre le dindon au cours des années. Pour certains pays, j'ai tenté de voir l'ensemble des livres; dans d'autres j'ai procédé à une sélection afin d'avoir des exemples pour toutes les époques. Je n'ai pas nécessairement comparé les éditions successives, qui pour certains livres à succès peuvent s'étaler sur plus d'un siècle (on trouvera la liste des livres consultés dans l'annexe 1).

Il convient de préciser la place historique et la fonction de cet objet singulier qu'est le livre de cuisine. En effet, on constatera une disparité dans les pays étudiés ici, en termes de date d'apparition, de nombre de titres et même de types d'ouvrage. Il faut aussi prendre en considération que la présence d'un aliment dans un livre de cuisine n'est en aucun cas une archive précise de son apparition. Les recettes de cuisine sont des traces, pas des preuves, et le panorama qu'elles offrent n'est qu'un reflet, une image, de la conception que l'on se fait d'un aliment dans un style alimentaire précis. De plus, les livres de cuisine s'adressent à des lecteurs particuliers, et de ce fait une liste de recettes ne peut pas être considérée comme l'état de l'alimentation d'une société. Jusqu'au $\mathrm{Xv}^{\mathrm{e}}$ siècle, les recettes de cuisine sont transmises dans des manuscrits, multiplement recopiés (Laurioux 1988). Puis l'histoire des livres de cuisine suit celle de l'imprimerie, mais ceux-ci ne sont qu'une expression particulière, alors qu'existent en parallèle des carnets, des manuscrits destinés à des utilisateurs privés, et qui maintiennent des usages, d'ailleurs le plus souvent transmis oralement.

Les livres de cuisine du Moyen Âge sont d'abord des manuscrits, qui se copient et s'amplifient au fil des copies en un réel « bricolage textuel » (Laurioux 1988). A un texte minimum de recettes conçu par un cuisinier professionnel, une sorte de cahier pensebête, sont ajoutées peu à peu des précisions indispensables aux utilisateurs communs (l'injonction), tout en ajoutant çà et là de nouvelles recettes (le truffage), puis en juxtaposant de nouveaux textes. Des livres imprimés au XVI e siècle à partir de manuels médiévaux manuscrits, on peut citer en France Le Viandier (première version imprimée en $1486^{54}$, puis jusqu'à 1555), en Espagne le Libre del coch ( $\mathrm{du} \mathrm{xv}^{\mathrm{e}}$ siècle, imprimé jusqu'en 1529) et en Angleterre The book of cookerye (également $\mathrm{du} \mathrm{xv}^{\mathrm{e}}$ s., encore imprimé vers 1575).

96 Cet ensemble de procédés reconnus dans la composition des manuscrits, se retrouve aisément dans les versions successives des livres imprimés aux XVII ${ }^{\mathrm{e}}$ et $\mathrm{XVIII}^{\mathrm{e}}$ siècles, dont on trouvera de nombreux exemples ci-après : en Italie L'arte di ben cucinare de Stefani, publié de 1662 à 1685, en Espagne Arte de cocina de Altamiras, publié de 1758 à 1850, en France Le cuisinier roïal et bourgeois par Massialot puis La Chapelle de 1705 à 1742, en Angleterre The art of cookery de Glasse, de 1747 à 1846.

$97 \mathrm{Au}$ départ les livres de cuisine imprimés sont essentiellement des recueils de recettes écrits par des cuisiniers, afin de les transmettre dans les bonnes maisons ${ }^{55}$. Certains indiquent également comment tenir une maison, en s'adressant à la fois au cuisinier, au maître d'hôtel et même à l'écuyer tranchant (ainsi La singolar dottrina de Romoli 1560, Li tre trattati di Messer Mattia Giegher 1639, ou encore L'escole parfaicte des officiers de bouche de 1662). Quelques livres comportent des menus types associés aux différentes saisons de l'année. Au cours du xvII siècle, il semble apparent que les usagers auxquels les livres sont destinés changent, et qu'ils s'adressent essentiellement non plus aux 
cuisiniers ou aux princes, mais aux bourgeois; on passe ainsi de la cuisine des nobles à une cuisine bourgeoise domestique. A titre d'exemple, pour le France, on passe du Nouveau et parfait maistre d'Hostel royal de Pierre de Lune (1662) au Cuisinier roïal et bourgeois de François Massialot en 1705.

\section{Livres espagnols}

Certaines recettes concernent explicitement « gallo y gallina de las Indias », ou aussi polla de Indias, qu'il semble distinguer de pauos, ainsi que des faisans, des poules et des chapons $^{64}$. J'ajoute que Granado est le seul livre consulté qui donne explicitement une recette pour le cochon d'Inde : " pastel de conejo de las Indias " (p. $\left.89 \mathrm{R}^{\circ}\right)$. D'après Allard (1988) puis Redondo Buey (2014), le livre de Granado est basé entièrement sur celui de Ruberto de Nola (1529) ainsi que sur les livres italiens de Bartolomeo Scappi (1570, 1610). Il semble en effet que les recettes concernant le dindon se ressemblent (Plouvier 1995).

La tendance ne se modifie pas au xIX ${ }^{e}$ siècle, la place du dindon n'y est pas plus grande. J'ai consulté quatre ouvrages (en plus des rééditions de Altamiras) : La nueva cocinera curiosa y económica y su marido de D. A. P. Z. G. (1822, 4 mentions $\left.{ }^{65}\right)$, Novísimo arte de cocina o aviso a la cocineras $\left(1845,1\right.$ seule recette $\left.{ }^{66}\right)$, Manual de la cocinera española $y$ americana de M. Brecarelli (1898, 5 recettes $\left.{ }^{67}\right)$. Trois de ceux-ci donnent des recettes 
avec les abats, ailerons, pattes, foie, cou, gésier (DAPZG, Manual del cocinero, Brecarelli). J'ai laissé à part le Manual del cocinero, cocinera y repostero $\left(1828,9\right.$ recettes $\left.{ }^{68}\right)$, qui est la traduction du Manuel Roret français de 1826, Manuel du cuisinier ${ }^{69}$. L'auteur, traducteur et adaptateur, D. Mariano de Rementería y Pica, précise que les jeunes dindons sont utilisés en guisados (ragoût) et les vieux en adobo (marinade), et que l'on préfère la dinde parce qu'elle a un goût plus délicat. Mais le livre original français comportait 19 recettes (dont 7 pour accommoder les ailerons)! Le traducteur n'en a donc choisi qu'une partie et réduit considérablement, probablement pour suivre le goût de ses lecteurs.

103 Allard (1988) attire l'attention sur le fait que ces rares traités culinaires espagnols des $\mathrm{XVI}^{\mathrm{e}}$ et XVII ${ }^{\mathrm{e}}$ ont été rédigés par des cuisiniers de cour, ou reconnus par la cour. Deux ont été considérés comme novateurs, en leur temps et après, et ont connus de grands succès éditoriaux, avec de multiples réimpressions pendant plus d'un siècle : Martinez Motiño, réédité 25 fois de 1611 à 1823, et Juan Altamiras, réédité pendant un siècle, de 1745 à 1850 on l'a vu. Toutefois, leur aspect novateur ne se remarque pas en ce qui concerne le dindon.

104 À l'inverse, l'ouvrage de Granado, qui apporte plus de recettes originales, a rencontré très peu de succès, avec seulement 3 éditions $(1599,1606$ et 1614). Du fait de son caractère compilatoire ( $\mathrm{du} \mathrm{Xv}$ siècle hispano-catalan d'une part et du $\mathrm{xVI}^{\mathrm{e}}$ italien de l'autre), Allard suggère que ce faible intérêt pourrait être dû « à l'italianité de la plupart des recettes et à l'ancienneté des autres?».

105 En conclusion, le dindon apparaît bien dans les livres de cuisine espagnol au XVII siècle, sans soulever un grand intérêt de la part des cuisiniers qui lui prêtent très peu de recettes spécifiques, même au XIX ${ }^{e}$ siècle; il n'est souvent qu'une faible possibilité parmi d'autres volailles.

\section{Livres italiens}


Figure 7 : Le rôtisseur et l'écuyer-tranchant servant à table à Venise au $17^{\mathrm{e}}$ siècle (page de titre de Dell'arte del cvcinare Scappi 1610)

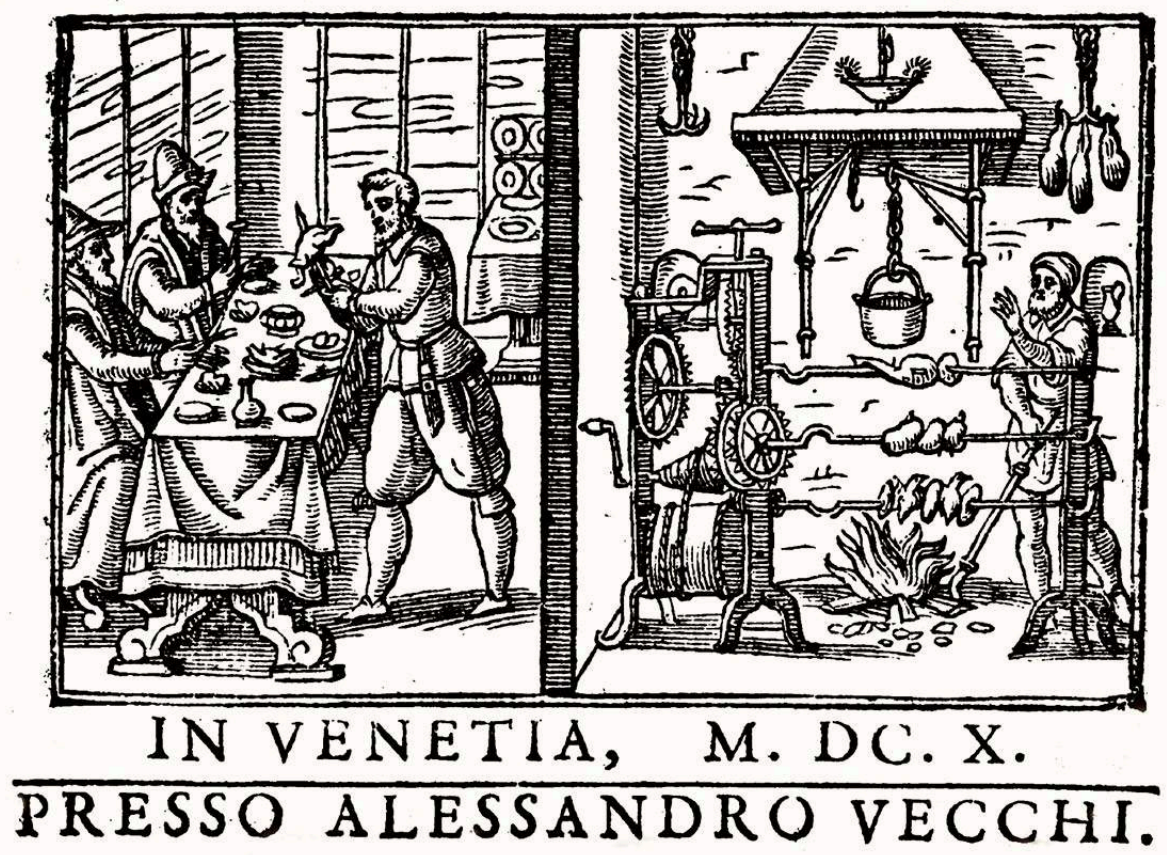

106 Le livre italien le plus important du début du XvI siècle, Banchetti compositioni di vivande et apparecchio generale de Christoforo di Messisbugo ${ }^{70}$ (1549), donne de nombreuses recettes de chapons, poules, poulardes, faisans, pigeons, même paon (pavo, pavoni), mais pas de dindons.

De même, le Trattato della natura de cibi e del bere de Baldassare Pisanelli (1583) pose un problème particulier, car s'il parle des qualités et usages du Gallo d'India, à côté du chapon et du paon, il précise dans la partie « histoire naturelle » : «ce sont ces oiseaux qui ont été apportés de Numidie, et non d'Inde, et ils sont appelés Meleagrides par les Grecs $»^{71} \ldots$ Il s'agit donc de la pintade, et pas du dindon.

Par la suite, dans la deuxième moitié du xvi ${ }^{\mathrm{e}}$ s., tous les livres accordent une belle place au dindon, mais les informations proviennent surtout des listes des plats qui sont donnés dans les menus de banquets, plus que des recettes proprement dites. Ainsi de Romoli, Cervio, Lancellotti, et même Scappi. Plusieurs de ces livres connurent plusieurs éditions, qui la plupart du temps ne comportent pas de modifications (ou très peu) : ainsi de Domenico Romoli (La singolar dottrina 1560, 1587), Bartolomeo Scappi (il Cvoco secreto 1570, Dell'arte del cvcinare 1610), Ottavio Stefani (L'arte di ben cucinare 1662, 1672, 1685).

109 En 1560, Romoli donne quatre plats de dindonneaux ou de dinde, il en ajoute un en $1587^{72}$. Le livre de Vincenzio Cervio, Il trinciante (« l'écuyer-tranchant », 1593 $3^{73}$ ) est très connu car il comporte une planche souvent reproduite, qui compare la découpe du dindon et celle du paon [Figure 8]. Décrivant plusieurs banquets des noces (comme celles du Prince de Mantoue en mai 1581, du duc de Paliano en novembre 1589), il cite huit plats de dindes farcies (d'ortolans, de truffes), avec diverses sauces (aux cardes, aux raviolis verts, aux asperges... $)^{74}$. 


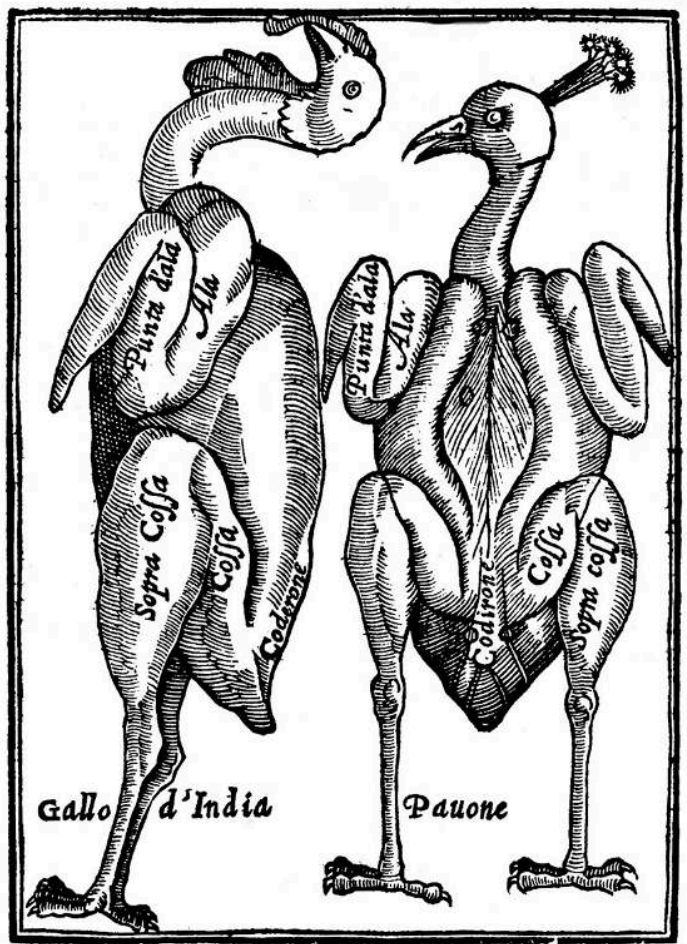

110 Les deux livres similaires de Bartolomeo Scappi ${ }^{75}$ se distinguent de tous les autres par leur ampleur. Scappi, « cuisiner secret du Pape ", est considéré comme le rénovateur de la cuisine italienne, transformant l'héritage médiéval et inventant des centaines de recettes, qui influencèrent durablement non seulement les cuisiniers italiens, mais toute l'Europe grâce à des traductions et des adaptations (voire des plagiats) dans d'autres langues (notamment Diego Granado en espagnol, on l'a vu). Scappi consacre des paragraphes aux animaux du Nouveau Monde, le dindon (Gallo d'India), mais aussi le canard musqué (Anatra d'India) et le cobaye (Coniglio d'India) ${ }^{76}$. Il mentionne 31 plats impliquant le dindon, 10 recettes et 21 plats listés dans les menus. Les recettes sont essentiellement des directives globales pour rôtir à la broche [Figure 9] ou cuire au bouillon toutes les volailles, et en utiliser les abats (foies, gésiers), faire des pâtés ou des consommés. Les plats sont basés sur ces rôts ou bouillis, diversement farcis (avec des prunes, des petits oiseaux ou des merles, des truffes, des cardes, de l'ogliapotrida...) et accommodés avec une grande variété de sauces (accompagnement: arroser de jus de bigarade, de coins, de petits citrons ; parsemer dessus des morceaux de citron, d'anis, des olives dénoyautées, des câpres de tailles diverses, du fromage, de fleurs de bourrache et de persil, et presque toujours, terminer en saupoudrant de sucre...). Scappi emploie le dindon (gallo), les dindes (galline), les dindonneaux (pollanche) et les petits (pollanchette) ${ }^{77}$. 
Figure 9 : Recette pour rôtir, dans Scappi, Cuoco secreto (1570)

\section{Per arroftire il Gallo, da Gallina d'India, liquali in alcuni locbi d'Italia fi dimundano pawoni d' India, Cap. $C X L I$.}

\begin{abstract}
T gallo, o la gallina d' India fon moleo pir grosfi di corpo cbe non dil pauone nostrale, et il gallo fa la ruota anchor egli come il payoue nost rale, et bale piume negre, et bianche, et il collo cre $\beta$ puto di pelle, et in capo la tefte un corno di carne, il qual quando il gallo fi corruccia, ganfia, et wien grof/o is modo che gli cuopre tutto il mo Raccio, et alcuni altri banno il detto corno roffo mefcolato di pauonazzo i largo di petto, et nella punta d'efjo petto ba una pannocchia di jetole a modo di quelle del porco congixnte nelle piume, et ha la carme molto piu bianca, et piu molle del panone nostrale, et if frob la piw prefo cbe il cappone, et altri fimili wolatili. Volendolo arroftire nello ßpedo, non fi lafci riposare dopò la fwa morte il $V$ erno con li fuoi interiori in corpo pin di quattro in feigierni, et l'Eftade piu di due gionni; fpiwmifi a fciutto o con acqua calda (come fi ba da piumanre ancho la gallina, )fpiwmato che Sara,set priwo delli fuoi interiori,ac commodifggli il petto,percioche ba un'oßo nel petto afai piu alto che non banno gli altri molatili,e taglifi la pelle da uma banda appreßio al detto ofBo, eftaccbifi con destrezza la carne dal detto offo,et taglafi las punts del detto oßo cö un coltello cbe rada, e ricufciaji la pelle,e nole defiempire empiafí duna delle cöpofitioni dette nel cap. 115. taglino
\end{abstract}

«Pour rôtir le coq et la poule d'Inde, que dans quelques lieux d'Italie on dénomme paons d'Inde »

Le livre de Vittorio Lancellotti Lo scalco pratico («le maître-d'hôtel pratique », 1627 ${ }^{78}$ ) est un recueil de menus de banquets donnés entre 1602 et 1627 . Les dindons et dindonneaux y sont présents dans presque tous les services, sous une vingtaine de formes, quelquefois utilisées à plusieurs occasions : les volailles sont rôties et lardées (de lard, de citron confit, de coing confit), farcies (de moelle, de saucisses «bouillies dans le [vin de] moscatel »), en pâtés (pasticci), mises en forme et décorées richement (avec des feuilles de pâte ou de massepain marzapane, de feuilles d'or, d'argent...), en forme d'aigle, d'aigle à deux têtes, en oglia podrita avec des cailles, accompagnées de pain d'Espagne, de pain rôti, de pâte, etc. ${ }^{79}$. Elles sont souvent servies froides, généralement dans le premier service. Deux exemples de ces recettes extraordinaires, montrant des plats luxueux destinés à des grands personnages :

Pollanchotte d'India arrosto assagianate, poi levate dalla carta, servite con fette di pane sotto, che era stato a mollo nel latte, indorate, e fritte, con salsa bastarda sopra, con fettoline di pane di Spagna intorno, in forma di lardoni, con copertoro sopra a gelosia, di zuccaro cannellato, tocco d'oro. (8 Mai 1603, Noces du Duc Allexandre de Modene) [Gros dindonneaux rôtis, assaisonnés, puis retirés de la papillote de papier, servis sur des tranches de pain ramollies dans du lait, dorées et frites, napées de sauce bâtarde, avec des petites tranches de pain d'Espagne autour, en forme de lardons, couverts en treillis de sucre cannelé, une touche d'or].

Pollanchotte d'India arrosto, servite con un rosone sotta di pasta di sfoglio, e quattro vuoti, che in ogni vuoto era una pollancha, in mezo al quale era un vaso fatto di pasta di zuccaro, tocco d'oro, con una coroncina di zuccaro intorno al piatto tocca d'oro. (Avril 1622, repas offert par le Cardinal Aldobrandino à l'illustrissime Ludovisi e Pio lors de sa visite à l'improviste). [Gros dindonneaux rôtis, servis avec une grosse rose en pâte feuilletée, et quatre ouvertures, dans chaque il y avait une petite dinde, et au milieu 
il y avait un vase fait de pâte de sucre, avec une touche d'or, et une couronne de sucre autour du plat, avec une touche d'or] et cocqs d'Inde d'indonneaux", sous forme de potage, de daube, de ragoût, de pâté. Il préfère nettement l'usage des formes jeunes («poulets»); il décrit des farces complexes, avec abats de pigeonneaux («beatilles»), marrons, champignons et truffes, et une recette de "poulet d'Inde à la framboise farcy ", où l'on rajoute selon la saison, une poignée de framboises sur le plat avant de le servir ${ }^{85}$ [Figure 10] ! 
Figure 10 : La recette du dindon à la framboise, de La Varenne (Le cuisinier françois, 1651)

$$
\begin{aligned}
& \text { Fran çorso } \\
& \text { Maniere d'apprefter les viandes des } \\
& \text { Entrées, dont la Table eftcy-defjus. }
\end{aligned}
$$

I. Poulet d' Inde à la Framboiffe.

Apres quil eft habillé leuez en le bricher, \& tirez la chair que vous acherez auec graiffe \& peu dechair de veau, que vous meflerez enfemble auec ieaunes d'œufs \& pigeonneaux, \& le tout bien affaifonné, vous remplirez voltre pouler d'Inde auec fel, poivre, cloubatu, \& ca. pres, puis le mettez à la broche \& le faites tourner bien doucement; eftant prefque cuit, tirez le \& le mettez dans vne terrine auec bon bouillon, champignons \& vn bouquet: pourlier la fauce prenez vn peu de lard coupé, le faites paffer par la poëfle, lequel eftant fondu yous tirerez, \& y mettrez vn peu de farine que vous laifferez bien rouffir , \& delayerez auec peu de boullion \& du vinaigre; la mettrez en fuite dans voftre terrine auec ius de citron, \& feruez : fi c'eft au temps des framboifes, vous y en mettrez vne poignée par deffus.

Source gallica.bnf.fr/Bibliothèque nationale de France

Peu après, Pierre de Lune publie Le cuisinier $(1656)^{86}$, avec 15 recettes pour dindon, dindonneau, poule d'Inde, poulets d'Inde, coq d'Inde. Il les prépare en potage (au chou blanc, aux morilles, au concombre), en pâtés froids ou chauds (dont un pasté à la portugaise avec cannelle, écorce de citron, dates du Levant, pistaches, prunes, raisins de Corinthe, et lard...), en grillades, en pot pourry, en rôtis - en précisant «Les dindes et les dindonneaux se doivent arroser en rotissant avec un filet de vinaigre, siboulle, un peu de sel, \& poivre blanc. ». La chair des blancs est employée pour la confection du boudin blanc, et de diverses farces (dont celle pour la tête d'agneau). Dans un livre ultérieur, Le nouveau et parfait maistre d'Hostel royal (1662), Pierre de Lune ajoute un «Traitte de cuisine à l'espagnole " qui contient plusieurs recettes de dindon ${ }^{87}$ qui comportent des amandes pilées, de la cannelle, ou du vin blanc, marrons, prunes, écorce de citron, ou encore lard, macarons, raisin de corinthe, dattes du levant, pignons... [Figure 11] 


\section{Poulets-dinde defojiz.}

Faites farce auec la mefme chair \& lard, marons, formage, \&x jaunes d'œufs; eftant farcie, paffez la à la poele, \& la faites cuire dans vne terrine auec bouillon; \& quand elle fera cuite, \& le boüil lon confommé, metrez capres, formage rapé, fafran, \&ziaunes d'oufs.

Dans la section « Entrées de table en viande à l'Espagnole » (p. 289)

Source gallica.bnf.fr/Bibliothèque nationale de France

L'escole parfaicte des officiers de bouche (1662) comme L'art de bien traiter de L.S.R. (1693) confirment l'usage du dindon d'âges divers, avec une prédilection pour les jeunes de l'année, dans toutes les préparations, rôtis, daubes, farces, pastez, en insistant sur la qualité du blanc: «le blanc en est le plus délicat» (...) «prenez garde de toujours couper le plus de l'estomach que vous pourrez, car comme j'ai dit, il est le morceau le plus délicat » insiste «l'officier de bouche » dans sa partie sur la «Dissection du Coq-d'Inde » [Figure 12]. 
Figure 12 : « Dissection du Coq-d'Inde » dans L'escole parfaite des officiers de bouche (1662)

Le Grand Efcryyer.Tranthant. 39

Diffection du Coq-d'Inde.

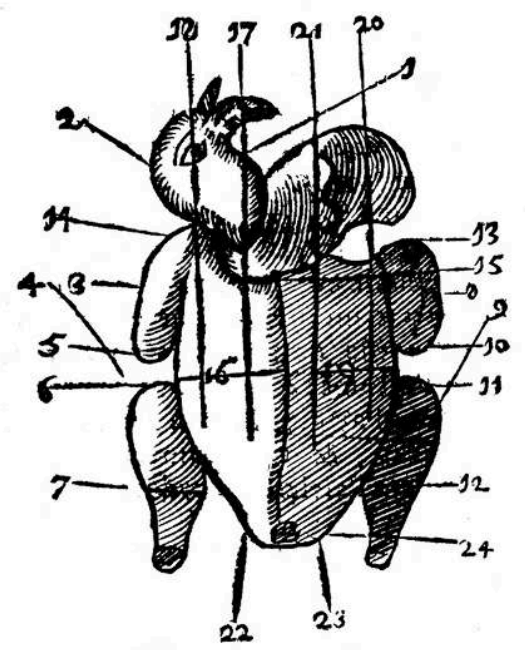

Source gallica.bnf.fr/Bibliothèque nationale de France

119 Plus riche est le cuisinier roïal et bourgeois de Massialot, dans sa deuxième édition de 1705, qui comporte une vingtaine de recettes consacrées aux jeunes individus (les dindons) ou aux poulets d'Inde, certaines destinées aussi aux gros pigeons ou aux chapons, ainsi qu'une liste de plats dans un choix de menus pour tous les mois de l'année (potages, rôtis, pâtés, pot-pourri, daube ${ }^{88}$, salmi). Je n'en citerai que quelques titres alléchants ou mystérieux: petits dindons à la chicorée blanche, potage de dindonneaux aux morilles farcies \& aux choux blancs, poulets d'Inde à la Suisse \& frits au concombre, dindon à la sausse au jambon, dindon en filets aux concombres... Il propose deux recettes qu'il apprécie grandement car, dit-il «ces deux-ci sont sans doute des plus nouvelles, \& celles par consequent qui meritent que nous en parlions les premieres. »: une entrée de Dindons farcis aux fines herbes (on farcit entre la peau et la chair, puis on rôtit à la broche), et une autre à l'essence d'oignons (pour accompagner des dindons rôtis). Le livre de Massialot sera repris et complété par Vincent La Chapelle, en 1735 (Le cuisinier moderne, en 4 tomes), puis à nouveau en 1741 (Le nouveau cuisinier royal, en 3 tomes, présenté sous forme de dictionnaire). Ces deux éditions présentent elles aussi un nombre considérable de recettes, sous toutes les formes, y compris plusieurs pour les ailerons [Figure 13]. 
Figure 13 : Liste « des entrées de dindons et dindonneaux » dans la table des matières du Cuisinier moderne de La Chapelle (1735)
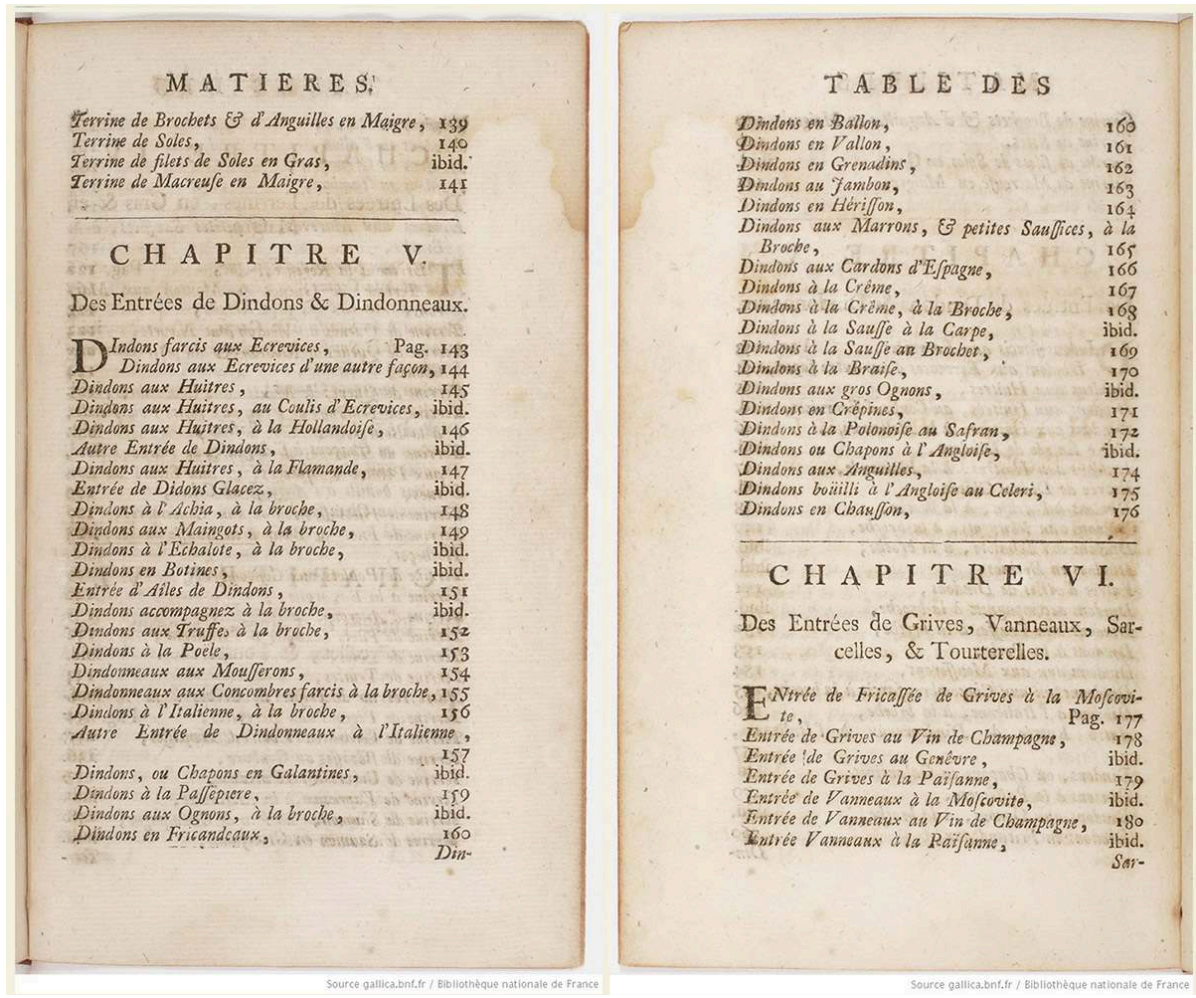

Source gallica.bnf.fr/Bibliothèque nationale de France

Avec 42 recettes, le Nouveau traité de cuisine de Menon (1739) consacre une section entière aux dindes et dindons, qu'il utilise à tous les âges, jeunes entiers à la broche, vieux en daube, en filets (en blanquette ou à la béchamel), en les découpant et séparant les « abattis » (ailerons, pattes, cou, foie, gésier) et les cuisses : «Vous ôtez les cuisses pour les préparer (...); il vous reste les ailes \& l'estomac pour faire l'escalope. La carcasse se met dans le pot pour la manger au gros sel.». La volaille d'Inde est transformée en pain, en galantine, en ballon, roulée, en brézolles ${ }^{89}$; les ailerons donnent lieu à pas moins de 19 recettes (aux petits oignons et fromage, en fricandeau, en matelote, à la purée verte, au vin de Champagne, aux écrevisses, à l'Espagnole, au parmesan...). Les éditions ultérieures (La cuisinière bourgeoise, 1746 et 1775) sont moins détaillées mais toutes aussi diversifiées pour les types de cuisson. ${ }^{90}$

En 1739, Les dons de Comus ou les délices de la table de François Marin vont encore plus loin, avec 74 recettes. Je le cite :

« Le Dindon vieux se met en pâte \& à la daube. Le Dindon jeune, ou le Dindonneau, fournit davantage à la cuisine, ou se diversifie davantage. Le corps se met à la broche \& fait du rot: pour entrée on le met à l'échalotte, en filet entier aux trufes, en galantines, roulé aux huitres, \& aux cornichons. Les ailes \& 1'estomach se mangent glacés dans leur jus (...) 》 (p. 38).

Il sépare les ailerons, les filets, les pattes (farcies), le foie, les abats, il prépare des cascaloppes, il fait des tourtes, des pâtés, des terrines, des galantines, des ballotines, des daubes, des pots, des bouillons, des fricassées, et bien évidemment des rôtis. Les dons de Comus, l'apothéose de la cuisine du dindon, que l'on prépare « d'une infinité d'autres 
façons (...) suivant la capacité de l'officier \& le goût du Maître. » selon ses propres termes!

Je terminerai par l'évocation de la cuisine du XIX ${ }^{e}$ siècle, qui accorde toujours une belle place au dindon, en citant simplement Le cuisinier impérial d'André Viard (1806) :

«Il y aurait trop à dire s'il fallait décrire tous les mets qu'on peut faire avec cette volaille : les meilleurs sont les jeunes et les plus gras.»

Figure 14 : La découpe des volailles dans le Manuel Roret du cuisinier (1826)

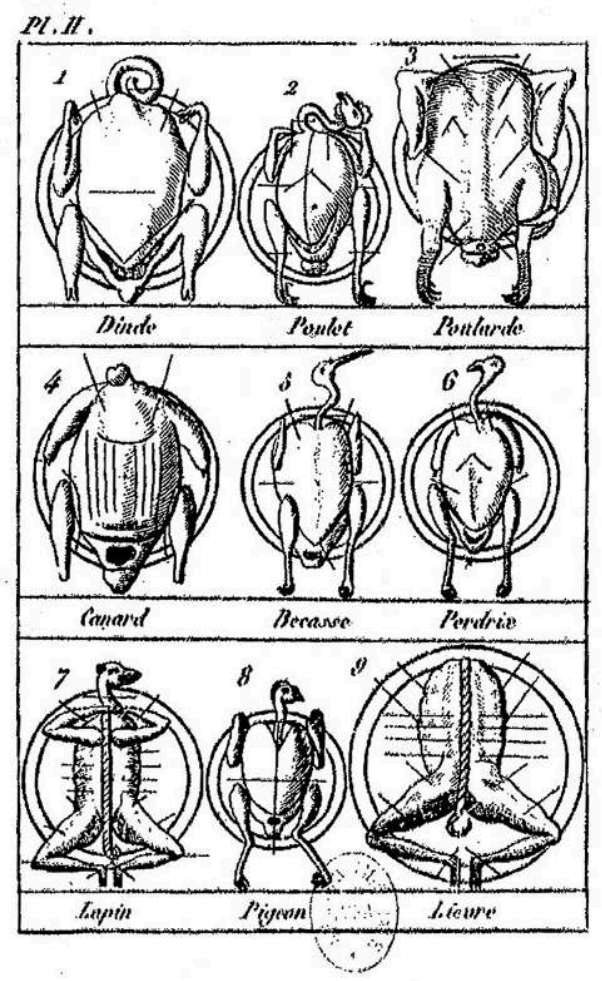

Source gallica.bnf.fr/Bibliothèque nationale de France

Le dindon, à tous ses âges, occupe une belle place dans la cuisine française à partir du $\mathrm{XVII}^{\mathrm{e}}$ siècle, et de nombreuses recettes et des modes de préparation variés lui sont consacrés, jusqu'au XIX ${ }^{\mathrm{e}}$, avec une apogée au milieu du XVIII ${ }^{\mathrm{e}}$ siècle. 
Figure $15:$ « 1-Dindon cru sur broche. 2- Dindon rôti débroché » dans Le livre de cuisine de Jules Gouffé ( $7^{\mathrm{e}}$ édition, 1888)

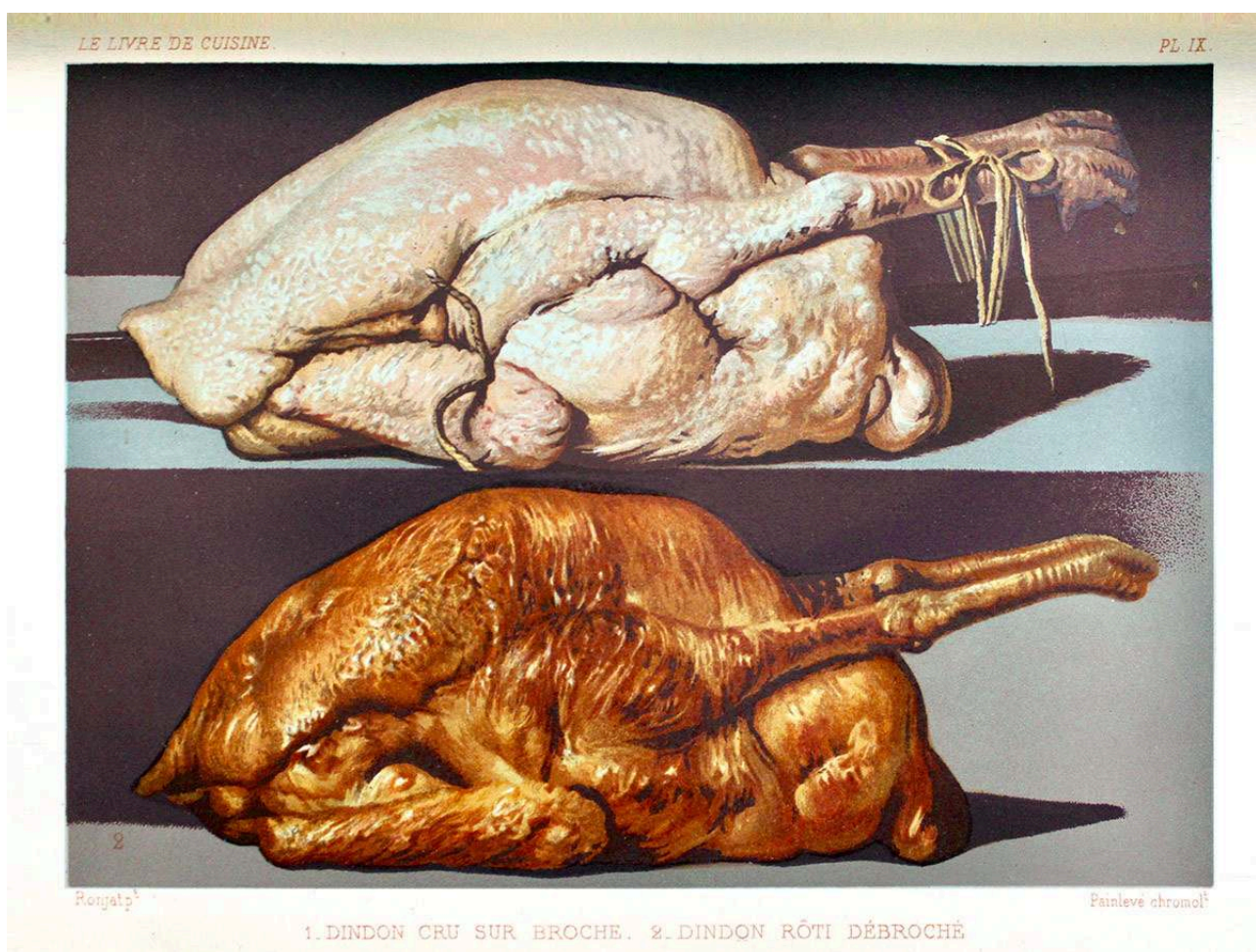

Cliché Sonia Fritsch

\section{Livres anglais}

A proper new book of cookerye, le livre le plus ancien consulté pour cette étude, imprimé vers 1575 , est en réalité un ouvrage du $\mathrm{Xv}^{\mathrm{e}}$ siècle. Il ne comporte évidemment pas de mention de Turkey, mais il présente des recettes de gros oiseaux, le paon et le cygne (Frere 1913).

126 A Book of Cookrye, de 1584, par A. W., de Londres, donne deux recettes pour la Turky Fowles : une sauce avec des oignons et du poivre pour l'accompagner, et une manière de cuire au four (to bake), désossée, également avec poivre écrasé, du sel et « une bonne dose de beurre à l'intérieur » et qui nécessite cinq heures de cuisson...

Par la suite, jusqu'au milieu du XvII ${ }^{\mathrm{e}}$ siècle, tous les ouvrages, ou presque, présentent quelques recettes concernant l'ensemble des Land-Fowls (oies, cygnes, faisans, chapons...), ce qui inclut les Turkies, et quelquefois nommément les dindons seuls: The good husvvifes Ievvell de Thomas Dawson (1587, 1 recette), The good Huswifes Handmaide for the Kitchin (1594, 2 recettes), The English Hus-wife de Gervase Markham (1615, 4 recettes), New book of cookerie de John Murrell (1615, 1 recette), jusqu'au The cooks guide de Hannah Wolley (1664, 1 recette). Certains ne mentionnent pas du tout le dindon (The Compleat Cook, 1658).

Les recettes de base sont le rôtissage et la cuisson au four, généralement désossé. D'autres modes de préparation apparaissent, le pâté (pie), en premier lieu, mais aussi la carbonade (charbonadoes ${ }^{91}$, "the invention thereof was first brought out of France as appears by the name", Markham en 1615). La seule recette dans The cooks guide de Wolley (1664) 
est très singulière, mais on la retrouve ensuite dans plusieurs autres livres, "To sowse a Turkey"92 [Figure 16] : l'oiseau désossé est bouilli dans de l'eau et du vin épicé de macis, de clous de girofle, de sel et de poivre ; à la fin on le place dans un pot de terre, que l'on remplit avec le bouillon éclairci, complété de vin blanc, de vinaigre, de sel. Soigneusement et hermétiquement refermé, on le laissera 12 à 14 jours, au frais, avant de l'ouvrir et de le consommer... On retrouve cette recette, To souce Turkeys, dans Nott 1725 (laissant reposer 3 ou 4 semaines), dans Court Cookery: Or The Complete English Cook de Robert Smith (1725 également, avec repos d'un mois) et encore dans Experienced housekeeper d'Elizabeth Raffald (1769).

Figure 16 : "To sowse a Turkey" dans The cooks guide de Hannah Wolley (1664: 51)

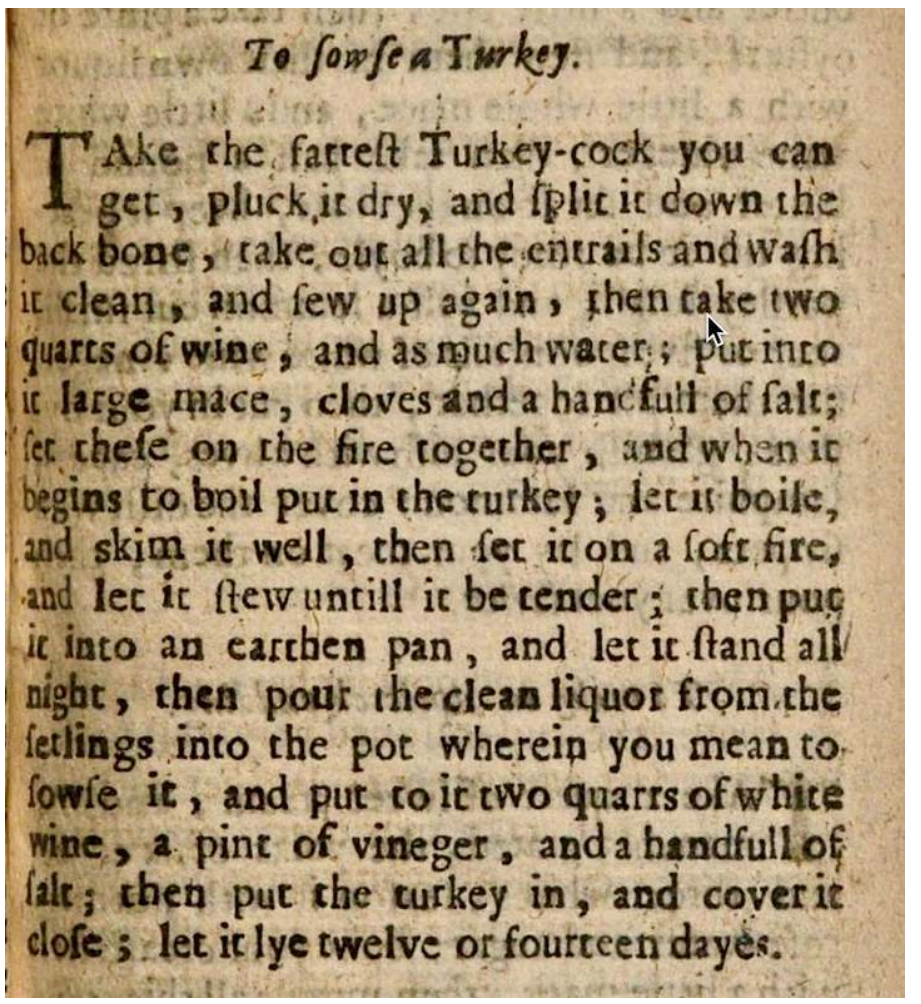

Les livres de la fin du XVII et du XVIII ${ }^{e}$ siècles portent plus d'attention au dindon, pas nécessairement isolément des autres volailles, cependant.

130 Sauf The England new way of all sorts of cookery d'Henry Howard (1708, 3 recettes seulement), The Compleat Housewife d'Eliza Smith (1737, 4 mentions dont une sauce $\left.{ }^{93}\right)$ et The House keeper's Pocket book de Sarah Harrison (1739, 2 recettes et 2 sauces $\left.^{94}\right)$, les autres donnent des préparations plus variées, en sus des classiques rôtissage et pâtés pies, et proposent plusieurs sauces différentes pour accompagner les volailles. Ainsi Cookery dissected de William Rabisha $\left(1673,7\right.$ recettes $\left.{ }^{95}\right)$, les déjà cités The Cooks and Confectioners Dictionary de John Nott, $\left(1725,8\right.$ recettes $\left.{ }^{96}\right)$ et Court Cookery de Smith (1725, 6 recettes $^{97}$ ) [Figure 17], The art of cookery by a Lady [Hannah Glasse] $\left(1747,15\right.$ recettes $\left.^{98}\right)$, A new and easy method of cookery d'Elizabeth Cleland (1755, 6 recettes $\left.{ }^{99}\right)$, Experienced housekeeper d'Elizabeth Raffald (1769, 7 recettes $\left.{ }^{100}\right)$ et enfin The Art of Cookery Made Easy and Refined de John Mollard (1802, 10 recettes $\left.^{101}\right)$.

131 Entre temps, ont été publiées les traductions de deux livres très importants de cuisine française : en 1653 The French Cook de La Varenne (Le cuisinier français, 1651), et en 1702 
The Court and Country Cook de Massialot (le Cuisinier roïal et bourgeois, 1691), dont on a vu la richesse des recettes concernant le dindon. Nul doute que ces ouvrages ont influencé les livres anglais de cette époque.

Figure 17 : "To boil a Turkey with Oysters" dans Court Cookery: or The complete English Cook de Robert Smith (1725)

\section{The Compleat Englifh $\mathrm{COOK}$. 25}

\section{To boil a Turkey with Oyfters.}

TAke half a Pint of Water, half an Anchovy, threa fpoonfuls of Oyfter $\mathbf{L i}$ guor; thicken it well with Flower over the Fire; then ftew your Oyfters with the reft of the Liquor, and two Blades of Mace, and a little whole Pepper; then take out your Oyfters, and ftrain all the Liquor: When your Turkey is almoft ready, put all your Sauce together, with a piece of Butter, and a fpoonful or two of Gravy, a fpoonful of White-wine, a little Lemon-Juice, and Thake it over the Fire, and pour it over the Turkey, and ferve it.

G. Lehmann (1999) distingue plusieurs périodes dans la publication des livres de cuisine, qui tous rencontrent un grand succès :

- Les livres basés sur des recueils manuscrits de recettes de familles aristocratiques, écrits par des hommes et destinés à la riche gentry, souvent adressés aux House-wives (entre 1580 et 1650 , fin $\mathrm{XVI}^{\mathrm{e}}$-mi XVII ${ }^{\mathrm{e}}$ siècles);

- À partir de la fin du XVII et surtout au XVIII ${ }^{e}$, des livres destinés à la bourgeoisie (qui n'a aucun désir d'imiter la mode aristocratique). En grande partie écrits par des femmes pour les femmes, ces livres basés sur leurs expériences et pratiques personnelles rencontreront tous un très grand succès, avec de nombreuses rééditions tout au long du siècle et au-delà (à partir de la $2^{\mathrm{e}}$ moitié du XVIII ${ }^{\mathrm{e}} \mathrm{s}$.).

Les dindes anglaises sont donc généralement préparées comme les autres volailles, en étant rôties, bouillies, en pâtés, avec quelques sauces particulières (fricasey, ragoo...), en salades (nommées sallet, salamongundy ${ }^{102}$ ), et un mode de maturation singulier, to souse, une marinade de plusieurs semaines. Il y a toutefois peu de recettes qui soient destinées spécifiquement au dindon. Toutes demandent une forte dose de beurre, ainsi que des épices et herbes, du vin blanc, du vinaigre, du verjus et du jus de citron.

Livres portugais

Le Portugal se distingue nettement des autres pays pour les livres de cuisine, par le très petit nombre de titres imprimés, quasiment un seul par siècle, et l'absence d'ouvrage 
avant 1680. Le premier livre de cuisine imprimé au Portugal est Arte de cozinha de Domingos Rodrigues (1637-1719), dont la première édition de 1680 sera suivie de 11 autres, jusqu'à 1844. Il sera remplacé en 1780 par le Cozinheiro moderno ou nova arte de cozinha, de Lucas Rigaud, qui connaîtra cinq éditions jusqu'à 1826.

Ces deux livres ont comme caractéristique d'être largement ouverts vers les cuisines des autres nations, qui se marque notamment par les noms des recettes. Les deux, cuisiniers professionnels, ont exercé à l'étranger avant d'œuvrer au Portugal, et Rigaud notamment a eu connaissance, voire s'est inspiré du livre de Vincent La Chapelle, Le cuisinier moderne, paru en 1735 (Braga 2006, Gomes 2016). On a ainsi pu dire que Rigaud a poursuivi le chemin ouvert par Rodrigues, pour « apporter la cuisine européenne sur les tables portugaises" (Gomes: 248). Le dindon est très présent dans les deux ouvrages, tant par des recettes qui lui sont directement dédiées, que par sa participation potentielle à des recettes d'autres viandes, des volailles (poulets, chapons) ou même du veau ou du bœuf.

Rodrigues (Arte de cozinha, 1680) consacre sept recettes au perù (ou perum, dans la première édition $)^{103}$ - en boulettes, en chaussons fourrés, rôti désossé ou non avec diverses sauces, en chair à saucisse. Il décrit aussi 18 autres recettes qui peuvent être appliquées au dindon. Pour celles-ci, on utilise l'oiseau, ou ses cuisses (gigote), en tourtes (pasteis) ou en pâtés (empadas), en soupes, en potage « à la française ", en rôti, à l'estouffade... et avec une multitude de sauces d'accompagnement. Enfin, en donnant des menus types pour tous les mois de l'année, il nous informe sur ses choix: les femelles (peruas) sont servies en hiver (janvier, février, novembre), les mâles (peruns) depuis l'été jusqu'à novembre ${ }^{104}$.

Lucas Rigaud consacre 32 recettes au peru, entier rôti ou braisé, désossé, pour la poitrine (peito), les cuisses (coxas) ou les ailes (alerões). L'influence étrangère se marque dans les noms et les ingrédients (à la provençale, à la sauce d'estragon, à la Périgord, à l'italienne, à la Montmorency, au fromage de parmesan).

$138 \mathrm{Au} \mathrm{XIX}$ siècle encore, la dinde est bien présente. Dans le Conzinheiro completo (1849), seulement trois recettes ${ }^{105}$ sont dédiées au seul peru, mais sept autres s'appliquent à lui comme à d'autres viandes (volailles, ou bœuf), et quatre autres sont énoncées dans les suggestions de menus ${ }^{106}$. Le dernier livre consulté est le Cozinheiro imperial de R. C. M., publié à Rio en $1840^{107}$. La dinde (R. C. M. précise que la chair de la femelle est plus tendre que celle du mâle) est très présente, puisque pas moins de 50 recettes la concernent, 30 spécifiquement, et 20 pour lesquelles la dinde est une possibilité avec d'autres volailles. On y reconnaît d'ailleurs plusieurs recettes des livres antérieurs (notons que l'Arte de cozinha de Rodrigues a été publié à Rio en 1838). Parmi les spécificités, des préparations avec du riz ([peru] com arroz, à la portugaise, à la persane), en pâtés empadas, plusieurs préparations pour les ailes désossées (azas). Je n'ai malheureusement pas pu consulter l'ouvrage de João da Matta Arte de Cosinha (1876).

AuX XVII ${ }^{\mathrm{e}}, \mathrm{XVIII}^{\mathrm{e}}$ et XIX ${ }^{\mathrm{e}}$ siècles, au Portugal, puis au Brésil, le dindon est très présent dans la cuisine moderne, au même titre que les autres volailles, et dans le même contexte d'influences européennes, avec des recettes inspirées de France ou d'Italie. 


\section{Conclusion}

Dès le premier regard sur le nouveau continent, ces gros oiseaux que les indigènes consomment, apparaissent remarquables et délicieux pour les conquérants. Introduit en Espagne vers 1511, le dindon est réservé aux nobles, à qui il est digne de l'offrir, et qui le jugent assez décoratif pour le placer dans leurs volières ou leurs jardins, comme le paon. Il prend place dans leurs banquets comme les gros oiseaux de luxe, paon, oie, cygne, outarde. Par les relations entre grandes familles, le dindon s'installe en Italie, où il est signalé en 1520, et en France, où il est connu avant 1534. En Angleterre il est également présent avant 1541.

$\mathrm{Au}$ milieu du $\mathrm{XvI}^{\mathrm{e}}$ siècle, moins de cinquante ans après sa découverte, cet oiseau provoque un tel engouement dans les hautes classes sociales que d'une part, elles en organisent la production par leurs fermiers, en dehors des volières princières, d'autre part plusieurs règlements cherchent à en limiter la consommation excessive (en Angleterre, en Italie du Nord).

142 Après des débuts difficiles, car les dindonneaux apparaissent très fragiles et sujets à une forte mortalité, son élevage est finalement maîtrisé, avec des petits gardiens qui mènent les oiseaux pâturer. En moins d'un siècle, on passe de quelques oiseaux dans les jardins nobles à des troupeaux d'une centaine de dindons, dans les fermes, troupeaux qui vont aller approvisionner les marchés des villes.

Cette phase correspond à la période d'acclimatation, d'apprentissage de son mode d'élevage, et d'appropriation par les cuisiniers qui définissent les modes de cuisson adéquats et les âges propices (les femelles et les jeunes pour le rôti, les mâles pour les ragoûts ou les pâtés).

144 L'oiseau s'impose dans les banquets et repas somptuaires ; tous les grands cuisiniers des maisons nobles d'Italie ( $\left(\mathrm{au} \mathrm{XVI}{ }^{\mathrm{e}}\right.$ siècle), puis de France (au XVII $)$ et du Portugal (au XVIII $\left.{ }^{\mathrm{e}}\right)$ lui consacrent de nombreuses recettes - mais fort peu en Espagne, paradoxalement. $\mathrm{Au}$ milieu du XVII ${ }^{\mathrm{e}}$ siècle, la bourgeoise s'approprie le dindon, comme en témoignent les livres de cuisine français et anglais.

145 Les menus qui sont proposés par les livres des grands cuisiniers montrent que le dindon s'installe à côté des chapons et poulets, en remplacement de l'oie qui semble peu présente et du paon qui disparait des tables aristocratiques au milieu du XVII ${ }^{e}$ siècle. On sait qu'aux XVI ${ }^{\mathrm{e}}$ et $\mathrm{XVII}^{\mathrm{e}}$ siècles, dans les différents pays d'Europe, les banquets étaient organisés en une succession de "services » en nombre variable, chacun proposant un assez grand nombre de plats disposés simultanément sur les tables. L'ordre en était très codifié avec (au moins) un service d'entrée, suivi d'un de rôtis, un d'entremets, puis une « issue de table » qui termine le repas (voir Flandrin 2002). Les préparations de dindons sont présentes dans tous ces services, sous des formes variées, certes en moindre fréquence que les plats à base de poulet, toutefois [Figure 18]. Le dindon se prêtait à des préparations diverses, et on l'accommodait en pâtés chauds ou froids et en daube pour les entremets, et en rôti pour le $2^{\mathrm{e}}$ service (voir Flandrin 1992). A titre d'illustration, on consultera le menu de trois services du souper du roi Louis XV du 29 avril 1751, que Flandrin reproduit (planche 1, face p. 160): le dindon est présent dans les Entrées (dindonneau en tachette et dindon à la gelée) et dans le Rôt (rosts de dindons). 
Figure 18 : Menu et plan d'une table de 15 couverts, dans Le cuisinier moderne de Vincent La Chapelle (1735)

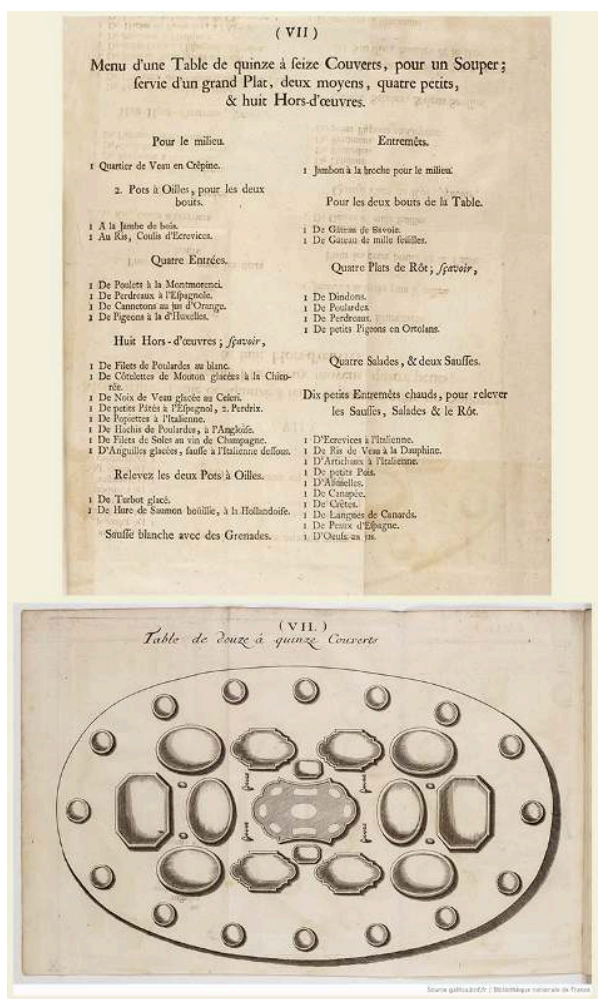

On trouve un plat de Dindons parmi les rôts

Source gallica.bnf.fr/Bibliothèque nationale de France

Ainsi cet oiseau américain prend place dans le cortège des animaux domestiques des fermes d'Europe; il y est fermement adopté en moins de 150 ans après son introduction. Passé la période initiale, où on le juge laid et finalement insipide, la taille de l'oiseau et la qualité de sa chair, une fois le choix bien maîtrisé, font que le dindon s'impose, finalement sans avoir rencontré de résistance durable.

Bray (1993) avait posé à titre d'hypothèse les principes généraux concernant l'adoption des produits du Nouveau Monde :

"1) Items that fill a vacant "cultural niche" are easily assimilated.(...) 2) Items that duplicate the role or function of an established product are likely to meet resistance.(...) 3) Items so exotic that they fall completely outside the frame of reference of the receiver-culture, or that conflict with entrenched beliefs and values, are likely to be rejected.(...)" (1993: 320-321).

Sans qu'il se prononce sur le cas du dindon, on peut comprendre que selon lui, il entre dans la deuxième catégorie, celle d'une certaine forme de résistance.

Pour Flandrin au contraire (1992: 72), le dindon a été accepté rapidement, "pratiquement dès son arrivée ", ce qu'il explique par le fait que «les Européens du Moyen Âge mangeaient toutes sortes d'oiseaux. (...) Pas de problème, donc pour manger $\mathrm{du}$ dindon, d'autant que les tables aristocratiques recherchaient particulièrement les grands et beaux oiseaux. », selon le principe qu'il énonce : « Lorsqu'un aliment nouveau est adopté par un peuple qui l'ignorait auparavant, c'est généralement parce qu'il est assimilable à un aliment traditionnel chez ce peuple. ». 
On peut cependant considérer que le dindon a subi une période d'observation, pendant laquelle il a été surtout un animal "décoratif ", à côté de gros oiseaux de luxe, et qu'il s'est passé un demi-siècle pour qu'il entre réellement dans les repas, jusqu'à finalement supplanter ces oiseaux princiers. Alors, il est réellement entré définitivement dans la série des animaux de basse-cour. L'étape ultime est celle, récente, où le dindon remplace complètement ce qui était la volaille de luxe par excellence, le chapon.

De ce point de vue, le dindon nous offre une observation historiquement datée de l'adoption d'une espèce domestique venant d'ailleurs, par un nouveau groupe d'utilisateurs. Cela permet notamment de reconstituer les décisions qui ont conduit à l'incorporation de cette espèce dans un ensemble d'autres "domesticats", un phénomène qui s'est produit à de nombreuses reprises dans l'histoire de l'humanité, mais à des périodes trop reculées pour que nous en ayons des images concrètes.

J'ai délibérément exclu de ce panorama historique la question de la « dinde de Noël » (à partir de quand est-elle devenue le plat nécessaire pour cette saison de l'année ?), ainsi que celle, beaucoup plus ample, de sa diffusion dans le monde en dehors de l'Europe. Les colons européens qui s'installent en Nouvelle Angleterre emportent avec eux des dindons domestiques d'Europe, qui vont supplanter les oiseaux de chasse, et s'imposer pour la fête du Thanks Giving. Quand et comment cela se réalise-t-il ? Comment les dindes atteignent-elles les pays d'Asie? On connait cette sublime miniature de Mansur, appartenant à l'empereur moghol Jahangir, datée de $1612^{108}$.

Et finalement, la dinde est maintenant l'oiseau-objet de l'élevage industriel qui s'impose dans le commerce mondial ${ }^{109}$, découpé ou en produits élaborés très éloignés, et combien plus simples, de ce que nous révèlent les livres de cuisine européens des siècles antérieurs. Désormais, tout un chacun accède à la viande préparée du dindon, devenue ordinaire.

154 Toutes ces questions nécessiteraient de nouveaux développements : « et ceci est une autre histoire... »

Figure 19 : «Dindon bridé pour relevé », dans Le livre de cuisine de Jules Gouffé ( $7^{e}$ édition, 1888 : 563)

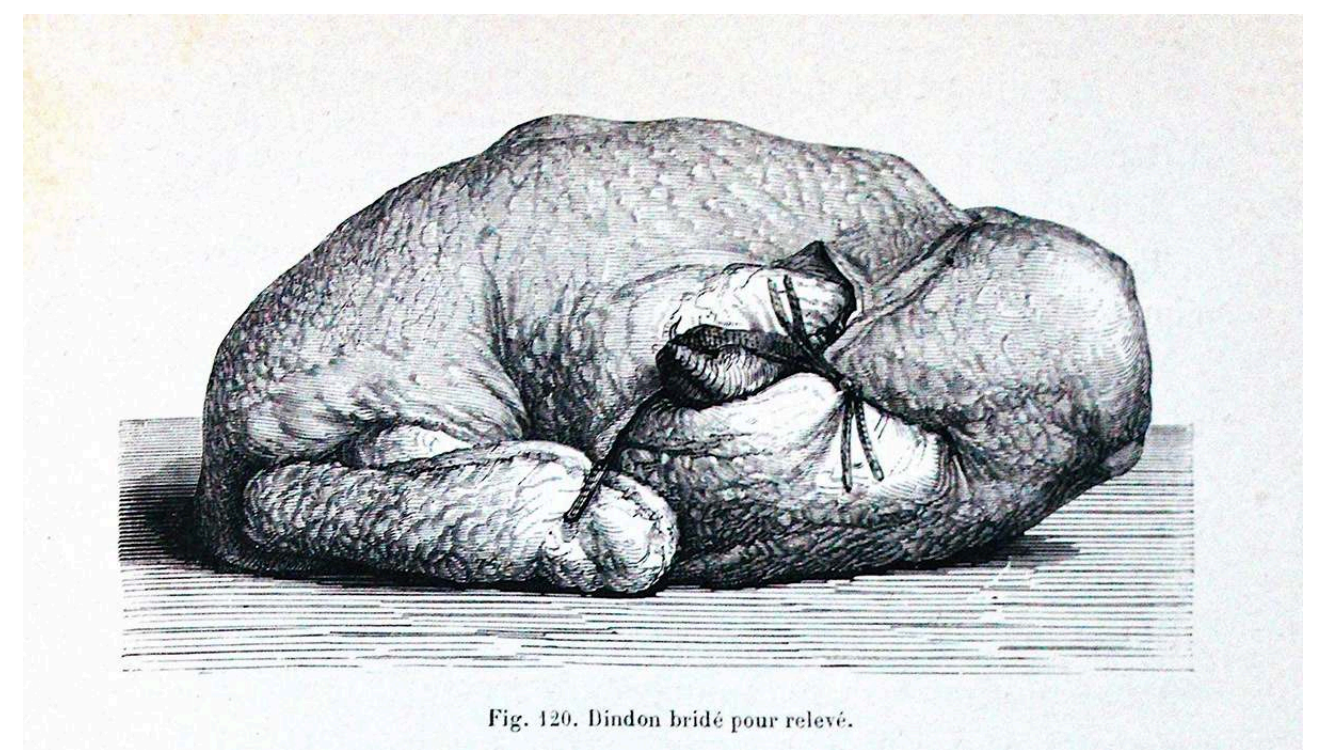


REMERCIEMENTS : Je remercie les archéozoologues Eduardo Corona et Aurélie Manin, qui m'ont engagé à écrire cet essai, et particulièrement Aurélie, pour qui l'histoire du dindon n'a plus de secrets, pour les commentaires qu'elle a bien voulus me communiquer. Je remercie également ma sœur Sylvie Bahuchet de son aide pour les traductions des recettes italiennes.

\section{BIBLIOGRAPHIE}

\section{Documents originaux anciens}

Les références des livres de cuisine sont indiquées dans les tableaux chronologiques en annexe : beaucoup d'ouvrages anciens ont été consultés grâce à plusieurs sites de l'internet qui mettent à disposition des facsimile des éditions originales : Gallica https://gallica.bnf.fr/, Biblioteca nacional de España http://www.bne.es/, Biblioteca nacional de Portugal http:// www.bnportugal.gov.pt/, ainsi que https://books.google.fr/, Internet Archive https:// archive.org/ et pour les livres de cuisine anglais http://www.foodsofengland.co.uk/ references.htm

Aldrovandi Ulyssis, 1600 - Ornithologiae tomus alter (Liber XIII). Bologne, Bellagamba.

Barcía Carballido y Zúñiga A.G. de (Ed.) 1749 - La historia de D. Fernando Colón en la qual se da particular, y verdadera relacion de la vida de el Almirante D. Christoval Colón. In : Historiadores primitivos de las Indias Occidentales, vol. I. Madrid.

Belon Pierre 1555 - De l'histoire de la nature des oiseaux, avec leurs descriptions et naïfs portraicts. Paris, Cuellat.

Buchoz 1777 - Traité économique et physique des oiseaux de basse-cour. Liège, Desoer.

Cardelli Pierre 1826 - Manuel du cuisinier et de la cuisinière, à l'usage de la ville et de la campagne. $4^{\mathrm{e}}$ éd. Paris, Manuel Roret.

Chomel Noël 1741 - Dictionnaire Economique. Commercy, Thomas.

Buffon Georges L. de 1771 - Histoire naturelle des oiseaux. Tome second. Paris, Imprimerie royale. de Acosta Joseph 1590 - Historia natural y moral de las Indias. Sevilla, Juan de Leon. Trad. fr. 1598 par Robert Regnault, Histoire naturelle et morale des Indes. Paris, Orry.

de Oviedo Gonzalo Fernandez 1526 - Somario de la natural y general historia de las Indias. Toledo, Valdes.

Diderot Denis \& Jean le Rond d'Alembert (Ed.) 1751 - Encyclopédie, ou dictionnaire raisonné des sciences, des arts et des métiers. Tome IV. Paris, Briasson et al.

Du Chesne Joseph 1627 - Le pourtraict de la santé. Paris, Morel.

Dugdale William 1666 - Origines Juridiciales. London, Warren.

Estienne Charles, 1565 - L'agriculture et maison rustique. Lyon, Martin. 
Gallo Agostino 1565 - Dieci giornate della vera agricoltura, e piaceri della villa. Venetia, Farri. Gessner Conrad 1553 - Icones avium omnium. Zurich, Froschover. Gessner Conrad 1555 - Historiae animalium Liber III qui est de Avium natura. Zurich, Froschover. Heresbach Conrad 1573 - Rei Rusticae Libri quatuor. Colonia, Birckmann. Johnston Jan 1657 - Historiae naturalis de avibus libri VI. Amsterdam, Schipperi.

La Mare N. de 1710 - Traité de la police. Tome II, Cot, Paris : 649-1496 [« Poule d'Inde » p. 1377]. Le thrésor de santé ou ménage de la vie humaine 1607. Lyon, Huguetan.

Le Grand d'Aussy P.J.-B. 1782 - Histoire de la vie privée des français. Paris, Pierres, 373 p.

Lemery Louis 1705 - Traité des aliments. $2^{\mathrm{e}}$ éd., Paris, Witte.

Li tre trattati di Messer Mattia Giegher 1639 - Padova, Frambotto.

Liger Louis 1700 - Oeconomie générale de la campagne, ou nouvelle maison rustique. Paris, de Sercy. Linocier Geofroy 1583 - L'histoire des plantes. Paris, Macé.

Mémoire statistique du département de l'Indre, par le $C^{\text {te }}$ d'Alphonse, préfet ; Paris, Imprimerie Nationale, an XII [1803-1804]

Núñez de Coria, Francisco, 1572 - Aviso de sanidad que trata de todos los generos de alimentos. Madrid, Cusin.

Núñez de Coria, Francisco, 1585 - Regimiento y aviso de sanitad. Medina del Campo, Landry.

Odolant-Desnos P. J. 1787 - Mémoires historiques sur la ville d'Alençon et sur ses seigneurs ; Tome second. Malassis le Jeune, Alençon, 640 p.

Pisanelli, Baldassare, 1583 - Trattato della natura de cibi e del bere. Roma, Bonfadino.

Le Choyselat, Prudent, 1569 - Discours oeconomique. Paris, Chesneau.

Rabelais, François, 1542 - La vie tres horrifique du Grand Gargantua (Livre 1). Lyon, Juste.

Rabelais, François, 1548 - Le Quart Livre, des faictz et dictz heroiques du noble Pantagruel. Lyon, Pierre de Tours.

Savonarola, Michel \& Bartolomeo Boldo, 1576 - Libro della natura e virtù delle cose che nutriscono. Venetia, Guerra.

Tanara, Vincenzo, 1644 - Economia del cittadino in villa. Bologna, Dozza.

Tanara, Vincenzo, 1674 - Economia del cittadino in villa. Venetia, Curti.

Zanon, Antonio, 1763 - Lettere sull' agricoltura, le arti e il commercio, vol. I. Venezia, Fenzo.

\section{Dictionnaires}

Alberti de Villeneuve, François d', 1796 - Nouveau dictionnaire françois-italien. Venise, Bassan. Antonini, Annibal, 1752 - Dictionnaire italien, latin et français. Lyon, Duplain. Bluteau, Raphael, 1728 - Vocabulario portuguez e latino. Coimbra, Companhia de Jesu. Canal, Pierre, 1603 - Dictionnaire français-italien. Genève, Chouet.

Cotgrave, Randle, 1611 - A dictionarie of the French and English tongues. London, Islip. 
de Covarrubias, Sebastián, 1611 - Tesoro de la lengua castellana. Madrid, Sanchez.

de las Casas, Cristóbal, 1570 - Vocabolario de las dos lenguas toscana y castellana. Sevilla, Aguilar. de Moraes Silva, Antonio, 1789 - Diccionario da lingua portugueza. Lisboa, Lacerdina.

de Nebrija, Antonio, 1495 - Dictionarium latinohispanicum, et vice versa. Antverp, Steelfij.

Dictionnaire universel françois et latin vulgairement appelé dictionnaire de Trévoux, 1738-1742 Nancy, Pierre Antoine.

Düez, Nathanaël, 1678 - Dictionnaire italien et français. Genève, de Tournes.

Féraud, Abbé, 1787 - Dictionnaire critique de la langue française, Tome I : A-D. Marseille, Mossy.

Furetière, Antoine, 1690 - Dictionnaire universel. La Haye, Leers.

Minsheu, John, 1617 - A Dictionnary in Spanish and English. London, Brown.

Oudin, Caesar, 1627 - Thresor des trois langues, espagnole, françoise, et italienne. Genève,

Crespin.

Oudin, Caesar, 1675 - Thresor des deux langues françoise et espagnolle. Lyon, Bourlier.

Percival, Richard, 1591 - Bibliotheca hispanica: Containing a grammar, with a Dictionarie in Spanish and English, and Latine. London, Iackscon.

Real Academia Española, 1737 - Diccionario de la lengua castellana. Madrid, del Hierro

Société typographique, 1829 - Vocabolario universale italiano. Napoli, Tramater.

Zambaldi F. 1889 - Vocabolario etimologico italiano. Città di Castello, S. Lapi tipografo-editore.

\section{Documents modernes}

Allard J. 1988 - La cuisine espagnole au Siècle d'Or. Mélanges de la Casa de Velásquez 24 : 177-190.

Bahuchet S. 2017 - Les jardiniers de la nature. Paris, Odile Jacob, 400 p.

Boudier V. 2009 - Appropriation et représentation des animaux du Nouveau Monde chez deux artistes nord italiens de la fin du XVIe siècle. Le cas du dindon. Food and History 7 (1) : 79-101.

Bouquet F. (Ed.) 1883 - La Parthénie, ou Banquet des palinods de Rouen en 1546 : poème latin du XVI siècle par Baptiste Le Chandelier (avec une introduction et des notes). Société des Bibliophiles normands, Rouen, CLXXXV + $151 \mathrm{p}$.

Braga I.D. 2006 - Influências estrangeiras nos livros de cozinha portugueses (séculos XVI-XIX). Alguns problemas de Análise. In : Estudos em Homenagem ao Prof. Doutor José Marques, 2. Porto, Faculdade de Letras : 237-247.

Bray W. 1993 - Crop plants and cannibals: Early European impressions of the New World. Proceedings of the British Academy 81 : 289-326.

Brillat-Savarin J. A. 2009 (1825) - Physiologie du goût. Paris, Flammarion, 399 p.

Capatti A. \& Montanari M. 2002 - La cuisine italienne. Histoire d'une culture. Paris, Seuil, 430 p.

Cimber L. \& Danjou F. 1835 - Archives curieuses de l'histoire de France. $1^{\text {re }}$ série, Tome 3. Paris, Ed. Beauvais.

Coron S. (Ed.) 2001 - Livres en bouche. Cinq siècles d'art culinaire français. Paris, Hermann, éditeurs des sciences et des arts / Bibliothèque nationale de France, 251 p. 
Couperie P. 1964 - L'alimentation au XVII ${ }^{\mathrm{e}}$ siècle : les marchés de pourvoierie. Annales. Economies, sociétés, civilisations 19 (3) : 467-479.

Dartigue C. 1937 - Traité passé par Henri D'Albret pour alimenter sa maison (1538). Annales du Midi : revue archéologique, historique et philologique de la France méridionale, 49 (196) : 409-418.

De Grossi Mazzorin, J. \& Epifani I. 2015 - Introduzione e diffusione in Italia di animali esotici dal Nuovo Mondo: il caso del tacchino (Meleagris gallopavo L.). L'Idomeneo (20) : 55-74.

Dictionnaire de l'Académie 1762 - 4e éd. Paris, Vve Brunet.

Eiche S. 2004 - Presenting the Turkey: the fabulous story of a flamboyant and flavourful bird. Florence, Centro Di, $127 \mathrm{p}$.

Estorach S. \& Lequenne M. (Ed.) 2002 - Christophe Colomb, la découverte de l'Amérique. Paris, La Découverte/Poche, $352+434 \mathrm{p}$.

Faugeron F. 2016 - Le luxe alimentaire à Venise à la fin du Moyen Âge et au début de l'époque moderne : entre lois somptuaires et fastes dogaux. Mélanges de l'École française de Rome-Antiquité 128-1. [En ligne], URL : http://journals.openedition.org.inshs.bib.cnrs.fr/mefra/3264

Flandrin J.-L. 1992 - Le dindon sur les tables européennes 16ème-18ème siècles. Ethnozootechnie $49: 71-84$.

Flandrin J.-L. 1996 - L'alimentation paysanne en économie de subsistance. In : Flandrin J.-L. et Montanari M. (Ed.) Histoire de l'alimentation. Paris, Fayard : 597-627.

Flandrin J.-L. 2002 - L'ordre des mets. Paris, Odile Jacob, 278 p.

Flandrin J.-L., Hyman P. \& Hyman M. 1983 - La cuisine dans la littérature de colportage. In : Flandrin J.-L., Hyman P. \& Hyman M. (textes présentés par) Le cuisinier françois, Paris, Montalba : 11-107. (Bibliothèque Bleue).

.Frere C.F. (Ed.) 1913 - A proper new book of cookerye. Cambridge, Heffer, clxiv+124 p.

Gaffarel P. (Ed. et trad.) 1907 - De orbe novo de Pierre Martyr Anghiera. Les Huit Décades traduites $\mathrm{du}$ latin, avec notes et commentaires. Paris, Leroux, 755 p.

Gauvin B. (Ed.) 2003 - Pietro Martire d'Anghiera, De Orbo Novo Decades ; « Décades du Nouveau monde. I, La décade océane ", suivi du "Quatrième voyage de Christophe Colomb». Paris, Les Belles lettres, $\mathrm{XCVII}+374 \mathrm{p}$.

Geoffroy Saint-Hilaire I. 1986 (1861) - Acclimatation et domestication des animaux utiles. Reéd. facsimilé Paris, La maison rustique/Flammarion, $536 \mathrm{p}$.

Gomes J.P. 2016 - Cozinhar «á Portugeza » com Lucas Rigaud. Identidade alimentar portuguesa no Cozinheiro Moderno. Revista de História da sociedade e da cultura 16 : 243-270.

Hyman P. \& Hyman M. 1996 - Imprimer la cuisine : les livres de cuisine en France entre le XVe et le XIX ${ }^{\mathrm{e}}$ siècle. In : Flandrin J.-L. \& Montanari M. (Ed.) Histoire de l'alimentation. Paris, Fayard : 643-655.

Larousse P. 1870 - Grand dictionnaire universel du XIX ${ }^{e}$ siècle, Tome 6. Paris, D. Admin. du grand dictionnaire, $1470 \mathrm{p}$.

Laurioux B. 1988 - Entre savoir et pratiques : le livre de cuisine à la fin du Moyen Âge. Médiévales $14: 59-71$.

Lehmann G. 1999 - Le livre de cuisine en Angleterre aux XVII ${ }^{\mathrm{e}}$ et XVIII ${ }^{\mathrm{e}}$ siècles : par qui, pour qui ? XVII-XVIII. Bulletin de la société d'études anglo-américaines des XVII et XVIII siècles 48 : 89-102. 
Lespinasse R. de 1886 - Les métiers et corporations de la ville de Paris XIVe-XVIII ${ }^{e}$ s. Paris, Imprimerie nationale.

MacNutt F.A. (Ed.) 1912 - De Orbe Novo. The Eight Decades of Peter Martyr D'Anghera. Translated from the Latin with Notes and Introduction. New York, Putnam, 2 volumes, 414+448 p.

Manin A. 2015 - Aspects matériels et symboliques de l'utilisation des animaux dans le nord de la Mésoamérique, entre le Classique et la Conquête (200-1521 ap. J.-C.). Archéologie et Préhistoire. Thèse, Muséum national d'Histoire naturelle, $656 \mathrm{p}$.

Manin A., Corona-M E., Alexander M., Craig A., Thornton E. K., Yang D. Y., Richards M. \& Speller C. F. 2018 - Diversity of management strategies in Mesoamerican turkeys: archaeological, isotopic and genetic evidence. Royal Society open science 5 (1) : 171613.

Orlandi A. 2011 - « Io hebbi il gallo et l'hebbi a caro ». Cenni sulla introduzione e la diffusione del tacchino. Rivista di Storia dell'Agricoltura, Accademia dei Georgofili LI (1) : 75-84.

Palmer S. \& del Carmen M. 2003 - Bibliografía de la gastronomía y la alimentación en España. Gijón, Trea, $477 \mathrm{p}$.

Peyrebonne N. (Ed.) 2011 - Le livre de cuisine de Roberto de Nola. Paris, Flammarion, 330 p. (Classiques Garnier).

Pianigiani O. 1907 - Vocabolario etimologico della ligua italiana. Segati, Società editrice Dante Alighieri di Albrighi.

Plouvier L. 1995 - Introduction de la dinde en Europe. Scientiarium Historia 21 (1) : 13-34.

Poplin F. 1992 - Panorama du dindon du Nouveau Monde à l'Ancien. Sa place dans notre bestiaire. Ethnozootechnie $49: 1-14$

Redondo Buey P. 2014 - El arte de cozina de Diego Granado (1599), primer libro de cocina en lengua castellana. Universidad de Valladolid. Facultad de Medicina, 50 p.

Robillard de Beaurepaire E. 1892 - Le journal du sire de Gouberville, publié sur la copie du manuscrit original faite par l'abbé Tollemer. Avec une introduction et un appendice. Mémoire de la Société des antiquaires de Normandie XXXI, 385 p.

Schorger A.W. 1966 - The wild turkey. Its history and domestication. Norman, University of Oklahoma Press, $625 \mathrm{p}$.

Serres O. de 1996 (1600) - Le théâtre d'agriculture et mesnage des champs. Arles, Actes Sud, 1545 p.

Wright A. H. 1914 - Early Records of the Wild Turkey. The Auk 31 (3) : 334-358.

\section{ANNEXES}




\section{Livres de cuisine consultés}

\section{Livres espagnols}

\begin{tabular}{|c|c|c|}
\hline Année & Titre (ville de publication et éditeur) & Nbre recettes \\
\hline 1542 & Lobera de Avila Vergel de sanidad (Alcala, de Brocar) & 0 \\
\hline 1572 & Núñez de Coria Aviso de sanidad (Madrid, Cusin) & 0 \\
\hline 1607 & Hernandez de Maceras Libro del Arte de Cozina (Salamanca, Ramirez) & 2 \\
\hline 1611 & Martinez Motiño Arte de cozina (Madrid, Sanchez) & 4 \\
\hline 1614 & Granado Libro del arte de cozina (Lerida, Manescal) & 6 \\
\hline 1758 & Altamiras Arte de cocina (Barcelona, de Bezères) & 2 \\
\hline 1822 & D. A. P. Z. G. La nueva cocinera (Madrid, Alvarez) & 3 \\
\hline 1828 & Manual del cocinero (Madrid, Amarita) & 9 \\
\hline 1845 & Novisimo arte de cocina (Madrid, Boix) & 1 \\
\hline 1898 & Brecarelli Manual de la cocinera española y americana (Madrid, Escribano) & 5 \\
\hline
\end{tabular}

\section{Livres italiens}

\begin{tabular}{c|l|c}
\hline Année & \multicolumn{1}{|c}{ Titre (ville de publication et éditeur) } & Nbre recettes \\
\hline 1549 & Christoforo di Messisbugo Banchetti (Ferrara, Bughlat \& Hucher) & 0 \\
\hline 1560 & Domenico Romoli La singolar dottrina (Venetia, Tramezzino) & 4 \\
\hline 1570 & Bartolomeo Scappi Cvoco secreto (Venetia, Tramezzino) & 31 \\
\hline 1587 & D. Romoli La singolare dottrina (Venetia, Farri) & 5 \\
\hline 1593 & Vincenzio Cervio II trinciante (Roma, Sabbia) & 8 \\
\hline 1610 & Bartolomeo Scappi Dell'arte del cvcinare (Venetia, Vecchi) & 31 \\
\hline 1627 & Vittorio Lancellotti Lo scalco pratico (Roma, Corbelletti) & 20 \\
\hline 1662 & Ottavio Stefani L'arte di ben cucinare (Mantova, Osanna) & 11 \\
\hline 1773 & Il cuoco galante [Vincenzo Corrado] (Napoli, Raimondi) & 15
\end{tabular}

\section{Livres français}

\begin{tabular}{l|l|c}
\hline Année & \multicolumn{1}{|c}{ Titre (ville de publication et éditeur) } & Nbre recettes \\
\hline 1555 & Livre fort excellent de cuysine (Lyon, Arnouillet) & 0 \\
\hline 1604 & Lancelot de Casteau Ouverture de cuisine (Liège, Streel) & 4 \\
\hline 1651 & La Varenne Le cuisinier françois (Paris, David) & 9 \\
\hline 1656 & Pierre de Lune Le cuisinier (Paris, David) & 15 \\
\hline 1661 & Le Cuisinier methodique (Pris, Promé) & 3 \\
\hline 1662 & Pierre de Lune Le nouveau et parfait maistre d'Hostel royal (Paris, Loyson) & 18 \\
\hline 1662 & L'escole parfaicte des officiers de bouche (Paris, Ribou) & 5 \\
\hline 1693 & L.S.R. L'art de bien traiter (Lyon, Bachelu) & 5 \\
\hline 1705 & Massialot Le cuisinier roïal et bourgeois (Paris, Prudhomme) & 20 \\
\hline 1735 & La Chapelle Le cuisinier moderne (La Haye, de Groot) & 54 \\
\hline 1739 & Les dons de Comus ou les délices de la table [François Marin] (Paris, Prault) & 74 \\
\hline 1739 & Menon Nouveau traité de cuisine (Paris, Paulus-du-Mesnil) & 42 \\
\hline 1741 & La Chapelle Le nouveau cuisinier royal (Paris, Prudhomme) & 51 \\
\hline 1746 & Menon La cuisinière bourgeoise (Paris, Guillyn) & 25 \\
\hline 1775 & Menon La cuisinière bourgeoise (Bruxelles, Foppens) & 28 \\
\hline 1806 & Viard Le cuisinier impérial (Paris, Barba) & 12 \\
\hline 1817 & Viard Le cuisinier royal (Paris, Barba) & 15 \\
\hline 1826 & Cardelli Manuel du cuisinier (Paris, Roret) & 19
\end{tabular}




\section{Livres anglais}

\begin{tabular}{|c|c|c|}
\hline Année & Titre (ville de publication et éditeur) & Nbre recettes \\
\hline 1584 & A.W. A book of cookrye (London, Allde) & 2 \\
\hline 1587 & Thomas Dawson THE good husvvifes levvell (London, Wolfe) & 1 \\
\hline 1594 & The good Huswifes Handmaide for the Kitchin (London, Jones) & 2 \\
\hline 1615 & Gervase Markham The English Hus-wife (London, Jackson) & 4 \\
\hline 1615 & John Murrell New book of cookerie (London, Brownie) & 1 \\
\hline 1658 & The Compleat Cook (London, E. B.) & 0 \\
\hline 1658 & Theodore Mayenne Archimagirus Anglogallicus (London, Bedel \& Collins) & 1 \\
\hline 1660 & Robert May The accomplisht cook (London, Brooke) & 7 \\
\hline 1664 & Hannah Wolley The cooks guide (London, Dring) & 1 \\
\hline 1673 & Cookery dissected [William Rabisha] (London, Calvert) & 7 \\
\hline 1708 & Henry Howard The England newest way of all sorts of cookery (London, Coningsby) & 3 \\
\hline 1714 & A Collection of Above Three Hundred Receipts (London, Wilkin) & 1 \\
\hline 1725 & Robert Smith Court Cookery: Or The Complete English Cook (London, Wotton) & 6 \\
\hline 1725 & John Nott The Cooks and Confectioners Dictionary (London, H. P.) & 8 \\
\hline 1737 & Eliza Smith The Compleat Housewife (London, Pemberton) & 4 \\
\hline 1739 & Sarah Harrison The House keeper's Pocket book (London, Ware) & 3 \\
\hline 1747 & The art of cookery by a Lady [Hannah Glasse] (London, the author) & 15 \\
\hline 1755 & Elizabeth Cleland A new and easy method of cookery (Edinburgh, Gordon et al.) & 6 \\
\hline 1769 & Elizabeth Raffald Experienced housekeeper (Manchester, Harrep) & 7 \\
\hline 1802 & John Mollard The Art of Cookery Made Easy and Refined (London, Nunn) & 10 \\
\hline
\end{tabular}

\section{Livres portugais}

\begin{tabular}{c|l|c}
\hline Année & \multicolumn{1}{|c}{ Titre (ville de publication et éditeur) } & Nbre recettes \\
\hline 1680 & Domingos Rodrigues Arte de cozinha (Lisboa, Galvaõ) & 25 \\
\hline 1780 & Lucas Rigaud Cozinheiro modern (Lisboa, Ameno) & 32 \\
\hline 1849 & Cozinheiro complete (Lisboa, Correia da Cunha) & 14 \\
\hline 1840 & R. C. M. Cozinheiro imperial (Rio de Janeiro, Laemmert)) & 50
\end{tabular}

\section{NOTES}

1. «Lettre de Christobal Colon, vice-roi et amiral des Indes, aux Très Chrétiens et Très puissants Roi et reine d'Espagne..., fait aux Indes, en l'île de la Janahica, le 7 juillet de l'année 1503 »; éd. Estorach \& Lequenne 2002, p. 362.

2. Pierre Martyr d'Anguiera, Pietro Martire d'Anghiera ou encore Pedro Mártir de Angliera (1457-1526), d'origine italienne, était attaché à la cour des Rois Catholiques en Espagne, puis il a été affecté au Conseil des Indes. Il s'est donné comme tâche d'être l'historien de la découverte, en recueillant directement les témoignages des découvreurs de l'Amérique, tout en transcrivant les documents officiels et les manuscrits, à partir de quoi il rédigeait des lettres destinées à la hiérarchie catholique romaine (dont les papes). Ces lettres ont été réunies et publiées par lui, dans les huit « Décades du Nouveau Monde » (De Orbe Novo Decades, de 1494 à 1526).

3. "[...] inter quas pro altilibus habent eas quas pauonibus feminis colore ac magnitudine similes esse, gustu etiam et sapore diximus aliquando.» [IV, § 5]. Ce texte est traduit ainsi par Gaffarel (1907): "Quant aux oiseaux, ils engraissent ceux dont nous avons parlé, et qui ressemblent à des paons femelles pour la couleur, la grandeur, le goût et la saveur.» (1907: 258), et en anglais par MacNutt : «The natives fatten those birds we have mentioned, as resembling peahens in colour, size and taste. » (1912: 318).

4. «[...] 200. cargados de varias suertes de bastimentos, con Gallinas de la Tierra, que son mejores que las nuestras [...]» (Barcía Carballido y Zúñiga 1749, I, 106). 
5. Yañez Pinzon et son frère effectuèrent un premier voyage vers la côte d'Amérique centrale en janvier 1500, mais il ne semble pas y avoir de mention d'oiseaux d'élevage dans le récit rapporté par Martyr ( $1^{\mathrm{e}}$ décade, chapitre 9$)$.

6. Richard Eden en 1555 dans The first three english books on America cité donne une traduction et une interprétation très différente, qui est citée par Wright (1914: 344) : “(..) a great multitude of theyr peacocks, both cockes and hennes, deade and alive, as well to satisfie theyr present necessitie, and also to cary with theym into Spayne for increase." (Eden 1555 : 79). En revanche, MacNut en 1912 a traduit ce texte dans des termes similaires à ceux de Gaffarel, c'est-à-dire sans mentionner l'Espagne: "In addition to the gold and the incense, they presented peacocks such as are not found elsewhere, for they differ largely from ours in the variety of their colours. The hens were alive, for they kept them to propagate the species, but the cocks, which they brought in great numbers, were dressed to be immediately eaten." (vol. 1 : 254).

7. "Ay unos pavos ruvios y otros negros y la colas tienenlas dela hechura a delas pavas de España/ pero en el plumaje y color : los unos son todos ruvios y la barriga cõ un poco del pecho blãco y los otros tienen sobre la cabeça una hermosa cresta o penacho d plumas bermejas el q es bermejo : y negras el es negro: $y$ son de mejor comer que los de España. Estos pavos son salvajes y algunos ay domesticos en las casas que los toman pequeños. Los vallesteros matan muchos dellos porque los ay en mucha cantidad. (...) ) (Pavos, Cap. xxxvij) 8. Cette hypothèse semble confirmée par les récentes études archéozoologiques (Manin et al. 2018).

9. "La carne destos pavos es muy buena y sin comparaciõ mejor y mas tierna que la delos pavos de España.»

10. Il gallo, e la gallina d'India son molto più grossi di corpo che non è il pauone nostrale, e il gallo fa la ruota ancor egli come il pauone nostrale, e ha le piume negre, e bianche, \& il collo cesputo di pelle, \& il capo la testa un corno di carne, ilqual quando il gallo si corruccia, gonfia, \& vien grosso in modo che li cuopra tutto il mostaccio,(...) e nella punta d'esso petto ha una pannocchia di setole a modo di quelle del porco congiunté nelle piume, e ha la carne molto piu bianca, e piu molle del pauone nostrale, e si frol la piu presto che il cappone, e altri simili uolatili.

11. « De gallo peregrino: Is quem ex novo orbe deportatum vidi (...) »; « Illius quem vidi (...)» (Gessner : 424-425; $c f$. aussi Plouvier : 16).

12. Ornithologiae tomus alter (Liber XIII), 1600 : De Gallopavone (pp. 35-44); gravure du mâle (Gallopavo mas cum oryza, p. 39) et de la femelle (Gallina Indica, p. 40). On sait qu'Aldrovandi avait fait dessiner un dindon pour la collection d'illustrations de son Cabinet (Bray 1993 : 305).

13. Cette gravure a été reprise dans le livre posthume Monstrorum historia (1642:324).

14. Minsheu reprend et complète le dictionnaire de Percival (1591); il introduit donc un nouveau sens.

15. Dans son livre Il cuoco segreto de 1570, Bartolomeo Scappi note (cap. 141) : ... «il Gallo \& la Gallina d'India, liquali in alcuni lochi d'Italia si dimandano pauoni d'India » (p. 61)

16. Livre I, chapitre XXXVII ; Livre IV, chapitres LI et LIX

17. Ce mot n'est pas dans Robert Cawdrey 1604 A Table Alphabetical.

18. Cf. Gessner 1553 : «Italice: Gallo d'India. Gallice : Coc d'Inde. German : Ein Indianischer oder Kalekuttischer Han. Angli: a kok of Inde ».

19. Schorger (1966 : 464) citant Cárcer y Disdier (1960) sur les archives des Indes.

20. Voir l'image : http://pares.mcu.es/ParesBusquedas20/catalogo/show/246126

21. La réquisition s'adresse aux Espagnols des Antilles, où les dindons étaient présents et élevés. Cette lettre ne prouve pas qu'ils l'étaient en Europe (A. Manin, comm. pers.).

22. Sur un bilan des connaissances sur la domestication et l'élevage du dindon au Mexique jusqu'à la conquête, on consultera Manin 2015.

23. Voir ce que rapporte Pierre Martyr de la description de Tenochtitlan (« Temistitan ») : "Their domestic animals are geese and ducks, and they also keep a number of peacocks, which we call hens, and which they rear as our housekeepers do their chickens. I have already somewhere said that these animals 
resemble our pea-hens in size and the colour of their plumage (...)" ( $5^{\mathrm{e}}$ décade, chapitre 3 , trad. MacNutt 1912 : 109). «Les indigènes élèvent aussi dans leurs maisons une quantité de paons, que nous appelons des poules. Ils les élèvent comme nos ménagères font pour les poulets. J'ai déjà dit quelque part que ces animaux ressemblaient à nos paons femelles pour la grosseur et la couleur des plumes (...) » (5e décade, chapitre 3, trad. Gaffarel $1907: 448-449)$.

24. Pour cette section et la suivante, je me suis basé sur les sources indiquées par Schorger 1966, Flandrin 1992, Eiche 2004, mais également sur celles de Le Grand D'Aussy 1782, et même du Grand dictionnaire de Pierre Larousse 1870, sources que j'ai toutes visitées autant que faire se peut.

25. Cet épisode est très antérieur au témoignage cité par Tanara (1644:217), selon qui les premiers Galli d'India vus à Bologne avaient été envoyé à Gènes en cadeau aux Seigneurs Boncompagni, au moment du décès du Pape Grégoire XIII (soit en 1585) : «i primi Galli d'India, che si vedessero in Bologna, furno mandati a Genova a donare a' Signori Boncompagni, mentre fioriua la Santa memoria di Gregorio XIII. ».

26. "Indicarum, ut vocãt, avium recens apud nos usus \& educatio: Nam ante annum redemptionis tricesimum supra sesqui millesimum apud nos non sunt visae, neque veteribus arbitror notas, tamet si non desint qui existiment inter Melegrides (...)»

27. Hispaniola correspond aux actuelles Haïti et République dominicaine.

28. « in gallo opus naturae mirabile apparer »

29. Marguerite d'Angoulême (1492-1549), sœur aînée de François $1^{\text {er }}$, était la femme de Henri II de Navarre (1503-1555); leur fille Jeanne d'Albret (1528-1572) sera la mère de Henri IV.

30. «On assigna à Pierre Beauchêne, parquier du château, 31 livres 8 sols 6 deniers par chacun an, pour l'entretien \& la nourriture de six coqs \& poules dindes de la princesse de Navarre qui se rendois au Plessis-lez-Tours. » (Odolant-Desnos 1787 : 567-568).

31. $1^{\mathrm{er}}$ service (des entrées) : «Gallina indica. Dimisso orbe tuo, nostris dum finibus erras, / Venisti, infaustis cursibus, ut caderes. Alliud. Gallinae in speciem me tellus barbara misit, / Sic notus vobis Indicus orbis erit.» («Les convives connaîtront le continent indien, cette terre barbare, qui a produit la Poule d'Inde. »). $2^{\mathrm{e}}$ service (des rôtis) : «Pulli indici. Inter aves cicures, si quis, me indice, certet, / Palmam (nec dubium est) Indica casta feret. » (« Poulets d'Inde. Parmi les oiseaux apprivoisés, si le débat était porté devant moi, la palme (ce n'est pas douteux) appartiendrait à la caste de l'Inde. »). Traduction de Bouquet.

32. Il s'agit du relevé des comptes des achats pour ce banquet, dans lequel apparaissent « soixante-six pouletz dinde, à 20 sols pièce. » et « Sept cocqs dinde pour faite trente cinq pastez, au faict de 30 sols pièce.» achetés à "Jehan Langlois et Blaise de Sallesbrusse, marchans rôtisseurs demourans à Paris ». Près de 1400 pièces, du pigeon au cochon, ont été achetées à ces rôtisseurs. Au «maistre paticier Pierre Moreau, dit Bridon", ont été payées 6 livres "pour la façon de quarante pastez de coq-dinde ». (Cimber \& Danjou 1835 : 417-419). On trouvera dans Flandrin (1992: 71) une comparaison des prix des diverses volailles commandées pour ce banquet.

33. "Turkies 2 , rated at $4^{\mathrm{s}}$ a piece, by Mr. Walpole ; (...) Turky-chicks 4 , rated at $4^{\mathrm{s}}$ a piece, jointly by Mr Morgan and Mr Catlyn"- par comparaison, une grue ou un cygne valent $10^{\mathrm{s}}$, un chapon $2^{\mathrm{s}} 6^{\mathrm{d}}$. (Dugdale 1666, ch. $48: 135$ ).

34. Cet événement est fréquemment cité, par exemple dans Le grand dictionnaire (Larousse 1870, s.v. dindon) ou Wright (1914), mais je n'ai pas réussi à trouver un document précis sur le menu, ni même sur le lieu de ce banquet.

35. Pasticci di Galli d'India in forma di Aquila (pâtés de dindons en forme d'aigle).

36. Pallanchotte d'India arrosto, lardate minutamente, servite con pane di Spagna (gros dindonneaux rôtis, finement lardés, servis avec du pain d'Espagne).

37. First (...) It was also probided, that of the greates fyshes or fowles, there should be but one in a dishe, as Crane, Swan, Turkeycocke, Hadocke, Pyke, Tench: and of lesse sortes but two, viz. Capons two, Pheasantes 
two, Conies two, Wodcockes two. (Constitutio Thomae Cranmeri Archiepiscopo, \& aliorum fratrum suorum, dans John Leland De rebus Britannicis collectanea $1774: 38$ ).

38. Décret du Conseil de Venise du 22 mars 1557 : De'Conviti Cap. XI : «(...) sia proibito dar fagiani, cotorni, francolini, galli selvatici, pavoni nostrani. E parimenti non si possano in detti Conviti metter in tavola pernici, e galli, che chiamamo d'India, se non in questo modo: cioè che ad elezione di chi farà il Convito nel numero delle due vivande arroste, come nel seguente Capitolo, si possan dare galli d'India, o pernici; ma non sia per modo alcuno lecito porre in tavola in un istesso Convito galli d'India, e pernici insieme, e separatamente. " (Zanon 1763 Lettere sull' agricoltura, le arti e il commercio, vol. I : 32).

39. Une loi somptuaire avait précédemment été émise en 1547 par le Sénat de Venise, interdisant la vente et la présentation en public des faisans, paons, dindons, francolins et coqs sylvestres (cité par De Grossi Mazzorin \& Epifani 2015 : 59).

40. « lors du Reglement qui fut fait (...) les Poules d'Indes n'y étoient pas encore bien communes, ni en assez grand nombre, pour être venduës dans les Marchez, ou par les Rotisseurs. Ce Reglement contient un denombrement fort ample de toutes les diferentes especes de Volailles \& de Gibier, qui etoient alors dans le Commerce, \& en fixe le prix. (...)» (La Mare 1710 : 1377).

41. Analysant le prix des volailles commandées pour le banquet de Catherine de Médicis en 1549, Flandrin constate que les dindons sont moins chers que les autres oiseaux de luxe (dindon 30 sols, dinde 20 sols), et suggère qu'ils n'étaient donc « déjà plus tellement rares. » (Flandrin 1992 : 71). En fait, ce sont les gibiers qui sont plus chers (faisan, outarde, grue, 70 à 80 sols); les oiseaux d'élevage sont soit d'un prix comparable (paon 40 sols) soit carrément hors de prix et donc très rares (cygne 100 sols).

42. ...i galli, e le galline d'India cuoprono una parte delle nostre campagne, sono divenute il cibo de Contadini, della plebe; mortificano i prezzi delle carni bovine, e de vitelli, e fanno un commercio attivo, colla Dominante.

43. [...] E benche costino assai nell'alleuarli; nondimeno, per essere delicati da mangiare, stà bene a tenerne, e massimamente ogni persona nobile, per honorarsi con gli amici, quando i maschi sono ben grassi, come alle uolte ne ho donati, e morti, che giungeuano a trenta, e trenta cinque libre l'uno; avenga che le femine sono apena la mitade, lequali covano i loro ovi d'ogni tempo, \& ogn'una sedici, fin diciotto. [...]

44. Mai non ho voluto tener di questi uccelli ; parte perche muoiono facilmente, mentre sono piccioli ; \& parte anco, perche sono sporchi, dishonesti, \& horridi da vedere por cõto della lora gresta [...]

45. Poi nati i polli, siano tenuti per un mese in luogo non freddo, e non lasciati andar fuori, fin che non sono ben coperti di piuma, o che faccia caldo, non mancando a pascerli di diverse herbe dell' horto cotte, di pane e di ricotta.

46. Dans toutes les éditions suivantes $(1572,1583,1658 \ldots)$, des précisions sont apportées, par exemple : «outre que l'un \& l'autre sont sales, \& hideux à voir, à cause de leur difformité de teste : car le masle n'a point de crestes eslevées comme nos coqs : mais au lieu de creste a une carnosité rouge, \& sous le menton un palais gros \& long qui s'enfle, \& est tendu de diverse couleur quand il entre en furie. » (1658, Chapitre $20: 83$ ).

47. hò veduto condurne due centenaia di questi dal Regno di Napoli a Roma, con suoi piedi, per camino di cento miglia. (éd. $1651: 217$ )

48. La sua polpa è doppia \& treppia, \& simimente difficile da digerire.

49. Quando (...) la Gallina d'India sono uecchie, sarà la carne loro buona nel maggior freddo dell'anno. Et $i$ pollastri loro nascendo di Marzo, sarã buoni d'Agosto, ; \& Settembre, perche uogliono esser di quattro mesi almeno, ma le femine, cioè pollanche uorranno hauer dell'una, et dell'altra cinque o sei mesi, \& quelle saranno eccelentissime.

50. « La stagione più propria di questi animali e delli mesi di Giugno, Luglio, \& Agosto riuscendo in questi tempi delicati, per essere piccoli, e teneri, vengono molto apprezzati nelle tavole de'Signori grandi. "

51. Granado (1614) reprend exactement les mêmes préconisations : "En el invierno despues de muerto el gallo o gallina de la India, la dexaras sin sacar las tripas quatro dias, y en el verano dos ». 
52. "Piglisi la pollancha giovane morta d'une giorno l'Estate, \& L'Invernata di tre, perche tal volatice presto si frolla, \& ha la carne assai piu bianca (...)"

53. La vera stagion del Gallo, e gallina d'India è la più fredda parte dell'anno, ed essendo essi di carne molto dura, è ben lasciarli per alquanti giorni star morti, accioche divengan frolli. Dei Galli, e galline giovani d'India non accaderebbe quasi far quì mentione, poiche ordinariamente non se n'ammazzano nel nostro paese; ma pure, se alcuno avesse gusto di mangiarne, sappia, che $i$ maschi vogliono essere almen di quatro mesi, e le femmine, o pollanche di cinque, o sei. (Li tre trattati di Messer Mattia Giegher 1639: 5)

54. Laurioux a pu montrer comment les versions imprimées du Viandier au XV $\mathrm{X}^{\mathrm{e}}$ siècle, diffèrent des manuscrits qui circulaient depuis le XIV $(1988: 62)$.

55. Sur l'histoire des livres de cuisine, on consultera : Braga 2006, Flandrin et al. 1983, Hyman 1996, Laurioux 1988, Lehmann 1999. Sur les livres en France, on consultera le catalogue de l'exposition de la Bibliothèque de l'Arsenal Livres en bouche (Coron 2001).

56. Voir édition française et commentaires (Peyrebonne 2011). Pour les références des sources sur la cuisine et la gastronomie espagnoles, voir Simón Palmer (2003) et Bibliothèque Nationale d'Espagne : http://www.bne.es/es/Micrositios/Guias/gastronomia/

57. Roi de Naples de 1458 à 1494.

58. Cortar de las aves, y primeramente del pavo; Salsa de pavo especias; Para hazer salsa de pavo; Emborroçamiento de pavos o capones.

59. Ce paragraphe se termine par des appréciations sur la qualité de la chair : «(...) son tenidos sus pollos crecidos acerca de los cortesanos, por gustosos y tiernos, pero quieren estar manidos de tres dias en inuierno. Los viejos son duros de digestiõ, y los nuevos no faciles: porque tienen mucha superfluydad: cuestan mucho su criança. "

60. La découpe et l'assaisonnement (Corte del pavo; Como se ha de adereçar vn pauo).

61. Rôtissage, une sauce, des empanadas (- de menudos, - en masa blanca).

62. Rôtissage (Pabos asados, pabo asado con verdure).

63. La découpe, la farce, le rôtissage, des pâtés pasteles, et des boulettes albondiguillas.

64. La terminologie utilisée n'est pas sans ambiguïté, car il alterne les précisions ou bien les recettes globales, par exemple : manière de découper «les oiseaux et en premier lieu le pavo » (corte de las aves, y primeramente del pavo, p. $9 \mathrm{~V}^{\circ}$ ) mais plus loin à propos du chapon : "...se quiere cortar, asi como el pauon, ò capon (...) aunque algunos hazen alguna diferencia en el corte del pauo al del capon, y de la gallina(...) ». De même p. 12 «emborraçamiento de pavos, o capones ». Et p. $47 \mathrm{~V}^{\circ}$ "para assar el gallo y la gallina de las Indias ".

65. Ce livre sépare les recettes de pabo, et celles de pabipollo, et pabipolla, noms qui désignent les dindonneaux. Les recettes: Despojos de pabo á la aldeana, Pabo en adobo, Pabo á la provenzana, Pabipolla al asador.

66. Pavo relleno asado.

67. Pavo asado, Pavo. relleno, Despojos de pavo, Alones, Alones con habichelas.

68. Parmi d'autres (rôti, marinade), Alones fritos, - a lo marinero, - mechados; pavo asado con criadillas, picadillo de pavo.

69. Manuel du cuisinier et de la cuisinière, à l'usage de la ville et de la campagne par P. Cardelli, 4 éd., Roret 1826.

70. Christoforo di Messisbugo est mort en 1548. Intendant de la Maison d'Este (à Ferrare), il donne de nombreuses recettes très innovantes, et passe pour l'inventeur des pâtes farcies (tortelloni).

71. Furono questi uccelli cõdotti di Numidia, e non d'India [...]. Sono detti da Greci Meleagrides [...]

72. Pollanche d'India stuffate con presciuto, piselli, \& agresto, \& savor di verzure; pollanche d'India stuffate con savor di verzure; pollanche d'India infagianate con salsa di pago; galline d'India arroste, e allesse, in più modi; auxquelles il ajoute en 1587 pollanche d'India infagiante (sic) configo di milangoliforti, zuccaro, cannella, et garofani. (Dindonneaux farcis de jambon, petits pois, verjus, et saveurs d'herbes; Dindonneau à la mode de faisan à la sauce aux griottes; Poules d'Inde rôties et 
bouillies, de diverses manières; Dindonneaux à la mode de faisan, confits avec des bigarades fortes, sucre, cannelle et clous de girofle).

73. Il trinciante mentionne à deux reprises les porcelletti d'India, mais qui sont des petits animaux animalucci vivants que l'on utilise pour orner "le jardin d'argent" où se tient le banquet, attachés « avec des colliers et sonnailles au pied des arbres » (pp. 94, 135).

74. Noms et descriptions de plats : Pollanche d'India arrostite; Polli d'India arostiti ripieni d'hortolani \& coperti di sparagi grossi cotti nel butiro; Pollanche d'India allessate coperte di ravioli verdi senza sfoglia; Galli d'India ripieni d'uccelletti, \& cervellati, \& tartufi, arostiti con caperini sopra, \& melangoli ; Polanche d'India allessate coperte du cardi, cervellati e formaggio; Pollanche d'India a modo d'Aquile, coperte de gielo, e fior de pignioli sopra; Galline d'India grosse, arrostite, armate di stecchi con prugnoli, \& ortolani sopra; Polanche d'India arosto, due per piatto adornate di pasta sfogliata. [Poulets d'Inde rôtis farcis d'ortolans et couverts de grosses asperges cuites dans le beurre ; Dindonneaux bouillis couverts de farce [de raviolis] verte sans la pâte ; Coqs d'Inde farcis de petits oiseaux, \& cervelas, \& truffes, rôtis avec des câpres dessus, \& des bigarades ; Dindonneaux bouillis couverts de cardes, cervelas et fromage ; Dinde en forme d'Aigle, couverte de gelée, et saupoudrée de pignons hachés ; Grosses dindes rôties, parées de brochettes portant des prunelles et des ortolans ; Dindonneaux rôtis, deux par plat ornés de pâte feuilletée]

75. Bartolomeo Scappi (v. 1500-1577).

76. Ce me semble être le premier livre à le faire (il sera repris en espagnol par Granado en 1614) sinon le seul.

77. Quelques exemples des noms de plats de Scappi : Pollanche d'India ripiene di prugnoli arrostite allo spedo servite con sugo di melangole [bigarades], \& zuccaro sopra; Galline d'India arrostite allo spedo, servite fredde con limoncelli, \& zuccaro sopra; Pollanche grosse d'India alessate, servite con fiori di borragine, \& petrosemolo sopra; Pollanche d'India alessate, servite con cardi cotti, \& cervellate spolverizzate di cascio [fromage], zuccaro, \& cannella; Galli d'India ripieni d'ogliapotrida alla Spagnola, arrostiti allo spedo, serviti con capperini ; \& zuccaro sopra, trinciati. [Dindonneaux farcis de prunelles, rôtis à la broche servis avec du jus de bigarade, \& saupoudrés de sucre ; Dindes rôties à la broche, servies froides avec des petits citrons, \& saupoudrées de sucre ; Gros dindonneaux bouillis, servis avec des fleurs de bourrache, \& saupoudrés de persil; Dindonneaux bouillis, servis avec des cardes cuites, \& du cervelas saupoudrés de fromage, sucre, \& cannelle; Dindons farcis d'ogliapotrida à l'Espagnole, rôtis à la broche, servis avec des câpres, \& saupoudrés de sucre, découpés]

78. Lancellotti était le maître d'hôtel du Cardinal Aldobrandino, Camerlingue du Pape à Rome.

79. Quelques exemples pour illustrer la variété et la beauté des titres : pasticci di Galli d'India in forma di Aquila... ; Starne arrosto (...) con sei nidi pieni di piccatiglio di petto di Galli d'India arrosto, stufato con medolla... ; Galli d'India arrosto, poi lardato di lardoni di cedra condito... ; 2 pollanchotte d'India assagianate servite con fette di pane di Spagna intorno, con copertoro di pasta di zuccaro fatto a gelosia ; Galli d'India bolliti, coperti di papardelle alla Romana, con zuccaro, e cannella sopra [Coqs d'Inde bouillis, couverts de pâtes à la romaine, saupoudrés du sucre, et de cannelle]; Pollanchotte d'India arrosto, lardate, servite con sfogliatelle tonde, ripiene di bianco magnare [Gros dindonneaux rôtis, lardés, servis avec des petits (gâteaux) feuilletés ronds, farcis de blanc-manger]...

80. Le coscie si possono mettere alla gradella, bagnate cõ aceto rosato, butiro overo oglio di Toscana, o d'altra qualità, purche sia buono. (Les cuisses peuvent se cuire sur un petit gril, [puis] baignées de vinaigre rosé, de beurre ou bien d'huile de Toscane, ou d'une autre sorte, pour que ce soit bon).

81. Gallinaci, o Galli d'India assagianati, regalati con osselloni alla Milanese, tramezati cõ lumache empite, fatte di pasta di marzapane, servite sopra con una salsa di capparini, e sopra un copretore di pasta sfogliata. [Coqs d'Inde assaisonnés avec des osselloni à la milanaise, partagés par le milieu et emplis d'escargots faits de massepain, servis avec une sauce aux câpres, et couverts d'une pâte feuilletée]

82. Vincenzo Corrado (1736-1836). 
83. Quelques noms de plats : Tacchina lessa ; in Gello per Entremets ; All'Arlechina ; Farsita al Butirro; Farsita alli Finocchi; Alla Contadina ; In Fricassea ; in Arrosto alla Contadina ; in arrosto all'Apiciana; Alla Beccaccina; In Galantina; Petti di Tacchina in Fricondò; Al Latte; Coscie di Tacchina Farsite; Al Salpicon. 84. Sur l'histoire et l'évolution de la cuisine italienne, on consultera Capatti \& Montanari (2002). 85. Cette recette n'est pas sans rappeler celle du coq (d'Inde ?) au Gevrey-Chambertin, que l'on cuit dans du gros-rouge, mais au cours de la cuisson on passe par trois fois une bouteille de Gevrey dans la vapeur de la marmite (est-il vraiment nécessaire de gaspiller un tel nectar ?).

86. Titre complet: Le nouveau et parfait maistre d'hostel royal, enseignant la manière de couvrir les tables dans les ordinaires \& festins, tant en viande qu'en poisson, suivant les quatre saisons de l'Année [Texte imprimé]. Le tout representé par un grand nombre de Figures. Ensemble un nouveau cuisinier à l'Espagnole, contenant une nouvelle façon d'apprester toutes sortes de mets, tant en chair qu'en poisson, d'une méthode fort agreable. Par le sieur Pierre de Lune... A Paris, Chez Estienne Loyson, au Palais, dans la Galerie des prisonniers, au nom de Jesus. M. DC. LXII.

87. Potage de dindonneaux, Ragoust de poulets d'inde à l'Espagnol, Poulets d'inde desossez et farcy, et divers Rostis à la broche.

88. "La daube est un ragoust qui se mange froid, \& qui est fort en usage aujourd'hui " explique Massialot. Pour cela, la viande est lardée, et assaisonnée de «sel, poivre, clous, muscade, laurier, ciboule, citron verd ".

89. La chair coupée en filets très fins, est cuite dans une casserole avec une tranche de jambon, de l'huile, du persil, des ciboules, des champignons, le tout haché très finement, par couches successives.

90. On y trouve seulement les modes de préparation, et non des recettes à proprement parler, dans le chapitre sur Dindons et dindonneaux : rôti à la broche, désossé en blanquette, à la béchamel, en ragoût, à la poêle, en fricandeau, galantine, ballon, daube ( avec une chopine de vin blanc»), roulé, en pain, en brézolles, «à la bourgeoise », les ailerons " diversifiés de plusieurs façons ", en fricassée, aux petits oignons, en matelote, au vin de Champagne, « en terrine à la purée verte »...

91. Il s'agit d'une viande désossée, d'abord semi-rôtie ou semi-bouillie, puis bouillie dans un plat sur la braise.

92. Il faut prendre le turkey-cock « le plus gras possible ».

93. A pye, a-la-daube, a pot, to stew; sauce for boiled Turkey

94. A pye, a sallad magundy (à partir d'une dinde rôtie avec des anchois et des huitres) et deux sauces

95. Carbonado (rôti, découpé avec la peau, sauté au beurre avec des épices de la chapelure et des anchois), a sallet (viande cuite, assaisonnée avec herbes, muscade, poivre, raifort gratté..), et un curieux to congeal (une forme de conserve où la viande, désossée et bouillie, est placée dans un pot par couches alternées avec épices, oignons, raifort, bacon, anchois, empli de vin blanc, bouché et cuit au bain marie pendant $6 \mathrm{~h}$; une fois refroidi, on casse le pot et l'on sert avec beaucoup d'épices).

96. Rôti, Pies (dont une in the French way), Carbonado, To souse, a ragoo, dinde farcie avec des fines herbes, dinde à l'essence d'oignon.

97. To boil with Oysters, a la daube, Turkey pie, to souse, et a salamongundy (hachis fin de chair de dinde et d'un peu de poulet- le mode de cuisson n'est pas précisé ; servir avec un hachis finement mêlé d'œufs durs, anchois, câpres, champignons, zestes de citron, herbes- oseille, cives, épinards-, arrosé de jus d'orange et citron, huile et vinaigre).

98. Outre les 3 modes de rôtissage (avec ou sans larder), avec les farces et les 5 sortes de sauces pour accompagner, le ragoût (to stew), H. Glasse donne plusieurs versions du salamongundy, dont une pour divers Fowls (viande froide de Fowl hachée finement, avec hareng, concombre, pommes, oignon, chou rouge pickled, du persil bouilli, du céleri, des œufs durs -blancs et jaunes séparés-, tous ingrédients hachés finement, qui peuvent être mêlés ou disposés séparément; servir avec des rondelles de citrons et des fleurs disposées autour). 
99. Turkey or fowles rôties, bouillies au céleri, en pie; a fricasey (une sauce à la crème et aux œufs revenue pour accompagner les volailles bouillies), a ragoo of livers (les foies sont revenus à la poêle avec du bouillon, du beurre, de la farine, sel, poivre, huîtres et ketchup).

100. To roast, to boil, to hash (désosser, détailler les chairs, les bouillir dans une poêle avec du bouillon et du citron « 6 ou 7 minutes »), souced Turkey, a stewed with celery sauce, et 2 sauces pour dinde rôtie ou bouillie.

101. A côté des rôtis avec diverses farces (dont à la truffe, à la châtaigne) et leurs sauces, des bouillons avec divers arrangements, des pâtés, on retrouve des recettes similaires sous des nom différent : Pulled Turkey ressemble au ragoo de Cleland (et Mollard compare à la benshamelle); en revanche son ragout est différent (le dindon est bouilli et détaillé, mais la sauce comporte des artichauts, des crêtes de coq bouillies, des champignons blancs, des œufs (durs ?), de la benshamelle, du sel, du jus de citron et du poivre de Cayenne. Il décrit Grills and sauce, which are generally eaten after dinner (des petits morceaux grillés, avec un coulis et diverses sauces).

102. On aura relevé les diverses graphies de ces plats: salamongundy, solomongondy, sallad magundy, et sallet.

103. Perum salchichado, almondegas de perum, perum de sopa branca, perum com salsa real, perum estilado, empadas de perum sem osso.

104. Quelques noms de plats : potagem a Franceza (avec du foie, moutarde, lard, oignons piqués, poivre, muscade, cardamome, jus de citron), perum Mourisco, peruas assadas sobre sopa de nata, perum em gigote de toucinho (lard) e vinho branco com substancia de vitella, pratinhos de pasteis saboianos de peito (blancs) de perum...

105. Perú a crema, e assado para uma entrada, peitos de perús para uma entrada, perú assado á italiana para uma entrada.

106. Sopa de assado, manjar branco amarello, perna armada, gallinha (ou perú) em pé, recheada (farcie), empadas (en pâté), alerões de vario modo. Plats dans les menus: Perú com salsa real, salchichado, estufado, assado com prezunto (jambon).

107. Ce livre a été un grand succès et a été réédité jusqu'à 1887. Pour ce qui concerne le dindon au moins, les recettes des éditions successives sont similaires.

108. Conservée dans les collections du Victoria and Albert Museum (Londres), n IM.135-1921; url : http://collections.vam.ac.uk/item/017088/painting-mansur/.

109. 500 millions de dindes sont élevées chaque année dans le monde...

\section{RÉSUMÉS}

Dans cet article, on examine les conditions et les conséquences de la découverte du dindon Meleagris gallopavo L. (Phasianideae). Je tente de cerner comment ce nouvel animal va s'introduire et s'implanter dans les langues, à travers la terminologie, dans le savoir scientifique, et dans les usages et les pratiques en vue de préciser les étapes de son acceptation jusqu'à son inclusion dans le corpus alimentaire européen. Pour cette enquête on analyse chronologiquement les témoignages écrits successifs, c'est-à-dire les archives qui ont pu être révélées par des historiens, et surtout les livres (de cuisine, d'agriculture, dictionnaires), afin de mettre en évidence les étapes de l'adoption du dindon dans notre civilisation européenne (Espagne, Italie, France et Angleterre). 
INDEX

Mots-clés : dindon, Europe, histoire, découverte, introduction, élevage, alimentation, cuisine

AUTEUR

SERGE BAHUCHET

Professeur 